\title{
Supporting Information A for The Significance of Environmental Attributes as Indicators of the Life Cycle Environmental Impacts of Packaging and Food Service Ware
}

Jorge Vendries ${ }^{1}$, Beverly Sauer ${ }^{1}$, Troy R. Hawkins ${ }^{2}$, David Allaway ${ }^{3}$, Peter Canepa ${ }^{3}$, Jonathan Rivin $^{3}$, and Minal Mistry,

${ }^{1}$ Franklin Associates, a Division of Eastern Research Group

${ }^{2}$ Argonne National Lab

${ }^{3}$ Oregon Department of Environmental Quality

*Corresponding author: minal.mistry@state.or.us

Number of pages: 102

Number of figures: 2

\section{Contents}

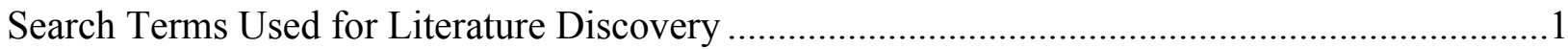

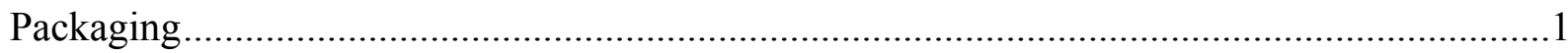

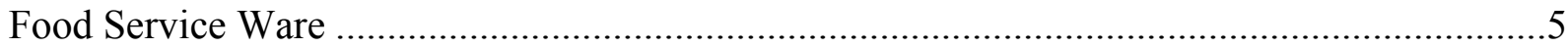

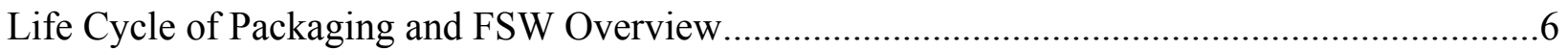

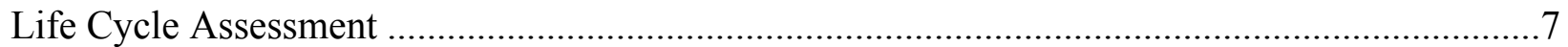

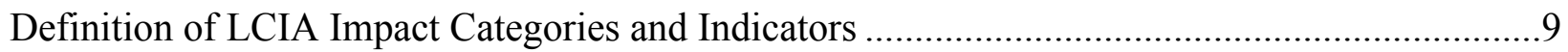

Midpoint impact categories calculated based on environmental releases ................................10

Midpoint indicators calculated based on resource use .......................................................10

Allocation Methods for Recyclable and Recycled Content Attributes..........................................11

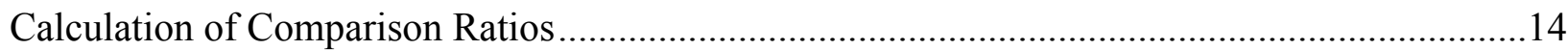

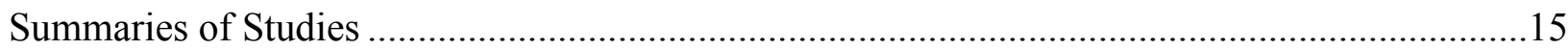

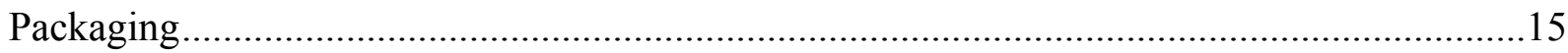

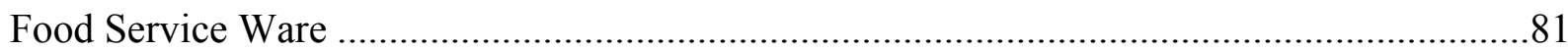

Considerations Related to Reusable Food Service Ware ………................................................98

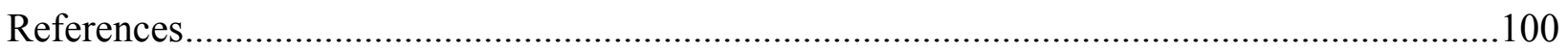




\section{Search Terms Used for Literature Discovery}

\section{Packaging}

\section{Recycled Content}

- Curated Database Search

- Database

- University of Cincinnati Library System ${ }^{1}$

- Search Terms

- Abstract:((LCA OR "life cycle") AND (packaging OR package OR container OR bag OR box OR clamshell OR bottle) AND ("recycled content" OR "recycled material" OR "recycled fiber" OR rPET OR cullet OR OCC))

- Journal-Specific Searches:

○ Journals

- International Journal of Life Cycle Assessment ${ }^{2}$

- Google Scholar

○ (LCA AND packaging) AND ("recycled content" OR "recycled material" OR "recycled fiber" OR rPET OR cullet OR OCC) AND source: International Journal of Life Cycle Assessment

- Journal of Cleaner Production ${ }^{3}$

- Journal of Industrial Ecology ${ }^{4}$

- Packaging Technology and Science 5

- Environmental Science and Technology 6

○ Search Terms for JCP, JIE, PT\&S, \& ES\&T

- (LCA OR "life cycle") AND (packaging OR package OR container OR bag OR box OR clamshell OR bottle) AND ("recycled content" OR "recycled material" OR "recycled fiber" OR rPET OR cullet OR OCC)

\footnotetext{
${ }^{1}$ http://uc.summon.serialssolutions.com/advanced\#!/advanced

2 https://link.springer.com/journal/volumesAndIssues/11367

$\left.{ }^{3} \mathrm{http}: / / w w w . s c i e n c e d i r e c t . c o m / s c i e n c e / j o u r n a l / 09596526 ? \mathrm{sdc}=1\right) ;(\mathrm{http}: / / \mathrm{www}$. sciencedirect.com/science/search

${ }^{4}$ http://onlinelibrary.wiley.com/journal/10.1111/(ISSN)1530-9290; http://onlinelibrary.wiley.com/advanced/search

5 http://onlinelibrary.wiley.com/journal/10.1002/(ISSN)1099-1522; http://onlinelibrary.wiley.com/advanced/search

${ }^{6}$ http://pubs.acs.org/journal/esthag; http://pubs.acs.org/search/advanced
} 


\section{Recyclable}

- Curated Database Search

- Database

- University of Pittsburgh Library System ${ }^{7}$

- Search Terms

- Combinations of "life cycle assessment", "recycl*", and "packaging", where "recycl*" is one of "recyclable", "recycling", or "recyclability"

- E.g. (Abstract:(life cycle assessment)) AND (Abstract:(recyclability)) AND (Abstract:(packaging))

- Similar searches excluding one of the search terms at a time.

- E.g., (Abstract:(recyclability)) AND (Abstract:(packaging))

- "Material recycling facilities" and "Material recycling facilities in the United States"

- "recyclate" and "recyclate quality", both using abstract search feature and without.

- Broad Search

○ Database

- Google Scholar ${ }^{8}$

○ Search Terms

- Combinations of "life cycle assessment", "recycl*", and "packaging", where "recycl*" is one of "recyclable", "recycling", "recyclability", as in the University of Pittsburgh Library System search.

${ }^{7}$ http://www.library.pitt.edu/

${ }^{8}$ http://scholar.google.com 


\section{Biobased}

- Search Engines

- Curated Database Search:

- DeepDyve

o Journal-Specific Searches:

- International Journal of Life Cycle Assessment ${ }^{9}$

- Journal of Cleaner Production ${ }^{10}$

- Journal of Industrial Ecology ${ }^{11}$

- Packaging Technology and Science ${ }^{12}$

- Environmental Science and Technology ${ }^{13}$

- Broad Search

- Google Scholar (http://scholar.google.com)

- General Search Terms

○ Attribute-Specific

- Biobased, Bio-based, Renewable, Bioplastics,

○ Packaging

- Package, Wrap, box, films

○ Materials

- LDPE, LLDPE, HDPE, PET, oxodegradable plastics, PS, EPS, PP, PLA, Composite, Biopolymers (natural, synthetic), LPB, Paper, Kraft, Wood, Model (from wood pulp), Tencel (from wood pulp), Corrugated Cardboard, paperboard, Bio-PX, PEF, bio PET, plant PET, bio LDPE, bio LLDPE, bio HDPE, PLA, PHA/PHB, Starch, Chitin, Chitosan, Algaebased, Protein, bio ethylene glycol, bioethanol, biobutanol, acrylonitrile, glucose, biomethanol, bioxylene, biopropylene, biobutadiene, biotoluene, biobenzene, Polyolefins, bio purified terephthalic acid (PTA)

\footnotetext{
${ }^{9}$ https://link.springer.com/journal/volumesAndIssues/11367

${ }^{10} \mathrm{http}: / /$ www.sciencedirect.com/science/journal/09596526? sdc=1; http://www.sciencedirect.com/science/search

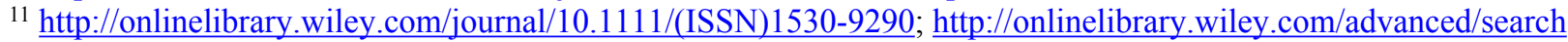

12 http://onlinelibrary.wiley.com/journal/10.1002/(ISSN)1099-1522; http://onlinelibrary.wiley.com/advanced/search

13 http://pubs.acs.org/journal/esthag; http://pubs.acs.org/search/advanced
} 


\section{Compostable}

- Curated Database Search

- Database

- University of Pittsburgh Library System (http://www.library.pitt.edu/)

- Search Terms

- (Abstract:(life cycle assessment)) AND (Abstract:(compostable)) AND (Abstract:(packaging))

- Combinations of "life cycle assessment", "compost*", and packaging terms, where packaging terms could be either one or multiple materials

○ E.g. "(((Abstract:(life cycle assessment)) AND

(Abstract:(compostable)) AND (Abstract:(box))) OR

(Abstract:(paper)) OR (Abstract:(plastic)) OR

(Abstract:(wood)) )"

- Similar search terms used included the first two terms and one of the packaging materials, searched for one at a time.

- (((Abstract:(landfill)) AND (Abstract:(compost)))

- Example of search term used to identify studies of other environmental impacts associated with biodegradable packaging, not necessary in an LCA study (((Abstract:(package)) AND (Abstract:(wildlife)))

- Journal-Specific Searches:

○ Journals

- Journal of Cleaner Production ${ }^{14}$

- International Journal of Life Cycle Assessment ${ }^{15}$

- Journal of Industrial Ecology ${ }^{16}$

- Environmental Science and Technology ${ }^{17}$

- Search Terms

- Combinations of "life cycle assessment", "compost*", and packaging terms, where packaging terms could be either one or multiple materials, as in the University of Pittsburgh Library System search.

- Broad Search

- Database

- Google Scholar ${ }^{18}$

○ Search Terms

- "LCA" "packaging" "compostable"

○ Combinations of "life cycle assessment", "compost*", and packaging terms, where packaging terms could be either one or multiple materials, as in the University of Pittsburgh Library System search.

\footnotetext{
${ }^{14} \mathrm{http} / / \mathrm{www}$. sciencedirect.com/science/journal/09596526? $\mathrm{sdc}=1$

${ }^{15} \mathrm{https}: / /$ link.springer.com/journal/volumesAndIssues/11367

${ }^{16} \mathrm{http}: / /$ onlinelibrary.wiley.com/journal/10.1111/(ISSN)1530-9290

${ }^{17} \mathrm{http://pubs.acs.org/journal/esthag}$

${ }^{18}$ http://scholar.google.com
} 


\section{Food Service Ware}

- Curated Database Search

○ Database

- University of Pittsburgh Library System ${ }^{19}$, Google Scholar ${ }^{20}$

○ Search Terms

- Combinations of three search terms, "life cycle assessment", "food service ware", and "attribute", where "attribute" is one of the following:

- For recycled content: "recycled content" or "recycled material" or "recycled fiber"

- For recyclable: "recyclable", "recycling", or "recyclability"

- For biobased/renewable: "biobased", "bio-based", "renewable", "bioplastics"

- For compostable: "compost", “compostable", "degradable”

- Examples:

O (Abstract:(life cycle assessment)) AND

(Abstract:(recyclability)) AND (Abstract:(food service ware))

○ (Abstract:(life cycle assessment)) AND (Abstract:(compostable)) AND (Abstract:(food service ware))

- Similar searches excluding one of the search terms at a time.

- E.g., (Abstract:(recyclability)) AND (Abstract:(food service ware))

- Similar searches but replacing "food service ware" with a specific product or group of products. E.g.,

- (Abstract:(life cycle assessment)) AND (Abstract:(recyclable)) AND (Abstract:(cutlery))

- (Abstract:(life cycle assessment)) AND (Abstract:(recyclable)) AND (Abstract:(spoon OR forks OR knives))

${ }^{19} \mathrm{http}: / /$ www.library.pitt.edu/

${ }^{20}$ http://scholar.google.com 


\section{Life Cycle of Packaging and FSW Overview}

The life cycle of packaging, as shown in Figure S1, includes raw material extraction, primary material production, packaging production, distribution, use, and end-of-life treatments consisting of recycling, reuse, composting or disposal. Litter refers to uncollected material releases to the environment produced from packaging, whether on land or water. LCA can be used to estimate the environmental impacts of many of these activities. Often comparative LCAs omit parts of the life cycle that are identical across comparisons. For example, when studying the impacts associated with different packaging options to package soft drinks, it isn't necessary to include the soft drink production steps (unless the soft drinks themselves are also being studied). For this reason, the environmental burdens related to the product contained in the package may or may not be included in LCAs examining packaging. This will affect the percent changes in impact metrics associated with packaging and food service ware scenarios. In most cases, the product itself contributes more to the overall life cycle impacts than the packaging.

The life cycle of food service ware (FSW) follows the same general stages as the life cycle for packaging, from raw material extraction through to disposal, as shown Figure S1, but each stage can vary considerably based on the specific product. FSW products include items such as knives, forks, spoons, cups, straws, dishes, wrappers, trays and tray liners, and clamshells and similar containers when used for takeaway food consumption. Bottles for liquid consumption are not necessarily takeaway food items, and thus are considered as packaging, not FSW. The FSW products included in this report are made from various plastic resins and wood fiber.

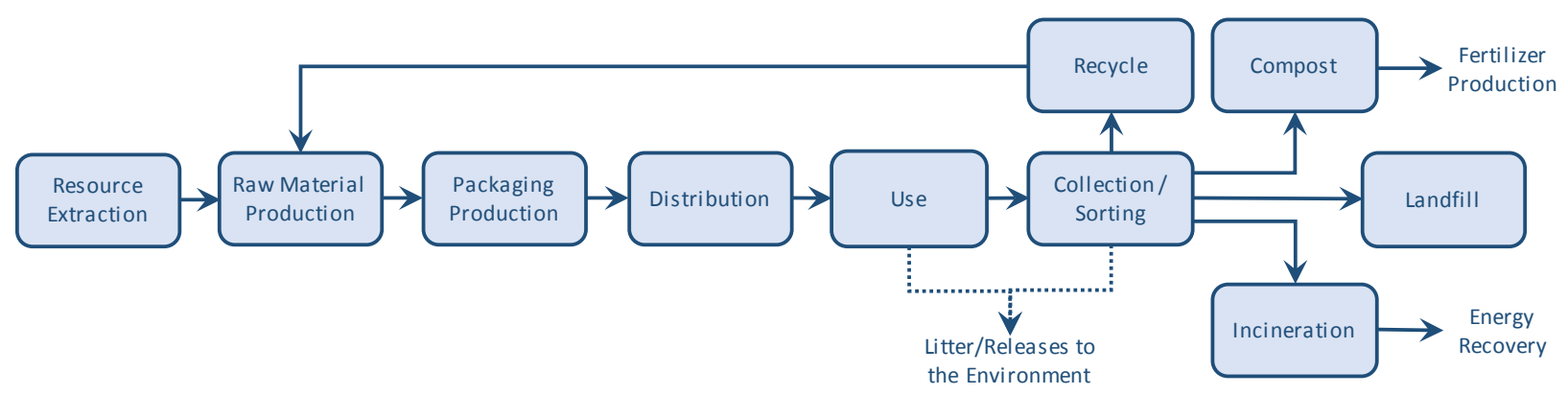

Figure S1: The life cycle of single-use packaging and food service ware. 


\section{Life Cycle Assessment}

LCA is a rigorous and standardized approach for quantifying the environmental impacts of a product (or service) across its entire life cycle, including the extraction or harvesting of raw materials from the earth through material processing, manufacturing, distribution, use, and endof-life. When done properly, an LCA should quantify all relevant environmental flows such as releases to the environment as well as the use of resources such as land, water, fossil fuels, and minerals. The International Standards Organization's (ISO) 14040 series of standards govern and provide guidance for those performing LCA studies. LCA studies begin with a clearly defined goal and scope, which includes the definition of a functional unit which serves as the basis for any comparisons made in the LCA and/or for the presentation of results. The functional unit ensures an apples-to-apples comparison. For example, two packaging options might be compared based on their ability to deliver a certain quantity of product. When necessary the system is expanded to include relevant inputs outside the packaging itself. For example, a comparison between a half gallon of ready to serve orange juice and frozen orange juice concentrate would also include the water and reusable pitcher used to prepare the juice from concentrate. And, of course, the impacts of producing the reusable pitcher would be allocated across many uses over its lifetime. Thus, although the basic concept of an LCA is somewhat simple, in practice resolving interactions between systems and comparing across different products is quite complex. Fortunately, a large body of research provides robust methods for performing LCA studies.

After the goal, scope, and functional unit are defined, the next steps in performing an LCA study are the life cycle inventory and life cycle impact assessment stages. In the life cycle inventory (LCI) stage, the practitioner prepares an inventory of releases to the environment and resource inputs from the environment involved in the life cycle of the product or service being assessed. LCA models are constructed of a series of unit processes, and releases and resource inputs are tracked for each unit process. Unit processes are also connected to one another when the output of one is used as an input to another. For example, iron ore concentrate from iron mining, coal from coal mining, and train transport would all be inputs to steel production. When creating an LCA model, typically the practitioner creates a series of custom unit process datasets for the unit processes that contribute most significantly to the results for their system of interest. These unit processes are referred to as the foreground unit processes. When creating foreground unit processes, the practitioner takes into consideration the location where each process occurs, and the technologies used. For example, the electricity grid in the northwest U.S. would reflect a higher percentage of hydroelectricity than the electricity grid in certain midwestern states for example which rely heavily on coal. The supply chains for less significant inputs as well as those for common and standardized inputs such as grid electricity, PET resin, or aluminum are often represented by off-the-shelf background datasets such as ecoinvent, GaBi, or the U.S. Life Cycle Inventory. The foreground and background datasets are brought together in an LCA tool such as SimaPro, openLCA, GaBi, or Umberto to resolve the connections between unit processes into the inventory of releases to the environment and resources from the environment associated with the provision of the functional unit.

Life cycle impact assessment (LCIA) involves calculating the potential environmental impacts associated with each release to the environment and resource from the environment included in 
the life cycle inventory. Typically, life cycle impact assessment is performed using generalized LCIA methods developed for characterizing various impacts in a given region. Examples of commonly used LCIA methods include the U.S. EPA's Tool for the Reduction and Assessment of Chemical and Environmental Impacts (TRACI), ReCiPe, and IMPACT 2002/IMPACT World + . These LCIA methods are a collection of models and estimation methods used to characterize various impacts. For example, both the TRACI and IMPACT World+ LCIA methods adopt the USEtox model to characterize human health and ecosystem quality impacts. In practice, LCIA methods are a collection of characterization factors describing the impact of a given release or resource input. For example, GWP is often characterized in terms of kilograms carbon dioxide equivalents, thus the release of one kilogram of carbon dioxide causes an impact of one kilogram carbon dioxide equivalent and the release of one kilogram of methane causes an impact of 28 kilograms of carbon dioxide equivalents ${ }^{1}$. 


\section{Definition of LCIA Impact Categories and Indicators}

Impacts can be tracked at the midpoint or endpoint level. Endpoint impacts are considered the ultimate impacts of interest, such as human health and ecosystem quality effects, measured in quality/disability adjusted life years (QALY/DALY) and partially disappeared species-square meter-years respectively. In some cases, resource scarcity is also tracked at the endpoint level in terms of the increased cost of providing energy following depletion of more easily available resources. Midpoint impacts are metrics defined along the cause-effect chain between releases and resource inputs and the endpoint impacts. Examples of midpoint impacts include GWP measured in kilograms carbon dioxide equivalents, particulate matter formation potential (leading to human respiratory effects) measured in kilograms particulate matter $2.5(<2.5$ microns) equivalents, acidification potential measured in kilograms sulfur dioxide equivalents, and human toxicity measured in common toxic units, a metric specifically developed for comparing toxicity in the context of LCA studies. While endpoint metrics reflect the actual impacts of interest, midpoint metrics are often reported in LCA studies because they relate more closely to the releases and resource inputs tracked in the life cycle inventory and can be reported with more certainty. Estimating endpoint impacts from midpoint impacts requires additional assumptions regarding uncertain effects and effects occurring over longer periods of time. For example, while estimating the radiative forcing effect of various greenhouse gases can be accomplished using atmospheric modeling, estimating specific human health and ecosystem quality effects of a warming climate involves more uncertainty.

In this study, we consider thirteen midpoint impact categories commonly tracked in LCA studies. Although different LCIA methods are used to estimate these impacts across LCA studies, the definition of each midpoint is consistent, and the differences in approaches are reflective of the fact that LCIA methods improve as researchers develop them over time. The thirteen midpoint impacts tracked in this review are defined below. While LCIA is useful for characterizing a wide range of environmental releases, not all releases are captured in the impact categories most commonly used in LCA studies. For example, marine debris is spoken of as an "impact" in the common vernacular, but it is not an impact category per se in most studies. Because of the wide range of ways environmental "impacts" from marine debris can occur (e.g. implications to the water chemistry, trophic variations in the water column, etc.) they are not well characterized in established impact categories, though research is ongoing in this area². 


\section{Midpoint impact categories calculated based on environmental releases}

- Global Warming Potential - The heat trapping capacity (radiative forcing potential) of greenhouse gases (GHGs) and their precursors. Calculated in terms of kilograms carbon dioxide equivalents.

- Eutrophication Potential - Enrichment of an ecosystem with nutrients that accelerate biological productivity. Eutrophication is characterized separately for freshwater and marine ecosystems as freshwater ecosystems are more frequently phosphorus limited while marine ecosystems are more frequently nitrogen limited. Calculated in terms of the nitrogen or phosphorous content of releases available to ecosystems and measured in kilograms nitrogen equivalents or kilograms phosphorus equivalents.

- Particulate Matter Formation Potential - Potential to form particulate matter leading to human respiratory effects.

- Smog Formation Potential - The relative reactivity of substances that produce groundlevel ozone in the presence of sunlight measured in kilograms ground-level ozone equivalents.

- Human Toxicity - Increase in morbidity in the total human population due to exposure to carcinogenic substances or substances resulting in non-cancer diseases measured in common toxic units or toxic chemical equivalency.

- Ecosystem Toxicity - Potential of chemicals to cause toxic effects on aquatic species. The models used to estimate ecosystem toxicity typically consider chemical fate, transport, and exposure of organisms. Measured in terms of common toxic units or toxic chemical equivalency. ${ }^{21}$

- Acidification Potential - The acidifying potential resulting from acid rain caused by inorganic air emissions measured in sulfur dioxide equivalents.

- Ozone Depletion Potential - Capacity of substances to deplete the stratospheric ozone, measured in kilograms chlorofluorocarbon-11 equivalents.

- Ionizing Radiation - The damage to human health and ecosystems that is linked to the emissions of radionuclides throughout a product or building life cycle. Most commonly linked to the use of nuclear power in an electricity mix. Measured in kg of uranium-235 (U235) equivalents or DALY.

\section{Midpoint indicators calculated based on resource use}

- Land Use/Occupation - Area of land occupied over time, characterized in terms of biological productivity. Measured in terms of area equivalent to an area of land of specified biological productivity.

\footnotetext{
${ }^{21}$ Note than the impacts of plastic debris, fragments, and degradation products on marine ecosystems are not explicitly tracked in the ecosystem toxicity impact assessment methods used in LCA studies. Marine debris is discussed in more detail in the following section.
} 
- Water Consumption - Water withdrawals less water returned to the same watershed, measured by volume.

- Fossil Energy Depletion - Amount of fossil energy extracted from the earth, measured in terms of equivalency to a reference fossil energy source, typically oil equivalents, in terms of relative abundance in the earth's crust.

- Mineral Depletion - Amount of scarce minerals extracted from the earth, measured in terms of equivalency to a reference mineral, for example iron equivalents, in terms of relative abundance in the earth's crust.

\section{Allocation Methods for Recyclable and Recycled Content Attributes}

When material from one product is recycled and then incorporated into a new product as recycled content, a decision must be made on how to allocate the burdens of virgin materials production, collection and recycling of the material, and final material disposal across the life cycles of the two or more products ${ }^{3}$. The recycled content method, avoided burden method, and $50 / 50$ method are three commonly used recycling allocation methods used in attributional LCAs 4,5. All three of these methods were represented in the studies reviewed in this project.

The recycled content method, also referred to as the cut-off or 100/0 method allocates the entire burden of primary material production to the first product while the burdens of material collection and processing for recycling are attributed to the subsequent product (see Figure S2) ${ }^{4}$. End-of-life disposal burdens are assigned to the product system from which the material is ultimately disposed, and no credits are granted for energy recovery resulting from disposal of materials.

The avoided burden approach ${ }^{4}$, also known as system expansion, end-of-life-recycling, recyclability substitution, or $0 / 100$, assigns the benefits of material recycling to products recycled at end-of-life and does not give credits for use of recycled content. The first product, when recycled, is credited for the avoided burdens of virgin material production for the form in which the material is used in the second product. The avoided material credit may not correspond exactly to the form in which the material was used in the first product. For example, polyethylene terephthalate (PET) bottles made of high viscosity food-grade PET may be recycled into amorphous PET and used in the second system without restoring the material to the same viscosity and level of decontamination as in its first use. In this case, the material credit would be based on avoiding the production of amorphous PET, a 'down-cycling' of the original high viscosity food-grade PET. The secondary product would then be associated with production impacts equal to the material credit of the first product, and is eligible for a material credit if it is also recycled (FTC, 2012).

The shared burden or 50/50 method assigns virgin material production, recycling, and final disposal burdens equally across the first and second products ${ }^{7}$. When a material is recycled across many product life cycles, the virgin material production, recycling, and final disposal burdens are divided equally across all product life cycles. 
Recycled Content or 100/0 Approach

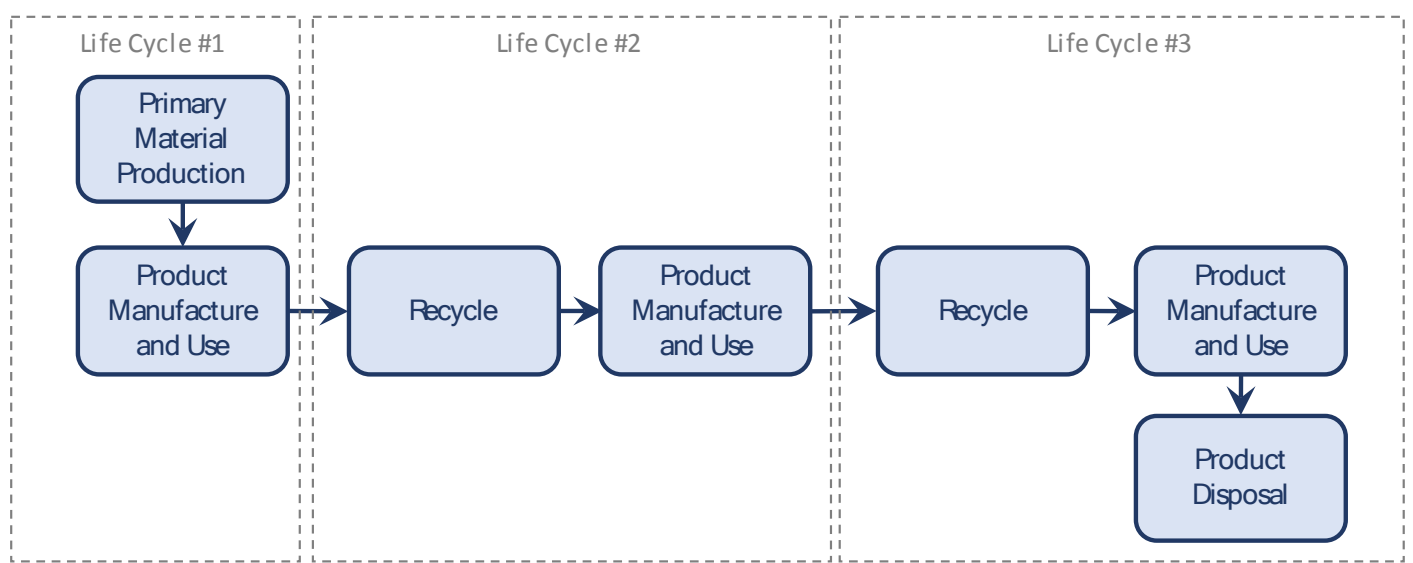

Avoided Burden or 0/100 Approach

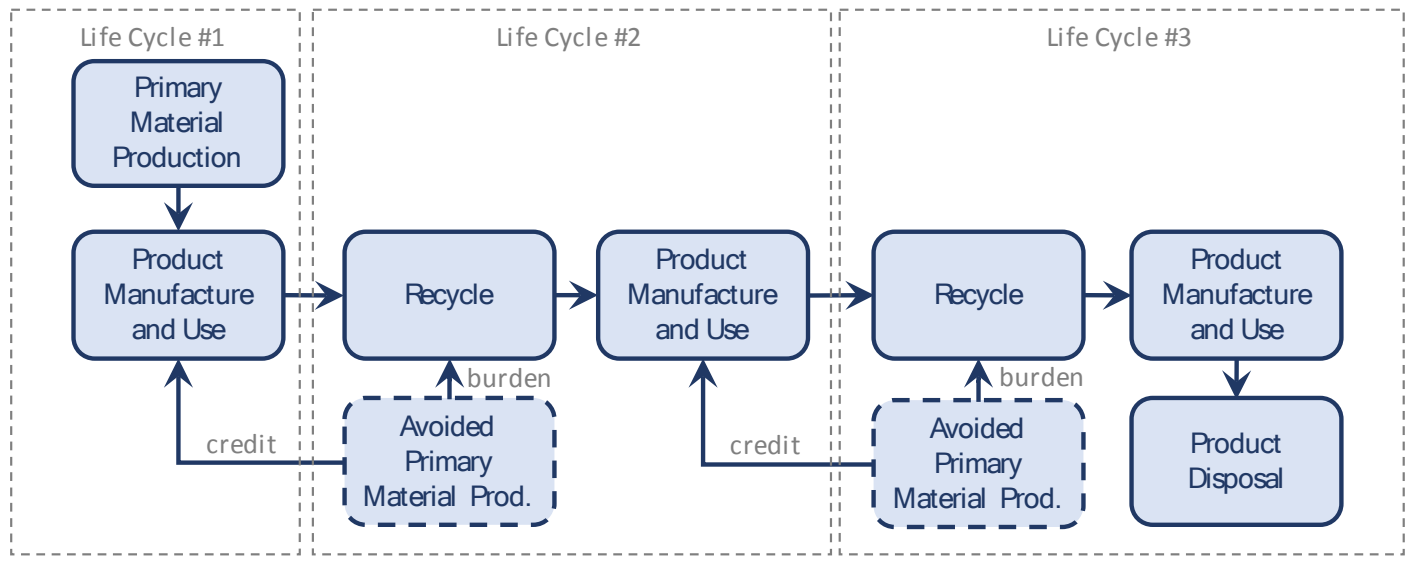

Shared Burden or 50/50 Approach

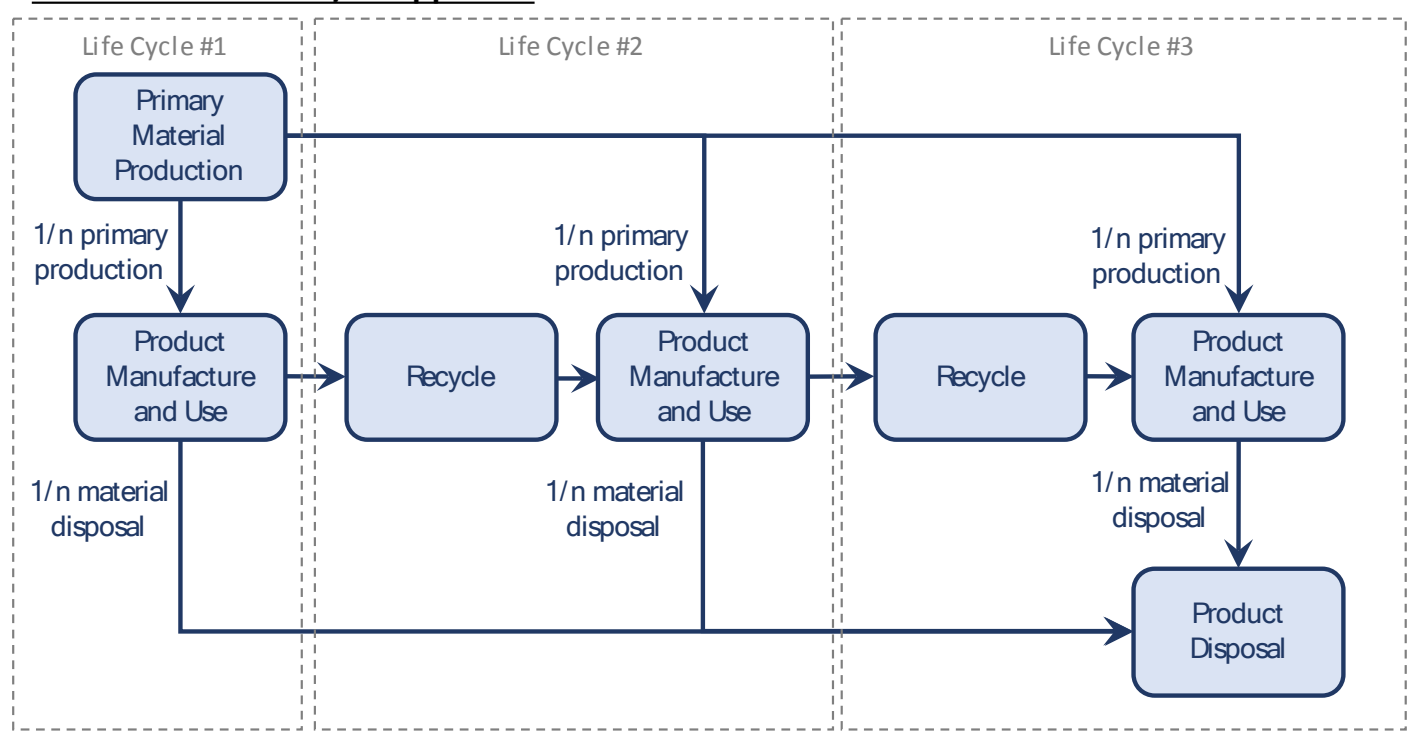

Figure S2. Recycling Allocation Methods Used in Life Cycle Assessment Studies. 
While statistics are available on recycling rates for certain materials/product types, data are not available to quantify the average number of product lifetimes in which a material is used.

Therefore, an LCA practitioner could only reasonably predict a material's use in two to three product lifetimes - for a product using virgin material that is recycled at the end of the product's useful life, the material will be incorporated into at least one more product before disposal, and for a product with recycled content, the practitioner knows that there was at least one prior use of the material and can assume one more use if the product being modeled is recycled at end-of-life. The recycled content approach favors products with high levels of recycled content because recycled material comes into the system free of virgin production burdens. Conversely, the avoided burden method results in lower impacts for products with high recycling rates. The avoided burden method is preferred by the metals industry as the supply of recycled metals is limited due to the long service life of many products utilizing metals. The metals industry contends that the benefits of material recycling should be attributed to recycling at the end-of-life to encourage recycling to increase the amount of secondary metals available ${ }^{5,8,9}$. The avoided burden approach is also employed in US EPA's WARM tool, which is widely used by recycling and solid waste professionals in the US. 


\section{Calculation of Comparison Ratios}

LCIA results were summarized and compared by creating ratios of results for a packaging or FSW option with the scenarios including the environmental attribute of interest (i.e. recycled content, recyclable, biobased, or compostable) divided by the results for the conventional option that provides the same function. Specifically, for each impact category included in a study, the comparisons were calculated using the following equation:

$$
\frac{[\text { LCIA result for attribute }]}{[\text { LCIA result for conventional }]}
$$

LCA inherently involves a considerable amount of data and modeling uncertainty. For this review, differences in comparisons are considered meaningful if the ratio of results is less than 0.75 or greater than 1.25 . More specifically, we classified the ratios of an option with the attribute to an option without the attribute as follows:

- lower impact $(<0.75)$

- marginal decrease in impact $(\geq 0.75$ and $<1.00)$

- no difference (1.0)

- marginal increase in impact $(>1.00$ and $\leq 1.25)$

- higher impact $(>1.25)$

The larger the ratio value, the greater the environmental impact of the material(s) being evaluated compared to the baseline material. These ranges are presented in the results sections and are used to interpret the comparisons found through the literature for each attribute.

In some cases, the LCIA results are presented as negative values, meaning they represent a net reduction in environmental impacts. This is usually a result of avoided burdens assigned to that scenario. For example, incineration of plastic waste may result in a negative GWP, as the energy recovered from the plastic may offset electricity or heat generated from more carbon intensive fossil-based sources. If a conventional packaging scenario results in a negative LCIA value, the normal ratio equation will not yield a result consistent with the previously introduced classifications. Instead, the percent difference between the two LCIA results is calculated, using the following equation:

$$
1-\frac{[\text { LCIA result for conventional }]-[\text { LCIA result for attribute }]}{[\text { LCIA result for conventional }]}
$$

This approach yields the same results as the simpler ratio equation for two positive values and ensures that comparisons where the conventional option has a negative value will yield an outcome consistent with the impact classifications presented. 


\section{Summaries of Studies}

\section{Packaging}

\section{Recycled Content}

Amienyo, D., Camilleri, C., \& Azapagic, A. (2014). Environmental impacts of consumption of Australian red wine in the UK. Journal of Cleaner Production, 72, 110-119. http://doi.org/10.1016/j.jclepro.2014.02.044
Product
Australian red wine consumed in UK
Geography
Australia/UK
Systems/
- Glass bottles
Scenarios
$\circ$ Baseline: $0.75 \mathrm{~L}$ glass bottle $\mathrm{w} / 85 \%$ recycled content
○ Sensitivity: 0.75L glass bottle w/ $0,70,80,90$, or $100 \%$ recycled content
○ Note: $85 \%$ bottles recycled at EOL in UK
- Laminate cartons
Key Findings - For every $10 \%$ increase in recycled glass content, GWP decreases by $2 \%$ and $0.7 \%$ to $1.2 \%$ decreases for other impact categories except water demand which is unchanged
- Lightweighting:
○ $10 \%$ reduction in glass weight results in $4 \%$ lower GWP and $3-7 \%$ lower for other impacts
○ $30 \%$ reduction in glass weight results in $11 \%$ lower GWP and $7-15 \%$ lower for other impacts

- Cartons vs. glass

○ Carton $=100 \%$ virgin materials, $100 \%$ landfill at EOL

○ GWP reduction of $51 \%$; reductions of $25 \%$ for EP to $70 \%$ Marine Ecotoxicity; no change for water demand

\begin{tabular}{|c|c|}
\hline $\begin{array}{l}\text { Functional } \\
\text { Unit }\end{array}$ & $0.75 \mathrm{~L}$ wine \\
\hline $\begin{array}{l}\text { System } \\
\text { boundary }\end{array}$ & $\begin{array}{l}\text { Cradle to grave - includes viticulture (cultivation and harvest of grapes), } \\
\text { wine production (vinification) and bottling, primary packaging (secondary } \\
\text { and tertiary not included), transport to retail, and EOL }\end{array}$ \\
\hline $\begin{array}{l}\text { LCI data } \\
\text { sources } \\
\text { Allocation } \\
\text { Method }\end{array}$ & $\begin{array}{l}\text { Primary data obtained for viticulture and vinification and bottling; all other } \\
\text { data from publicly available literature, ecoinvent, GaBi, and CCaLC } \\
\text { Recycled content method }\end{array}$ \\
\hline $\begin{array}{l}\text { LCIA Method } \\
\text { Result/Impact } \\
\text { Categories }\end{array}$ & $\begin{array}{cl}\text { CML } & 2001 \text { midpoint } \\
\text { - } & \text { Global warming } \\
\text { - } & \text { Acidification } \\
\text { - } & \text { Eutrophication } \\
\end{array}$ \\
\hline
\end{tabular}


- Ozone depletion

- Smog formation

- Human toxicity, cancer

- Freshwater ecotoxicity

- Marine ecotoxicity

- Terrestrial ecotoxicity

- Primary energy demand

- Abiotic depletion

- Water depletion

Belley, C. (2011). Comparative life cycle assessment report of food packaging products. Montreal, QC. Retrieved from https://www.cascades.com/media/multiuploader_images/6/12/41/LCAFoodPackagingProducts_1.pdf

Product

Geography

Systems/Scenarios

Key Findings

\section{Fruit and vegetable trays}

UK

- $100 \%$ virgin extruded polystyrene foam (XPS)

- $90 \%$ virgin- $10 \%$ recycled oriented polystyrene (OPS)

- $90 \%$ virgin- $10 \%$ recycled polyethylene terephthalate (PET)

- $100 \%$ recycled PET (RPET)

- $90 \%$ virgin- $10 \%$ recycled polylactide polymer (PLA)

- $90 \%$ virgin- $10 \%$ recycled polypropylene (PP)

- $100 \%$ recycled molded pulp (MP)

- PLA tray had highest impact in all categories except second highest in resource depletion; PET and PP (both w/ 10\% RC) also performed poorly; performance of OPS and $100 \%$ rPET trays tended to fall in the middle of the range.

- XPS tray had lowest impacts in ecosystems quality, climate change, and aquatic eutrophication; second lowest in human health, resource depletion, and aquatic acidification

- Molded pulp had lowest impacts in human health, resource depletion, and aquatic acidification; second lowest in ecosystems quality and climate change; 4th lowest in aquatic eutrophication, but only about $40 \%$ greater than XPS (lowest impact)

\footnotetext{
Functional Unit $\quad 1$ tray measuring 8.38 inches in length, 5.88 inches in width and 1.06 inches

System boundary

LCI data sources in height. (Full functional unit description: Contain and permit the stacking and retailing of an amount of fruits or vegetables that can be contained in a tray volume of 52 in. 3 to consumers in Québec in 2010.)

Cradle to grave - includes production, distribution, and EOL of trays

Primary data from manufacturer, some from literature, background data from ecoinvent 2.0
} 


\begin{tabular}{ll} 
Allocation Method & Recycled content method \\
\hline LCIA Method & Impact2002+ \\
Result/Impact & - Global warming \\
Categories & - Aquatic acidification \\
& - Aquatic eutrophication \\
& - Ozone depletion \\
& - Smog formation \\
& - Ecosystem quality \\
& - Resource depletion \\
\hline
\end{tabular}

Cleary, Julian. (2013). Life cycle assessments of wine and spirit packaging at the product and the municipal scale: A Toronto, Canada case study. Journal of Cleaner Production. 44. 143-151. 10.1016/j.jclepro.2013.01.009.

\section{Product Wine; Spirits}

Geography Toronto, Canada

Systems/

Scenarios

Key Findings - For individual packages, the results from least to most net level impacts

- Two research objectives

- Compare the net life cycle impacts of five types of $1 \mathrm{~L}$ wine packages and four types of $750 \mathrm{ml}$ spirit packages

- $1 \mathrm{~L}$ wine \& $.75 \mathrm{~L}$ spirits:

- Lightweight single use (LSU) glass bottles

- Refillable glass (RFG) bottles (assume 15 refills)

- PET bottles

- Conventional single use (CSU) glass containers

- 1 L wine only

- Aseptic Cartons (ACs)

- Compare the net life cycle impacts from existing wine and spirit packaging consumption at a municipal scale with an alternative scenario comprising only lightweight and refillable forms of packaging

- 2008 reference scenario: wine \& spirit packaging supplied to Toronto residents and based on the Liquor Control Board of Ontario (LCBO) sales data

- Alternate scenario: packaging weight mass reduction of $47 \%$ due to replacement of all CSU glass containers with lightweight and refillable alternatives. are as follows for both wine (W) and spirits (S)

\footnotetext{
- $\mathrm{RFG}(\mathrm{W} \& \mathrm{~S})<\mathrm{AC}(\mathrm{W})<\mathrm{PET}(\mathrm{W} \& \mathrm{~S})<\mathrm{LSU}(\mathrm{W} \& \mathrm{~S})<\mathrm{CSU}$
} $(\mathrm{W} \& \mathrm{~S})$ 
- The decrease in container mass from the AC and PET substitutions drive the environmental savings when compared to the glass containers.

- For the municipal scale:

- Alternative packaging scenario averages $40 \%$ reductions in environmental impacts for most categories, excluding water (27\% reduction; greater water consumption during AC and PET production) and metal depletion ( $10 \%$ reduction; similar secondary packaging).

- Sensitivity analysis

- Transportation a main contributor of environmental impacts for all types of packaging analyzed

- Refillable bottles remain environmentally preferable if refills reduced to 10 .

Functional $1 \mathrm{~L}$ of wine; $750 \mathrm{ml}$ of spirits.

Unit

System Cradle to grave

boundary

LCI data Primary data (field and lab research) for mass of wine and spirit containers sources ( $\quad \mathrm{CBO}$ ), distances traveled from manufacturer to packager (questionnaires). Secondary data from US ecoinvent database and literature for containers and secondary packaging.

Allocation Avoided Burden. PET and glass bottles are based on closed loop recycling. AC Method is hydro-pulped, which allows the cardboard component to be recycled as pulp, while the aluminum and plastic components are landfilled.

$\begin{array}{ll}\text { LCIA Method } & \text { Recipe v } 1.02 \\ \text { Result/Impact } & \text { - Acidification } \\ \text { Categories } & \text { - Ecotoxicity } \\ & \text { - Eutrophication } \\ & \text { - Fossil energy depletion } \\ & \text { - Global warming } \\ & \text { - Human Toxicity } \\ & \text { - Land Use } \\ & \text { Ozone Depletion } \\ & - \text { Resource Depletion } \\ & \text { - Smog } \\ & - \text { Water Depletion }\end{array}$


Dormer, A., Finn, D. P., Ward, P., \& Cullen, J. (2013). Carbon footprint analysis in plastics manufacturing. Journal of Cleaner Production, 51, 133-141.

http://doi.org/10.1016/j.jclepro.2013.01.014

\section{Product Plastic food trays}

Geography UK

Systems/

Scenarios

- Baseline: PET tray $\mathrm{w} / 85 \%$ recycled content (23\% recycled)

- Virgin PET tray

- $100 \%$ rPET tray

Key Findings - Raw materials accounted for $45 \%$ of carbon footprint despite high recycled content

- Carbon footprint for $85 \%$ RC PET tray is $58 \%$ lower than for $100 \%$ virgin PET tray

- Carbon footprint for $100 \%$ RC PET tray would be $24 \%$ lower than for $85 \%$ RC PET tray

- This would be feasible for certain food applications where sealing the tray is not required

- In contrast, every $10 \%$ reduction in tray weight results in a $9.3 \%$ reduction in carbon footprint. (Also see recycling section.)

- Uncertainty analysis available - shows effects of processing efficiency

Functional Delivery of $14 \mathrm{~kg}$ of mushrooms

Unit

System Cradle to grave - includes virgin and recycled material production, secondary

boundary packaging, food production, filling, and refrigeration not included, transport to retail (not including product weight), and EOL

LCI data Excel model; primary data obtained for PET tray production; other data from sources ecoinvent, $\mathrm{GaBi}$, and other publicly available literature

Allocation Recycled content method

Method

LCIA Method Carbon footprint

Result/Impact • Global warming

Categories

Mattila, T., Kujanpää, M., Dahlbo, H., Soukka, R., \& Myllymaa, T. (2011). Uncertainty and Sensitivity in the Carbon Footprint of Shopping Bags. Journal of Industrial Ecology, 15(2), 217-227. http://doi.org/10.1111/j.1530-9290.2010.00326.x

\section{Product Shopping Bags}

Geography Finland 
Systems/

Scenarios
Key Findings

- Bag types included

$\begin{array}{ll}\circ & \text { LDPE } \\ \circ & \text { LDPE with } 60 \% \text { Recycled Content } \\ \circ & \text { Bleached Paper } \\ \circ & \text { Cotton } \\ \circ & \text { Biodegradable modified starch }\end{array}$

- Under current Finnish conditions, recycled PE bags had the lowest carbon footprint followed by cotton, paper, PE, and lastly biodegradable starch bags

- Uncertainty and sensitivity analyses available

Functional

Unit

Carrying devices for the transportation of goods from grocery stores for 1 year

System in Finland

boundary packaging, food production, filling, and refrigeration not included, transport to retail (not including product weight), and EOL

LCI data

sources

Allocation

Primary data obtained for bag production from manufacturers; other data from ecoinvent 2.0, GaBi, and other publicly available literature

- Credited use of plastic or modified starch bags as trash can liner with

Method avoided production of a polyethylene liner bag.

- Credited use of modified starch bags for compost bin liner with avoided production of a compost bag and for peat replaced by compost produced; carbon sequestration not included

\section{LCIA Method Carbon footprint}

Result/Impact • Global warming Categories

Franklin Associates. (2004). Life Cycle Inventory of Packaging Options for Shipment of Retail Mail-Order Soft Goods: Final Peer-Reviewed report. Prepared for Oregon Department of Environmental Quality. Prairie Village, KS. Retrieved from http://www.oregon.gov/deq/FilterDocs/wprLifeCycleInventory.pdf

Product

Corrugated boxes with dunnage or shipping bags for retail mail-order soft goods

Geography Oregon, US

Systems/

Scenarios

- $38 \%$ RC corrugated box with dunnage options below

- Virgin LDPE air packets

$\circ \quad$ Virgin EPS loose fill (peanuts)

- Virgin cornstarch based loose fill

- $100 \%$ RC molded pulp loose fill

○ Virgin crumpled unbleached kraft paper 
- $10 \%$ RC crumpled newsprint

- $100 \%$ RC shredded corrugated paperboard

- $100 \%$ RC shredded office paper

- $80 \%$ RC corrugated box with dunnage

- $30 \%$ RC LDPE air packets

- $30 \%$ RC EPS loose fill

- Virgin cornstarch based loose fill

- $100 \%$ RC molded pulp loose fill

- $50 \%$ RC crumpled unbleached kraft paper

- $50 \% \mathrm{RC}$ crumpled newsprint

- $100 \%$ RC shredded corrugated paperboard

- $100 \%$ RC shredded office paper

- Virgin unpadded bleached kraft paper shipping bag

- $30 \%$ RC unpadded bleached kraft paper shipping bag

- Virgin bleached kraft paper shipping bag with virgin unbleached kraft inner and $100 \%$ RC shredded newspaper pad

- $30 \%$ RC bleached kraft paper shipping bag with $30 \%$ unbleached kraft inner and $100 \%$ RC shredded newspaper pad

- Virgin bleached kraft paper shipping bag with virgin LDPE/ LLDPE bubble wrap padding

- $30 \% \mathrm{RC}$ bleached kraft paper shipping bag with $30 \% \mathrm{RC}$

LDPE/LLDPE bubble wrap padding

- Virgin unpadded LLDPE film shipping bag

- $30 \%$ RC unpadded LLDPE film shipping bag

- Virgin LLDPE film shipping bag with virgin LDPE/ LLDPE bubble wrap padding

- $30 \%$ RC LLDPE film shipping bag with 30\% RC LDPE/LLDPE bubble wrap padding

Key Findings - $\quad$ Total Energy Demand (million Btu/10,000 packages)

- All shipping bag life cycle scenarios require less than 75 MMBtu

- The packaging combinations with the lowest energy demand are the $30 \% \mathrm{RC}$ unpadded bleached kraft paper bag, the $30 \% \mathrm{RC}$ bubble-wrap padded bleached kraft paper bag, the virgin LLDPE unpadded film bag, and the 30\% RC LLDPE unpadded film bag.

- Energy demand for the $80 \%$ RC corrugated box using dunnage with high recycled content is around 250 million Btu regardless of dunnage material type, except for with $100 \%$ RC molded pulp loose fill, which is higher at over 300 million Btu 
- Energy demand for the $38 \% \mathrm{RC}$ corrugated box using dunnage with virgin or low $\mathrm{RC}$ material is around 300 million Btu regardless of dunnage material type, except for with $100 \% \mathrm{RC}$ molded pulp loose fill, which is higher at over 350 million Btu

- Increasing the recycled content of any given material (newsprint; LDPE) reduces energy demand when looking at packaging options of the same material, but the level of recycled content does not correlate with lowest energy demand when looking across material options - e.g., $80 \%$ RC box with $100 \%$ molded pulp fill has the second highest energy demand while the virgin unpadded LLDPE film bag has the second lowest energy demand

- The process of making $100 \% \mathrm{RC}$ molded pulp (pulping PCR ONP, pouring the pulp into molds, and drying) makes it energy intensive. Plus, molded pulp is heavier than other dunnage options, which adds to energy required for transportation.

Functional Packaging required to deliver 10,000 representative packages of soft goods Unit items to customers

System Cradle to grave - includes material production, packaging fabrication, transport boundary of packaging to order fulfillment center, distribution of packaging (does not include distribution burdens for product), and EOL of packaging

\begin{tabular}{|c|c|}
\hline $\begin{array}{l}\text { LCI data } \\
\text { sources }\end{array}$ & $\begin{array}{l}\text { Primary data from a large OR mail-order company and Pack Edge } \\
\text { Development, public and private LCA packaging case studies, US LCI } \\
\text { Database, Franklin Associates private LCI database, some datasets adapted } \\
\text { from ecoinvent } 2.0 \text { to reflect North American conditions. }\end{array}$ \\
\hline $\begin{array}{l}\text { Allocation } \\
\text { Method }\end{array}$ & $50 / 50$ method \\
\hline LCIA Method & None \\
\hline $\begin{array}{l}\text { Result/Impact } \\
\text { Categories }\end{array}$ & $\begin{array}{l}\text { - Total energy demand } \\
\text { - Solid waste } \\
\text { - Global warming }\end{array}$ \\
\hline
\end{tabular}

Franklin Associates. (2009). Life Cycle Assessment of Drinking Water Systems: Bottled Water, Tap Water, and Home/Office Delivery Water. Prepared for Oregon Department of Environmental Quality. Retrieved from http://www.oregon.gov/deq/FilterDocs/wprLCycleAssessDW.pdf Product Water delivery options - bottled water, tap water, and bulk water delivery

Geography Oregon, US

Systems/ - Bottled water

Scenarios 
- Virgin PET (8 oz, $16.9 \mathrm{oz}, \& 1 \mathrm{~L})$

○ $25 \%$ RC PET $(16.9 \mathrm{oz})$

○ Virgin PLA (16.9 oz)

- Tap water consumed in reusable containers

- Virgin aluminum bottle w/ plastic closure $(20 \mathrm{oz})$

- Virgin steel bottle w/ plastic closure (27 oz)

- Virgin plastic bottle w/ plastic closure (32 oz)

$\circ$ Drinking glass with mix of virgin and RC $(16 \mathrm{oz})$

- Home/office delivery

- Delivered in virgin PC bottles

- Delivered in virgin PET bottles

- Same reusable containers as listed for tap water scenarios

Key Findings Across all impact categories, the general trend across multiple scenarios is that tap water with reusable drinking container performs the best, then HOD with reusable drinking container, and bottled water is the worst. While increasing RC of a material used for bottled water, HOD container, or reusable drinking container improves the performance of a given system, it does not have a large enough impact to change the overall comparative results, especially between bottled water and tap water

Functional Delivering 1,000 gallons of drinking water to consumers

Unit

System Cradle to grave - includes material production, packaging fabrication, transport of boundary packaging to water filling locations, water treatment, bottle cleaning and filling, distribution of filled containers (including consumer transport for bottled water), water chilling, washing of reusable containers, and EOL of packaging

\begin{tabular}{|c|c|}
\hline $\begin{array}{l}\text { LCI data } \\
\text { sources }\end{array}$ & $\begin{array}{l}\text { Some primary data for container weights, US LCI Database, Franklin Associates } \\
\text { private LCI database, some datasets adapted from ecoinvent } 2.0 \text { to reflect North } \\
\text { American conditions. }\end{array}$ \\
\hline Allocation & Method 1: 50/50 method \\
\hline Method & Method 2: Recycled content method \\
\hline LCIA Method & U.S. EPA TRACI v1 \\
\hline $\begin{array}{l}\text { Result/Impact } \\
\text { Categories }\end{array}$ & $\begin{array}{l}\text { - Total energy demand } \\
\text { - Solid waste } \\
\text { - Acobal warming } \\
\text { - Acidification } \\
\text { - Oztrophication } \\
\text { - Smone depletion } \\
\text { - Human toxicity, cancer } \\
\text { - Human toxicity, non-cancer } \\
\text { - Particulate matter } \\
\text { - Freshwater ecotoxicity }\end{array}$ \\
\hline
\end{tabular}


Franklin Associates. (2008). LCI Summary for Six Tuna Packaging Systems: Peer Reviewed Final Report. Prepared for American Chemistry Council Plastics Division. Prairie Village, KS. Retrieved from https://plastics.americanchemistry.com/LCI-Summary-for-6-TunaPackaging-Systems

Product

Geography

Systems/

Scenarios

Key Findings

\section{Tuna packaging}

US

- 12 oz $33 \%$ RC (postconsumer) steel can

- $12 \mathrm{oz}$ virgin PET/aluminum foil/Nylon/PP laminate pouch

- 6 oz 33\% RC (postconsumer) steel can

- Three 3 oz 33\% RC (postconsumer) steel cans in 10\% RC paperboard sleeve

- Two 2.8 oz virgin PP plastic cups in 10\% RC paperboard sleeve

- Note steel packaging systems are assumed to have a recycling rate of $62 \%$. All other packaging systems are assumed to be disposed as U.S. average MSW (80\% landfill/20\% WTE incineration), including paperboard sleeves

- Energy demand is lowest for $12 \mathrm{oz}$ laminate pouch - less than half of energy demand for $12 \mathrm{oz}$ steel can. The system of three $3 \mathrm{oz}$ steel cans in paperboard sleeve has the highest energy demand - more than 1.5 times greater than the $3 \mathrm{oz}$ laminated pouch or the $2.8 \mathrm{oz}$ PP cups in paperboard sleeve

- GWP results follow a similar pattern to energy demand except GWP is lower for the $2.8 \mathrm{oz}$ PP cups than the 3 oz pouches.

- Note: Results should be interpreted with caution as neither secondary packaging nor potential refrigeration of the $12 \mathrm{oz}$ and $6 \mathrm{oz}$ packages are not included

\section{Functional $\quad 100,000 \mathrm{oz}$ tuna sold to consumers}

Unit

System Cradle to grave - includes material production, packaging fabrication, and

boundary EOL of packaging. (Excludes secondary packaging, transport to filling, filling, storage, distribution, and consumer activities.)

LCI data

sources

Some primary data for container weights, 2007 ULS report: A Study of Packaging Efficiency as it Relates to Waste Prevention, US LCI Database, Franklin Associates private LCI database, some datasets adapted from ecoinvent 2.0 to reflect North American conditions.

Allocation $\quad 50 / 50$ method

Method

LCIA Method None 
Result/Impact • Total energy demand

Categories

- Solid waste

- Global warming

Franklin Associates. (2008). LCI Summary for Eight Coffee Packaging Systems: Peer Reviewed Final Report. Prepared for American Chemistry Council Plastics Division. Prairie Village, KS. Retrieved from https://plastics.americanchemistry.com/LCI-Summary-for-8-Coffee-PackagingSystems

Product Ground coffee packaging

Geography US

Systems/

Scenarios
$\quad-26 \mathrm{oz}$ fiberboard and steel canister

- $15 \mathrm{oz}$ fiberboard and steel canister

○ $0 \%, 50 \%$ and $100 \% \mathrm{RC}$ fiberboard

- $11.5 \mathrm{oz} 33 \% \mathrm{RC}$ (postconsumer) steel can

- $34.5 \mathrm{oz} 33 \% \mathrm{RC}$ (postconsumer) steel can

- 11.5 oz HDPE canister

- 34.5 oz HDPE canister

- 12 oz virgin PET/LLDPE/aluminum foil laminate bag

- 13 oz virgin PET/LLDPE/aluminum foil brick pack

- Note: recycling rate assumed to be $62 \%$ for steel canisters and $15.4 \%$ for HDPE canisters. All other packaging systems are assumed to be disposed as U.S. average MSW ( $80 \%$ landfill $/ 20 \%$ WTE incineration). Steel bottoms of the fiberboard canisters sent to WTE are collected and recycled.

Key Findings - Energy demand is lowest for 13 oz laminate brick - less than a quarter and third of the energy required for the $11.5 \mathrm{oz}$ and $34.5 \mathrm{oz}$ HDPE canister, respectively and around half of the energy demand for either fiberboard and steel canister or either steel can. The laminated pouch used $\sim 25 \%$ more energy than the laminated brick pack.

- GWP results follow a similar pattern to energy demand except GWP for the $34.5 \mathrm{oz}$ and $11.5 \mathrm{oz}$ steel cans is similar in magnitude to the HDPE canisters, resulting in approximately 3 and 4 times more GWP than the brick pack, respectively.

Functional $\quad 10,000 \mathrm{oz}$ ground coffee sold to consumers

Unit

System Cradle to grave - includes material production, packaging fabrication, and EOL of boundary packaging. (Excludes secondary packaging, transport to filling, filling, storage, distribution, and consumer activities.) 


\begin{tabular}{|c|c|}
\hline $\begin{array}{l}\text { LCI data } \\
\text { sources }\end{array}$ & $\begin{array}{l}\text { Some primary data for container weights, } 2007 \text { ULS report: } A \text { Study of Packaging } \\
\text { Efficiency as it Relates to Waste Prevention, US LCI Database, Franklin Associates } \\
\text { private LCI database, some datasets adapted from ecoinvent } 2.0 \text { to reflect North } \\
\text { American conditions. }\end{array}$ \\
\hline $\begin{array}{l}\text { Allocation } \\
\text { Method }\end{array}$ & $50 / 50$ method \\
\hline LCIA Method & None \\
\hline $\begin{array}{l}\text { Result/Impact } \\
\text { Categories }\end{array}$ & $\begin{array}{l}\text { - Total energy demand } \\
\text { - Solid waste } \\
\text { - Global warming } \\
\end{array}$ \\
\hline
\end{tabular}

Dhaliwal, H., Browne, M., Flanagan, W., Laurin, L., \& Hamilton, M. (2014). A life cycle assessment of packaging options for contrast media delivery: comparing polymer bottle vs. glass bottle. International Journal of Life Cycle Assessment, 19(12), 1965-1973. http://doi.org/10.1007/s11367-014-0795-1

- Dhaliwal et al looks at plastic vs glass vials for global distribution of contrast media for $\mathrm{x}$-rays. The baseline analysis includes $20 \%$ glass cullet in the glass vial, while the plastic vial is $100 \%$ virgin polypropylene (PP). Baseline results show that the PP vial impacts range from $20 \%$ to $60 \%$ of glass vial impacts.

- Results not sensitive to allocation method (cutoff vs market-based), end of life disposal method (incineration, landfill or recycle), bottle size, transport method, or increased recycled content for the glass vial

- Materials specifications for the glass vial allow $10-30 \%$ cullet, which is less than the typical $60 \% \mathrm{RC}$ content for borosilicate. Even if materials specifications allowed $60 \%$ cullet, glass vial impacts would only decrease by about $20 \%$. The PP vial still performs better than the glass vial (roughly $30 \%$ to $75 \%$ of glass impacts).

- Comparative results are somewhat sensitive to secondary packaging and shipping configuration: whether the vials are shipped in multipacks or single packs. When shipped in single packs, the PP vials perform more similarly to the glass vials, and in one scenario where single-pack vials are filled in Cork, Ireland, the PP vials perform slightly worse than the glass vials in GWP, ODP, PCOP, and resource depletion. 
Amienyo, D., Gujba, H., Stichnothe, H., \& Azapagic, A. (2013). Life cycle environmental impacts of carbonated soft drinks. International Journal of Life Cycle Assessment, 18(1), 77-92. http://doi.org/10.1007/s11367-012-0459-y

- Comparison of typical carbonated soft drink packaging (functional unit $=1 \mathrm{~L}$ ) in the UK:

- $330 \mathrm{ml} \mathrm{Al} \mathrm{can} \mathrm{w} / 48 \% \mathrm{RC}$ for can body, virgin $\mathrm{Al}$ for can ends; $48 \%$ recycled, $52 \%$ landfilled

- $\mathrm{GWP}=312 \mathrm{~g} / \mathrm{L}$

- $750 \mathrm{ml}$ white glass bottle $\mathrm{w} / 35 \% \mathrm{RC} ; 35 \%$ recycled, $65 \%$ landfilled

- $\mathrm{GWP}=555 \mathrm{~g} / \mathrm{L}$

○ $500 \mathrm{ml}$ virgin PET bottle; $24 \%$ recycled, $76 \%$ landfilled

- $\mathrm{GWP}=293 \mathrm{~g} / \mathrm{L}$

- $2 \mathrm{~L}$ virgin PET bottle; $24 \%$ recycled, $76 \%$ landfilled

- $\mathrm{GWP}=151 \mathrm{~g} / \mathrm{L}$

- GWP similar for $0.5 \mathrm{~L}$ virgin PET bottle and $330 \mathrm{ml} \mathrm{Al} \mathrm{can} \mathrm{w/} \mathrm{48 \%} \mathrm{RC}$

- Note that this comparison is somewhat unfair given the different sizes

- GWP for 2 L virgin PET bottle impact is $27 \%$ of the GWP for the glass bottle and $48 \%$ of the impact of the $\mathrm{Al}$ can.

- Note that this comparison could be considered unfair because the $2 \mathrm{~L}$ bottle would be considered a multiple-serving container as compared to the other single serve containers. Furthermore, the use phase impacts of either disposable or reusable cups to serve the beverage from the $2 \mathrm{~L}$ bottle are not included in this study.

- Effect of increased PET recycling

○ $500 \mathrm{ml}$ virgin PET bottle;

- $24 \%$ recycled, $76 \%$ landfilled (baseline): $\mathrm{GWP}=293 \mathrm{~g} / \mathrm{L}$

- $40 \%$ recycled, $60 \%$ landfilled: $\mathrm{GWP}=197 \mathrm{~g} / \mathrm{L} \rightarrow 1.6 \mathrm{x}$ recycle rate $=$ $33 \%$ LC impact reduction

- $60 \%$ recycled, $40 \%$ landfilled: $\mathrm{GWP}=152 \mathrm{~g} / \mathrm{L} \rightarrow 2.5 \mathrm{x}$ recycle rate $=$ $48 \%$ LC impact reduction

Zampori, L., \& Dotelli, G. (2014). Design of a sustainable packaging in the food sector by applying LCA. International Journal of Life Cycle Assessment, 19(1), 206-217. http://doi.org/10.1007/s11367-013-0618-9

- Poultry product packaging - comparison of PS-based tray (virgin material, $61 \% \mathrm{RR}$ ) and $\mathrm{Al}$ tray (30\% RC aluminum, 72\% RR); sensitivity analysis with 100\% RC Al tray

- Packaging production - results for PS tray lower (by 75-97.5\%) than 30\% RC Al tray. PS tray production impacts also notably lower for all impact categories compared to $100 \% \mathrm{RC}$ Al tray.

$\circ$ GWP (kg CO2eq): Al tray $=0.372$ PS tray $=0.136$ (PS tray $\sim 1 / 3$ of Al tray GWP) 
- EOL impact - Cutoff scenario: small impacts for both (GWP $<0.01 \mathrm{~kg} \mathrm{CO}$ eq); System expansion: EOL produces credits for both $-0.181 \mathrm{~kg}$ CO2eq for Al tray and $-0.125 \mathrm{~kg}$ CO2eq for PS tray

- Use phase of cooking chicken in electric oven included in study because Al tray specifically designed to be used in cooking of chicken and reduces cooking time (and therefore energy use) relative to cooking in a typical ceramic pan. (Ceramic pan and washing was accounted for in the PS tray system but made insignificant contribution to overall results.) Use phase is by far the largest contributor to overall GWP results for poultry packaging. The Al tray use phase impacts are 13\% lower than for the PS tray.

- Overall

- With cut-off method (Fig 7), PS tray is lower than 30\% RC Al tray in all ILCD midpoint impact categories except water depletion: PS tray was slightly $(0-15 \%)$ lower in GWP, ODP, PM, PCOP, AP, Terrestrial EuP, Marine EuP, and Land Use; moderately (20-30\%) lower in Human toxicity non-cancer and Ionizing radiation - both $\mathrm{HH}$ and E; considerably (40-60\%) lower in Freshwater EuP, Freshwater Ecotox, and resource depletion; over $80 \%$ lower in human toxicity cancer results.

○ With system expansion (Fig 8), results are more mixed: 30\% RC Al tray had lower impacts for GWP, ODP, and PM, but higher for human toxicity impacts and resource depletion.

- Increasing RC content of $\mathrm{Al}$ tray from $30 \%$ to $100 \%$ decreased most production impacts from $60-80 \%$; water depletion and human toxicity cancer decreased $50 \%$ and just over $40 \%$, respectively (Fig 12 ).

- With cut-off method, $100 \% \mathrm{RC} \mathrm{Al} \mathrm{tray} \mathrm{(Fig} \mathrm{11)} \mathrm{is} \mathrm{slightly} \mathrm{lower} \mathrm{or} \mathrm{very} \mathrm{similar} \mathrm{to}$ PS tray impacts in 10 of the 16 ILCD impact categories (GWP, ODP, PM, Ionizing radiation $\mathrm{HH}$ and $\mathrm{E}, \mathrm{PCOP}, \mathrm{AP}$, Terr. EuP, Mar. EuP, and Land use), considerably (over 60\%) lower in water depletion, but still somewhat higher in Fw EuP, Fw Ecotox, resource depletion and human toxicity non-cancer, and considerably higher in human toxicity cancer effects. Monte Carlo analysis found the differences between $100 \% \mathrm{Al}$ tray and PS tray significant except in the case of ionizing radiation ( $\mathrm{HH}$ and $\mathrm{E}$ ), freshwater ecotoxicity, and resource depletion.

- GWP results are somewhat sensitive to electricity grid mix (especially for the use phase) $-100 \% \mathrm{RC}$ Al tray had lower life cycle GWP when modeling the average national grids for Italy, UK, Germany, Holland, and Denmark, but higher for France since the French grid has such a high percentage of nuclear power which has very low associated GHG emissions 
Arena, U., Mastellone, M. L., \& Perugini, F. (2003). Life Cycle assessment of a plastic packaging recycling system. The International Journal of Life Cycle Assessment, 8(2), 92-98. http://doi.org/10.1007/BF02978432

- Study carried out an LCI of recycling process of PE and PET liquid containers in Italy.

- Found gross energy consumption for recycled PET to range from 42-55 MJ vs $>77 \mathrm{MJ}$ for virgin

- Found gross energy consumption for recycled PE to range from 40-49 MJ vs $\sim 80 \mathrm{MJ}$ for virgin

- Note: Further details are provided on energy consumption, solid waste production, air emissions, water emissions, GHG emissions, and water consumption, but they are totals reported in terms of a bundled product of $1 \mathrm{~kg}$ of PET and $0.39 \mathrm{~kg}$ PE flake. The authors do not attempt to allocate the impacts of collection between the two material types.

- Note: It is unclear how the authors arrived at the gross energy consumption values for virgin and $100 \%$ RC PE and PET provided in the abstract and listed above since allocation between the two resins is not described in the body of the paper.

Markwardt, S., \& Wellenreuther, F. (2016). Sensitivity analysis as a tool to extend the applicability of LCA findings. International Journal of Life Cycle Assessment, 21(8), 11481158. http://doi.org/10.1007/s11367-016-1094-9

- Markwardt and Wellenreuther look at various types of liquid food packaging systems used in the European market including two food cartons, laminate pouch, 59\% external cullet glass jar, steel can, and a plastic container. Despite the recycled content in the glass jar, the glass packaging system has either the highest or second highest results for all of the impact categories examined while the lighter-weight cartons perform the best. Only the plastic container performed worse than the glass jar in the summer smog, aquatic eutrophication, and abiotic resource depletion categories.

Kuczenski, B., \& Geyer, R. (2013). PET bottle reverse logistics - Environmental performance of California's CRV program. International Journal of Life Cycle Assessment, 18(2), 456-471. http://doi.org/10.1007/s11367-012-0495-7

- Kuczenski and Geyer completed an LCA of recycling of PET bottles collected in California's bottle redemption program and subsequent production of rPET pellets. Results for rPET pellets are compared to a scenario with virgin PET pellets and landfilling of PET bottles (based on the system expansion method which assumes that the PET bottles will be landfilled if the PET pellet demand is met by virgin material instead of rPET).

- Net impacts for in-state reclamation of rPET pellets were significantly lower for the GWP, criteria pollutants, primary energy demand, and smog/PCOP categories, ranging from $17 \%$ to $57 \%$ of impact levels for the virgin PET pellets (plus 
landfilling of PET bottles). Eutrophication impacts are considerably higher based on the TRACI impact method due to wastewater emissions from the reclamation process.

- The authors assume that the rPET produced is of the same quality as virgin bottle grade PET, which they acknowledge is optimistic and provides an upper bound for impact reduction possible using rPET

- Results were sensitive to the assumptions used to allocate burdens for consumer drop-off collection, fuel efficiency for curbside collection, and the distance recovered bottles are transported to the reclamation facility (in-state vs out-of-state vs East Asia)

Krystofik, M., Babbitt, C. W., \& Gaustad, G. (2014). When consumer behavior dictates life cycle performance beyond the use phase: Case study of inkjet cartridge end-of-life management. International Journal of Life Cycle Assessment, 19(5), 1129-1145. http://doi.org/10.1007/s11367-014-0713-6

- In a sensitivity analysis, this article looks at the effect of increasing recycled PET content in ink cartridges on production and life cycle GWP and CED impacts.

\section{Reviewed studies not recommended for use:}

The American Chemistry Council (ACC) and The Canadian Plastics Industry Association (CPIA) (2014). Impact of plastics packaging on life cycle energy consumption \& greenhouse gas emissions in the United States and Canada: Substitution Analysis. Prepared by Franklin Associates, A Division of Eastern Research Group (ERG). Retrieved from https://plastics.americanchemistry.com/Education-Resources/Publications/Impact-of-PlasticsPackaging.pdf

Product

Comparison of a range of plastic packaging to alternative materials used for the same product

Geography

Systems/

Scenarios

\section{North America}

- Product types:

○ Other rigid packaging (includes the subcategories non-bulk rigid packaging, rigid protective packaging, and rigid bulk packaging)

- Other flexible packaging (includes the subcategories converted flexible packaging, flexible protective packaging, and flexible bulk packaging)

○ Beverage packaging

- Carrier bags

○ Shrink and stretch film 
- Caps and closures

- Resin types included:

○ Low-Density Polyethylene (LDPE)

- High-Density Polyethylene (HDPE)

○ Polypropylene (PP)

○ Polyvinyl Chloride (PVC)

- Polystyrene (PS)

- Expanded Polystyrene (EPS)

- Polyethylene Terephthalate (PET)

- Alternative material types include:

○ steel;

○ aluminum;

○ glass;

- paper-based packaging including corrugated board, packaging paper, cardboard (both coated and uncoated), molded fiber, paper-based composites and laminates;

$\circ$ fiber-based textiles; and

o wood

- (Cork and rubber only considered for closures)

Key Findings If plastic packaging were replaced with alternatives -

- GWP (as measured in $\mathrm{CO} 2$ eq) would be:

$\circ 0.05$ to 0.28 million metric tons (MMT) lower for caps and closures

- 9.60 to 9.70 MMT higher for beverage containers

$\circ \quad 10.5$ to 11.1 MMT higher for stretch and shrink wrap

- 8.65 to 10.6 MMT higher for carrier bags

- 26.8 to 37.7 MMT higher for other flexible packaging

○ 20.4 to 20.7 MMT higher for other rigid packaging

- Cumulative energy demand (CED) would be:

- 38.8 to 39.0 billion MJ lower for caps and closures

- 117 to 118 billion MJ higher for beverage containers

- 178 to 180 billion MJ higher for stretch and shrink wrap

○ 71.4 to 72.6 billion MJ higher for carrier bags

- 714 to 725 billion MJ higher for other flexible packaging

○ 52.3 to 52.7 billion MJ higher for other rigid packaging

Results not usable for current study since they are aggregated for all packaging types and materials

Functional Unit
- Functional unit of the overall study is the substitution of total consumption of plastic used in each packaging category for the data year in which the most recent market data is available. Because the 
function of plastic packaging products differs amongst the investigated packaging categories, the functional unit is unique for each packaging category (see table below).

Table ES-1. Functional Unit of Comparison for Investigated Packaging (

\begin{tabular}{|c|c|}
\hline Category: & $\begin{array}{l}\text { Functional Unit of Comparison } \\
\text { for Altemative Material Weight Required: }\end{array}$ \\
\hline \multirow{2}{*}{ Other Rigid } & Volume Capacity for Non-Bulk \& Bulk Rigid Packagin \\
\hline & Protective Performance for Protective Packaging \\
\hline \multirow{3}{*}{ Other Flexible } & Volume Capacity for Converted \& Bulk Packaging (except str. \\
\hline & Protective Performance for Protective Packaging \\
\hline & Unitizing Performance for Flexible Bulk Strapping \\
\hline Beverage Containers & Volume Capacity \\
\hline Camier Bags & Number of Units (adjusted for difference in capacity) \\
\hline Stretch \& Shrink & Square Footage adjusted for performance \\
\hline Caps \& Closures & Number of Units \\
\hline
\end{tabular}

System Cradle to grave - includes raw material production, packaging fabrication, boundary distribution transport (to and from product packaging location), and EOL. Filling, storage, refrigeration, and/or freezing of products are excluded

LCI data Freedonia Market Reports, public and private LCA packaging case studies, sources US LCI Database, Franklin Associates private LCI database, some datasets adapted from ecoinvent 2.0 to reflect North American conditions.

Allocation Avoided burden method

Method

LCIA Method None

Result/Impact

Categories

- Total energy demand

- Solid waste

- Global warming

Accorsi, R., Versari, L., \& Manzini, R. (2015). Glass vs. Plastic: Life Cycle Assessment of Extra-Virgin Olive Oil Bottles across Global Supply Chains. Sustainability, 7(3), 2818-2840. http://doi.org/10.3390/su7032818

\section{Product Olive oil packaging}

Geography Italy/Global

Systems/

Scenarios

- Baseline: PET tray w/ 85\% recycled content (23\% recycled)

- Virgin PET tray

- $100 \%$ rPET tray 
Key Findings - Not enough information/ confusing explanations about EOL scenarios make the results from this study very difficult to interpret. Would recommend excluding from our study

Functional $1 \mathrm{~L}$ bottle of EVOO produced in Italy and consumed globally

Unit

System Cradle to grave - includes consolidation of EVOO and packaging (primary and

boundary secondary), the processing and bottling, the storage and all of the required transport operations, and EOL

LCI data Primary data obtained for EVOO processing and bottling and distribution; all sources other data from ecoinvent 2.2, plus some publicly available literature

Allocation Consequential system expansion

Method

- Assumes $100 \%$ of recycled glass is used in new bottles and is therefore an avoided burden. Not clear where, i.e. which life cycle stages, burdens and benefits of recycled material and recycling collection and processing are included.

- Assumes 50\% of recycled PET is used in new bottles and is therefore an avoided burden. Unclear if burdens of recycling collection and processing are included. In alternative scenario 4 (rPET), remainder of recycled plastic is used to make woven plastic materials and benefits are outside the system boundaries.

\section{LCIA Method EDIP 2003 midpoint}

Result/Impact

Categories

Almeida, C. M. V. B., Rodrigues, A. J. M., Agostinho, F., \& Giannetti, B. F. (2017). Material selection for environmental responsibility: the case of soft drinks packaging in Brazil. Journal of Cleaner Production, 142, 173-179. http://doi.org/10.1016/j.jclepro.2016.04.130

\section{Product Soft drink packaging}

Geography Brazil

Systems/

Scenarios

- $290 \mathrm{ml}$ glass bottle

- $100 \%$ virgin (Glass)

- $25 \%$ recycled content (Glass-R)

- $100 \%$ virgin, reused 20 times (Glass-20)

- $25 \%$ recycled content, reused 20 times (Glass-20R)

- $25 \%$ recycled content, reused 40 times (Glass-20R)

- 2L PET bottles

- $100 \%$ virgin

○ $40 \%(?)$ recycled content 
- $350 \mathrm{ml}$ (average vol.) aluminum can

○ $100 \%$ virgin

○ $91.5 \%$ recycled content

Key Findings - Results show reusable glass bottles with recycled content is the best option, followed by PET bottles and aluminum cans, both with recycled content

- Scenarios and methodology are not well defined making it difficult to interpret the meaning of results. Not recommended to include in our study.

Functional $\quad 1,000 \mathrm{~L}$ of soft drink

Unit

System Cradle to grave

boundary

LCI data

sources

Allocation

Consequential system expansion

Method

- Assumes $100 \%$ of recycled glass is used in new bottles and is therefore an avoided burden. Not clear where, i.e. which life cycle stages, burdens and benefits of recycled material and recycling collection and processing are included.

- Assumes 50\% of recycled PET is used in new bottles and is therefore an avoided burden. Unclear if burdens of recycling collection and processing are included. In alternative scenario 4 (rPET), remainder of recycled plastic is used to make woven plastic materials and benefits are outside the system boundaries.

LCIA Method Emergy analysis (Note that emergy is a method for tracking the amount of energy from natural systems embodied in the resources used by a product or service. The term emergy comes from the combination of embodied and energy. Emergy can also be thought of as a measure of the quality of different forms of energy.)

Result/Impact

Categories

Arena, N., Sinclair, P., Lee, J., \& Clift, R. (2017). Life cycle engineering of production, use and recovery of self-chilling beverage cans. Journal of Cleaner Production, 142, 1562-1570. http://doi.org/10.1016/j.jclepro.2016.11.148

Product Self-chilling beverage can

Geography 
Systems/

Scenarios

Key Findings - Brief review of paper found that self-chilling can would require very high recovery, reuse, and recycling rates of components (aluminum inner can, steel outer can, and activated carbon) and production of activated carbon in a location with an electricity grid that has a high percentage of renewable energy in order for impacts to be comparable to impacts of convention can chilled in open-front (inefficient) coolers.

- Given that the most optimistic (and unrealistic) scenario for the selfchilling cans is only comparable or slightly better than the worst-case scenarios using conventional cans, this technology is not likely to be pursued, so it does not seem like including the results will contribute to this study

Functional

Unit

System

boundary

LCI data

sources

Allocation

Method

LCIA Method

Result/Impact

Categories

Zabaniotou, A., \& Kassidi, E. (2003). Life cycle assessment applied to egg packaging made from polystyrene and recycled paper. Journal of Cleaner Production, 11(5), 549-559. http://doi.org/10.1016/S0959-6526(02)00076-8

- Comparative LCA study between virgin PS and 100\% recycled paper egg carton produced and used in Greece.

- Figure 4 shows that GWP, AP, EuP, ODP, winter smog, and summer smog (POCP) results are all lower for the $100 \% \mathrm{RC}$ paper egg carton than the PS egg carton. However, the paper egg carton had higher life cycle levels of carcinogenic substances and heavy metals (HM).

- NOTE: Confidence in the accuracy of these results is not high because the text describing the results in the discussion and conclusions sections contradicts the results shown graphically in figure 4. 
Iosip, A., Dobon, A., Hortal, M., \& Bobu, E. (2012). The influence of contaminants in the environmental impact of recovered paper: A life cycle assessment perspective. International Journal of Life Cycle Assessment, 17(8), 1050-1058. http://doi.org/10.1007/s11367-012-0430-y

- An examination of the change in impacts for manufacturing recycled paperboard (testliner) in Romania with increasing amounts of contamination

- Does not compare to virgin paperboard (kraftliner) or to recycling processes for other materials, so useful for this study 


\section{Recyclable}

Humbert, S., Rossi, V., Margni, M. et al. (2009). Life cycle assessment of two baby food packaging alternatives: glass jars vs. plastic pots. Int J Life Cycle Assess (2009) 14:95-106. DOI 10.1007/s11367-008-0052-6.

\section{Product \\ Baby food}

Geography

Systems/

Scenarios

Key Findings
Europe (Reference case Germany; other cases France, Spain).

- Glass jar packaging

○ GER: $86 / 14 \mathrm{R} / \mathrm{L}$

- Plastic pot packaging

○ GER: PP for plastic pot recycled at $40 \%$ according to fig. 5 .

- Table 3 says 75/25 “energy valorized"/incinerated;

- Assume 40/60 Recycled/Incinerated

- Plastic pots perform better for most impact categories except ionizing radiation when comparing same travel distance.

- This advantage of plastic pots is due to the sum of three effects: (a) production of plastic pot (including its end-of-life; $43 \%$ to $51 \%$ of total benefit), (b) reduction of mass to be distributed due to lighter packaging ( $20 \%$ to $35 \%$ of total benefit), and (c) new preservation process permitted by the plastic system leading to a limited on-site energy consumption ( $23 \%$ to $34 \%$ of total benefit).

- Increasing transportation distance reduces the advantage of plastic pots but not enough to make glass more beneficial.

Functional provide a proper vehicle for a child's baby food meal in France, Spain, and Unit Germany in 2007 (200 g packaging sizes)

System Cradle to grave - package production, product assembly, distribution, and boundary packaging fate at the end of its useful life. Does not include product use.

LCI data Primary data and information are obtained from Nestlé and their suppliers. sources Secondary data are obtained from the scientific literature and the Ecoinvent database.

Allocation $\quad$ System expansion (Avoided Burden)

Method

LCIA Method IMPACT 2002+, CML 2001 used for sensitivity

Result/Impact - Acidification

Categories $\quad$ Ecotoxicity

- Eutrophication

- Fossil Energy Depletion

- Global Warming 
- Human Toxicity

- Land Occupation

- Ozone Depletion

- Resource Depletion

- $\mathrm{Smog}$

Xie, M., Li, L., Qiao, Q., Sun, Q., \& Sun, T. (2011). A comparative study on milk packaging using life cycle assessment: from PA-PE-Al laminate and polyethylene in China. Journal of Cleaner Production, 19(17), 2100-2106.

\section{Product \\ Milk}

Geography

Systems/

Scenarios

Key Findings
China

- Aseptic packaging

○ Paper, PE, Aluminum composite (PA-PE-AL)

○ $28.56 \mathrm{~g}$

- $15 \%$ recycling rate rest landfilled

- LDPE packaging

○ $3.55 \mathrm{~g}$

○ $30 \%$ recycling rate rest landfilled

- Plastic pots perform better for most impact categories except ionizing radiation when comparing same travel distance.

- This advantage of plastic pots is due to the sum of three effects: (a) production of plastic pot (including its end-of-life; $43 \%$ to $51 \%$ of total benefit), (b) reduction of mass to be distributed due to lighter packaging ( $20 \%$ to $35 \%$ of total benefit), and (c) new preservation process permitted by the plastic system leading to a limited on-site energy consumption ( $23 \%$ to $34 \%$ of total benefit).

- Increasing transportation distance reduces the advantage of plastic pots but not enough to make glass more beneficial.

Functional provide a proper vehicle for a child's baby food meal in France, Spain, and

Unit Germany in 2007 (200 g packaging sizes)

System Cradle to grave.

boundary

LCI data

Aseptic packaging data - modelled with ecoinvent (cardboard, plastic) and sources literature data (aluminum).

Plastic packaging data - modelled from literature data. 
Primary data used for modeling recycling process; ecoinvent used for modeling landfill disposal.

Allocation Avoided burden (explicitly assumes 1:1 primary material displacement). Method

LCIA Method Eco-Indicator 99 method

Result/Impact - Acidification/Eutrophication (one metric in this LCIA method)

Categories

- Ecotoxicity

- Global warming

- Fossil energy depletion

- Human toxicity

- Land occupation

- Mineral depletion

- Ozone Depletion

Niero, M., \& Olsen, S. (2016). Circular economy: To be or not to be in a closed product loop? A Life Cycle Assessment of aluminum cans with inclusion of alloying elements. "Resources, Conservation and Recycling", 114, 18-31. https://doi.org/10.1016/j.resconrec.2016.06.023

\section{Product \\ Geography \\ UK}

Systems/

Scenarios

Key Findings

\section{Aluminum cans}

- Secondary Aluminum

- From Used Beverage Cans (UBC)

$\circ$ From Mixed Aluminum Packaging (MAP)

- EOL scenarios considered:

○ Recycling

- Closed loop recycling (UBC) is preferable over open loop recycling (MAP)

- UBC impacts lower in most categories but only conclusively so for Global Warming.

- Higher recycling rates show decrease in impacts

○ However, higher recycling rates are harder to achieve due to higher $\%$ of alloys (e.g. $\mathrm{Mn}$ ) required to be added to every cycle, as well as accumulation of impurities, eventually imposing limits to both the recycling rate and the amount of times a given material can be recycled.

- Possible solutions for improving closed loop recycling include development of unialloy products or more efficient material separation.

- Comparison of LCAs of open loop aluminum can recycling using a standard FU and this study's circular FU shows the circular FU results in higher impacts per same amount of $\mathrm{Al}$ recycled (both studies by same authors). This is due to the definition of the circular FU and the additional materials required to produce a recycled can over several loops. 


\begin{tabular}{|c|c|}
\hline $\begin{array}{l}\text { Functional } \\
\text { Unit }\end{array}$ & $\begin{array}{l}\text { Containment of } 1 \mathrm{hl} \text { of beer until the expiry date and supply of resource after its use } \\
\text { stage for } 30 \text { loops. This is considered by the authors to be a "circular economy } \\
\text { inspired functional unit". }\end{array}$ \\
\hline $\begin{array}{l}\text { System } \\
\text { boundary }\end{array}$ & Cradle to cradle for 30 loops. \\
\hline $\begin{array}{l}\text { LCI data } \\
\text { sources }\end{array}$ & $\begin{array}{l}\text { - Simapro, Ecoinvent v3.1. for multiple product system modeling (i.e. multiple } \\
\text { loops). } \\
\text { - Primary data provided by case study company for UK market for weight of } \\
\text { lid and body, and electricity and heat consumption. } \\
\text { - Sensitivity analysis performed on } \\
\text { ○ Decrease on can weight (-6.3\%, either lid or body) for current UK } \\
\text { recycling rate }(55 \%) \\
\text { O Separation of lid and body at collection point for recycling rates of } \\
75 \% \text { and } 95 \%\end{array}$ \\
\hline $\begin{array}{l}\text { Allocation } \\
\text { Method }\end{array}$ & $\begin{array}{l}\text { "EOL equation provided by the Product Environmental Footprint (PEF) guide". This } \\
\text { equation considers both recycled content (fixed at } 67.8 \% \text { ) and recycling rates } \\
\text { (varies) for each loop, so conceptually it is similar to the } 50 / 50 \text { method (?). }\end{array}$ \\
\hline LCIA Method & $\begin{array}{l}\text { - ILCD recommended LCIA method for midpoints (main) } \\
\text { - Cumulative Exergy Demand (CexD, measured in MJ, for abiotic depletion) } \\
\text { - Recipe } 2008+\text { at the endpoints (measured in } \$ \text {, for abiotic depletion). }\end{array}$ \\
\hline $\begin{array}{l}\text { Result/Impact } \\
\text { Categories }\end{array}$ & $\begin{array}{l}\text { - Global Warming } \\
\text { - Fossil Energy Demand }\end{array}$ \\
\hline
\end{tabular}

Sara Toniolo, Anna Mazzi, Monia Niero, Filippo Zuliani, Antonio Scipioni: Comparative LCA to evaluate how much recycling is environmentally favorable for food packaging. Resources, Conservation and Recycling, Volume 77, 2013, Pages 61-68, ISSN 0921-3449, https://doi.org/10.1016/j.resconrec.2013.06.003.

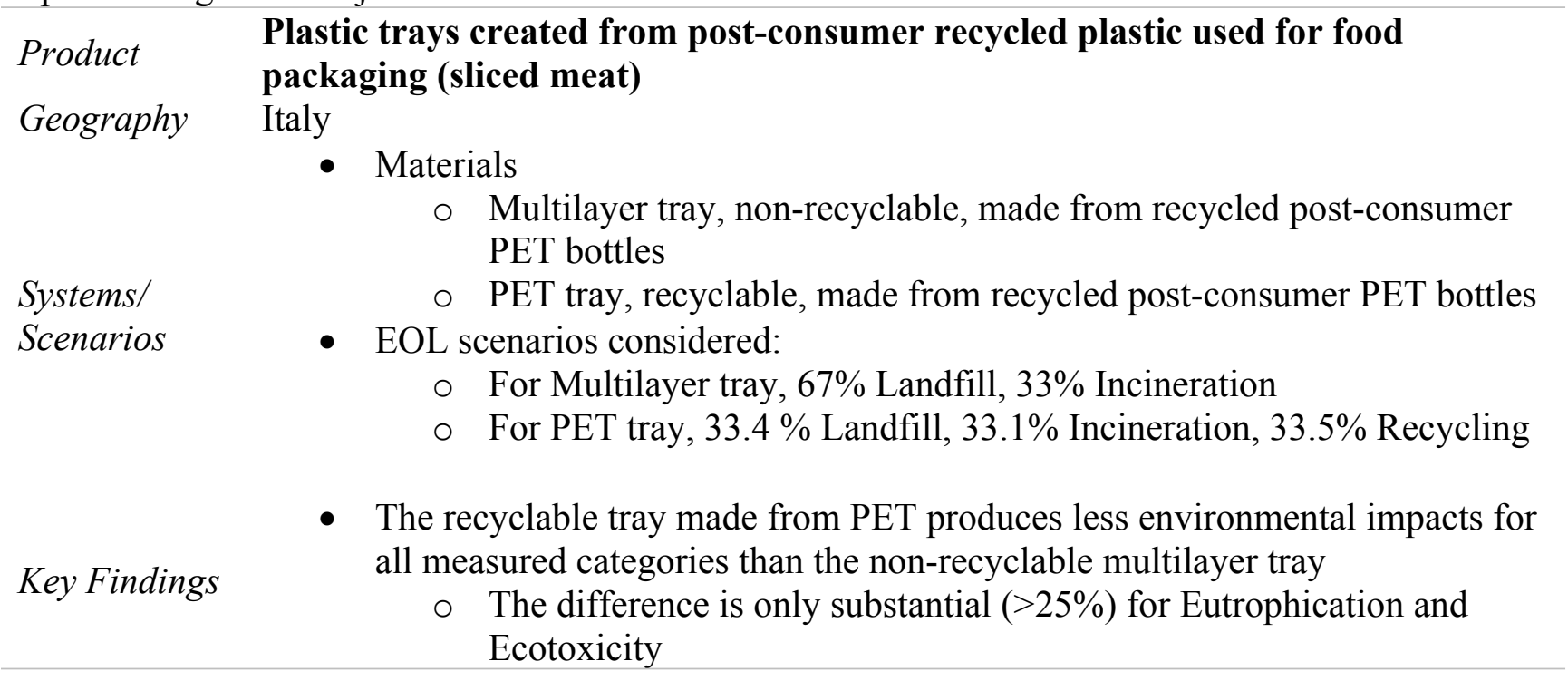


- The base results are obtained using the Recycled Content allocation method, but they do not change if the Avoided Burden method is used instead. This is corroborated in the study using sensitivity analysis and calculating the results using the $\mathrm{AB}$ method as well.

\begin{tabular}{|c|c|}
\hline $\begin{array}{l}\text { Functional } \\
\text { Unit } \\
\text { System } \\
\text { boundary }\end{array}$ & Tray with sealed lid with a capacity of $0.54 \mathrm{~L}$. \\
\hline $\begin{array}{l}\text { LCI data } \\
\text { sources }\end{array}$ & $\begin{array}{l}\text { - Primary data for the two types of trays for cradle to gate for the two types of } \\
\text { trays, obtained from "data sheets" } \\
\text { - Secondary data for end of life treatment }\end{array}$ \\
\hline $\begin{array}{l}\text { Allocation } \\
\text { Method }\end{array}$ & $\begin{array}{l}\text { Recycled Content as the base case; Avoided burden used as part of sensitivity } \\
\text { analysis. }\end{array}$ \\
\hline LCIA Method & Recipe $2008+$ with midpoint methodology \\
\hline $\begin{array}{l}\text { Result/Impact } \\
\text { Categories }\end{array}$ & $\begin{array}{l}\text { - Global Warming } \\
\text { - } \text { Acidification } \\
\text { - Eutrophication } \\
\text { - Ozone Depletion } \\
\text { - Smog } \\
\text { - Human Toxicity } \\
\text { - Ecotoxicity } \\
\text { - Fossil Energy Depletion } \\
\text { - Mineral Depletion } \\
\text { - Water Consumption } \\
\text { - Land Occupation }\end{array}$ \\
\hline
\end{tabular}

Xie, Minghui, Qi Qiao, Qihong Sun, and Linlin Zhang. "Life cycle assessment of composite packaging waste management - a Chinese case study on aseptic packaging." The International Journal of Life Cycle Assessment 18.3 (2012): 626-635. https://doi.org/10.1007/s11367-0120516-6
Product
Geography

\section{Aseptic packaging}
China
- Composite aseptic packaging/Tetra Pak
- 75/20/5 Carton/PE/Al foil
- EOL scenarios considered:
Systems/
- Landfill
Scenarios
- Incineration with energy recovery (electricity)
- Paper recycling for the carton components, landfill for the other components.
- Paper recycling for the carton components, separation for PE/Al foil components.

Key Findings - Landfill is the worst EOL scenario for aseptic packaging disposal 
- The impacts of the recycling scenarios are worse than incineration if the $\mathrm{PE} / \mathrm{Al}$ foil are landfilled, but better if they are separated due to the avoided landfill impacts of these materials

\begin{tabular}{|c|c|}
\hline $\begin{array}{l}\text { Functional } \\
\text { Unit } \\
\text { System } \\
\text { boundary }\end{array}$ & 1 tonne of post consumption Tetra Pak waste \\
\hline $\begin{array}{l}\text { LCI data } \\
\text { sources }\end{array}$ & $\begin{array}{l}\text { - Ecoinvent for landfill and incineration scenarios } \\
\text { - Primary data from two composite package recovery fac } \\
\text { - Secondary sources for energy (e.g. Lui et al. 2010) and } \\
\text { Ma et al. 2008) LCI }\end{array}$ \\
\hline $\begin{array}{l}\text { Allocation } \\
\text { Method }\end{array}$ & Avoided burden (denoted in the study as system expansion). \\
\hline LCIA Method & EcoIndi \\
\hline $\begin{array}{l}\text { Result/Impact } \\
\text { Categories }\end{array}$ & $\begin{array}{l}\text { - Global Warming } \\
\text { - Acidification/Eutrophication (combined in one metric) } \\
\text { - Human Toxicity } \\
\text { - Fossil Energy Depletion } \\
\text { - Mineral Depletion } \\
\text { - Land Occupation } \\
\text { - Ecotoxicity }\end{array}$ \\
\hline
\end{tabular}

Mourad AL, Garcia EES, Vilela GB, von Zuben F (2008): Environmental Effects from a Recycling Rate Increase of Cardboard of Aseptic Packaging System for Milk Using Life Cycle Approach. Int J LCA 13 (2) 140-146. http://dx.doi.org/10.1065/lca2007.06.340
Product
Geography
Aseptic Packaging System for Milk (Tetra Pak)
Brazil
- Aseptic packaging
Systems/
$\circ$ Laminate paper (70\%), PE, and aluminum foil
Scenarios
- EOL scenarios considered:
$\circ 2 \%$ recycling (default)
○ $22 \%$ recycling

Key Findings

- Increase in recycling rate decreases impacts in most categories

- Increase in recycling rate resulted in substantial increases in total suspended solids (57\%).

"The functional unit considers the complete packaging system: 1,000 liters of milk,

Functional distributed in corrugated paperboard trays with $12 \times 1 \mathrm{~L}$ units, wrapped with

Unit

polyethylene shrink film, arranged on one-way wooden pallets." (Mourad et al., 2008)

System

boundary

Cradle to cradle for the aseptic packaging, excluding milk production and preconsumer treatment (e.g. sterilization); and the production of inputs used in packaging material manufacturing (e.g., caustic soda, starch, etc.) 
- Secondary data for energy use (Brazil average, Coltro 2003).

\begin{tabular}{ll}
$\begin{array}{ll}\begin{array}{l}\text { LCI data } \\
\text { sources }\end{array} & \text { Primary data for production of cardboard packaging from manufacturer } \\
& \text { (Tetra Pak, Mourad 2000), and secondary data for PE and aluminum foil } \\
\text { production }\end{array}$ \\
$\begin{array}{ll}\text { Allocation } \\
\text { Method }\end{array}$ & Avoided burden \\
LCIA Method & Not specified \\
& - Global Warming \\
Result/Impact & - Human Toxicity \\
Categories & - Fossil Energy Depletion \\
& - Water Use \\
& - Land Occupation \\
\hline
\end{tabular}

Ferreira, S., Cabral, M., Jaeger, S., Da Cruz, N., Simões, P., \& Marques, R. (2015). Life cycle assessment and valuation of the packaging waste recycling system in Belgium. Journal of Material Cycles and Waste Management, 19(1), 144-154. https://doi.org/10.1007/s10163-0150383-x.
Product
Geography

\section{Packaging waste recycling system in Belgium} Belgium
- Plastic, Metal, and Drink (PMD) packaging
- EOL scenarios considered:
Systems/
Scenarios
○ Collection, sorting, and recycling of PMD
- Materials rejected from sorting or recycling operations sent to incineration in this scenario.
- Incineration of PMD

Key Findings

- Recycling results in lower impacts for all categories considered

$\circ$ The impacts are measured in monetary units, and results suggest that prevention of impacts through recycling is more cost effective than "repairing" the environment to a sustainable level.

Functional Total amount of packaging waste selectively collected (and non-packaging paper) in Unit Belgium in 2010, equal to 1,237,362 tonnes.

System boundary

Packaging waste system (EoL of packaging).

- Primary data obtained from operators (e.g. Belgian national and regional waste authorities) for foreground system (waste management activities from

LCI data sources

Allocation Method collection to recycling to disposal)

- Secondary data obtained for background system (systems supplying energy and materials, including avoided energy/materials resulting from recycling process). Data obtained from EcoInvent and BUWAL databases.

LCIA Method Ecocosts 2012, Stepwise 2006, Ecovalue 08 


\begin{tabular}{lll} 
& $\bullet$ Global Warming \\
Result/Impact & $\bullet$ Acidification \\
Categories & $\bullet$ Human Toxicity \\
& $\bullet$ Eutrophication \\
\hline
\end{tabular}

Oliveira, M.C.; Magrini, A. Life Cycle Assessment of Lubricant Oil Plastic Containers in Brazil. Sustainability 2017, 9, 576. http://www.mdpi.com/2071-1050/9/4/576

\begin{tabular}{|c|c|}
\hline \multirow{6}{*}{$\begin{array}{l}\text { Product } \\
\text { Geography }\end{array}$} & $\begin{array}{l}\text { Lubricant Oil Plastic Containers } \\
\text { Rrazil }\end{array}$ \\
\hline & Brazil \\
\hline & $\begin{array}{l}\text { - Materials Considered: } \\
\quad \text { o Lubricant Oil Plastic Containers (HDPE) }\end{array}$ \\
\hline & - EOL scenarios considered: \\
\hline & - Scenario 0 (Current): $16 \%$ recycling, $84 \%$ Landfill \\
\hline & Scenario 2: 16/16/68 Recycling/Incineration/Landfill \\
\hline \multirow{3}{*}{$\begin{array}{l}\text { Systems/ } \\
\text { Scenarios }\end{array}$} & S Scenario 3: 50/50 recycling/incineration \\
\hline & $\begin{array}{l}\text { - Note that recycling is open-loop, and incineration is with energy (electricity) } \\
\text { generation. The study assumes } 1: 1 \text { substitution ratio for virgin HDPE } \\
\text { (recycling) and energy (incineration). }\end{array}$ \\
\hline & $\begin{array}{l}\text { - Sensitivity scenario included, which assumes that only } 90 \text { or } 95 \% \text { of the } \\
\text { HDPE goes to recycling or incineration instead of } 100 \% \text { collection rate. }\end{array}$ \\
\hline \multirow{2}{*}{ Key Findings } & $\begin{array}{l}\text { Increase in recycling rates performs better than landfilling for all impact } \\
\text { categories }\end{array}$ \\
\hline & $\begin{array}{l}\text { - Incineration results in better impact estimates than landfilling for all impact } \\
\text { categories except global warming and smog. }\end{array}$ \\
\hline $\begin{array}{l}\text { Functional } \\
\text { Unit }\end{array}$ & \multirow[t]{2}{*}{ One tonne of high density polyethylene (HDPE) } \\
\hline $\begin{array}{l}\text { System } \\
\text { boundary }\end{array}$ & \\
\hline \multirow{2}{*}{$\begin{array}{l}\text { LCI data } \\
\text { sources } \\
\text { Allocation } \\
\text { Method }\end{array}$} & $\begin{array}{l}\text { Primary data for production and distribution of LOPC, as well as HDPE } \\
\text { recycling. } \\
\text { - Secondary data for several processes from literature sources and EcoInvent. }\end{array}$ \\
\hline & Avoided Burden (System boundary expansion) \\
\hline \multirow[t]{2}{*}{ LCIA Method } & Recipe 2008 midpoint. \\
\hline & - Global Warming \\
\hline \multirow{2}{*}{$\begin{array}{l}\text { Result/Impact } \\
\text { Categories }\end{array}$} & - Acidification \\
\hline & $\begin{array}{l}\text { - Human Toxicity } \\
\text { - Eutrophication }\end{array}$ \\
\hline
\end{tabular}


- Smog

- Ecotoxicity

- Land Occupation

- Water Depletion

- Fossil Energy Depletion

- Mineral Depletion

Marion, S. (2005). Environmental Costs and Environmental Benefits Analysis of Packaging Waste Recovery and Recycling Targets. PhD Thesis, University of Sheffield.
Product
Packaging Waste
Geography
Europe/UK
- Materials
- Cardboard packaging waste
- EOL scenarios considered:
Systems/
Scenarios
- Scenario 1 (Base scenario, UK situation): 53/43/4 recycling/landfill/incineration
- Scenario 2: 60/37/3 recycling/landfill/incineration
- Scenario 3: 70/30 recycling/landfill
- Scenario 4: 80/20 recycling/landfill
- Scenario 5: 35/65 recycling/landfill
- Scenario 6: 100 landfill
- Scenario 7: 100 incineration

- Findings based on characterization results (not valuations)

- In general, increased recycling rate results in lower environmental impacts for most categories.

- Sensitivity analysis performed:

- Assuming increased distance of transportation for recycling

Key Findings diminishes the benefits of recycling for most categories in all scenarios, but overall results still less environmentally impactful than baseline comparison.

- Assuming increased use of renewable energy lowers the environmental impacts for most categories in all scenarios, but some emissions (e.g. VOC) are unaffected.

Functional One tonne of cardboard packaging waste. Chosen because it represents $56 \%$ of Unit paperboard packaging waste.

System boundary Cradle to grave

LCI data sources

Allocation Method LCIA Method CML midpoint

- Secondary data: literature sources for input of wood pulp, energy input, waste management, and transportation; cardboard manufacturing data from PEMS and BUWAL databases.

Avoided burden 
- Global Warming

- Acidification

Result/Impact

- Eutrophication

Categories

- Human Toxicity

- Ecotoxicity

- Smog

- Fossil Energy Depletion

Jorgelina Pasqualino, Montse Meneses, Francesc Castells. The carbon footprint and energy consumption of beverage packaging selection and disposal. Journal of Food Engineering, Volume 103, Issue 4, 2011, Pages 357-365, ISSN 0260-8774. https://doi.org/10.1016/j.jfoodeng.2010.11.005.

Product

Geography

Systems/

Scenarios

Key Findings
Packaging options for juice, beer, and water

Spain

- Materials

○ Juice: Aseptic carton (75\% cardboard layers, recycled; aluminum and LDPE, landfilled), glass, HDPE

- Beer: Aluminum can, glass, HDPE

- Water: PET, glass

- EOL scenarios considered:

$\circ$ Landfilling

$\circ$ Incineration with energy recovery

○ Recycling

- All beverage packaging materials and sizes have a lesser impact on the environment in they are recycled rather than incinerated or landfilled.

- Larger packages always have a lower environmental impact than smaller packages. This is due to reduction in packaging material needed per unit of product when a single larger format was used.

\begin{tabular}{|c|c|}
\hline $\begin{array}{l}\text { Functional } \\
\text { Unit } \\
\text { System } \\
\text { boundary }\end{array}$ & System boundary \\
\hline $\begin{array}{l}\text { LCI data } \\
\text { sources }\end{array}$ & $\begin{array}{l}\text { - Packaging LCI obtained } \\
\text { - Environmental data for } \\
\text { from Ecoinvent } 2.1\end{array}$ \\
\hline $\begin{array}{l}\text { Allocation } \\
\text { Method }\end{array}$ & Avoided Burden \\
\hline LCIA Method & Inventory based \\
\hline $\begin{array}{l}\text { Result/Impact } \\
\text { Categories }\end{array}$ & $\begin{array}{ll}\text { - } & \text { Global Warming } \\
\text { - } & \text { Fossil Energy Depletio } \\
\end{array}$ \\
\hline
\end{tabular}




\section{Biobased}

Akanuma, Y., Selke, S.E. and Auras, R. (2014). A preliminary LCA case study: comparison of different pathways to produce purified terephthalic acid suitable for synthesis of 100\% bio-based PET. The International Journal of Life Cycle Assessment, 19(6), pp.1238-1246. http://doi.org/x10.1007/s11367-014-0725-2

\section{Product $\quad \mathbf{1 0 0 \%}$ bio-based PET resin}

Geography

Systems/

Scenarios

Key Findings
- Three different production pathways for bio-based purified PTA resin suitable for production of $100 \%$ bio based PET:

- Stover wheat muconic acid

- Corn butanol

- Poplar BTX

- Poplar BTX has lower environmental impacts than the other biobased pathways for PTA resin for all considered environmental impact categories.

- When compared to petro- and bio-based MEG resins, the bio-basedPTA only had fewer environmental impacts where non-renewable energy and mineral extraction were concerned (with the petro-based resin generally having the lowest impacts across other categories).

\begin{tabular}{ll}
$\begin{array}{l}\text { Functional } \\
\text { Unit } \\
\text { System } \\
\text { boundary }\end{array}$ & Cradle to gate \\
\hline $\begin{array}{l}\text { LCI data } \\
\text { sources } \\
\text { Allocation }\end{array}$ & LCI data not largely available so LCA based on information on related \\
Method & commercial scale processes \\
LCIA Method & IMPACT 2002+ \\
$\begin{array}{l}\text { Result/Impact } \\
\text { Categories }\end{array}$ & - Acidification \\
& - Climate Change \\
& $\bullet$ Futrophication \\
& $\bullet$ Ressil Fuel Depletion/Energy \\
\hline
\end{tabular}


Bohlmann, G. M. (2004). Biodegradable packaging life-cycle assessment. Environ. Prog., 23: 342-346. http://onlinelibrary.wiley.com/doi/10.1002/ep.10053/abstract

\section{Product PLA}

Geography United States

Systems/

- PLA from corn

Scenarios

- PP from natural gas

Key Findings - General information only; assessment not provided by detailed impact categories.

- PLA is a more energy efficient polymer than PP for food packaging such as a thermoformed yogurt cup. In large part, this is because PLA consumes almost no feedstock energy.

\begin{tabular}{ll}
$\begin{array}{l}\text { Functional } \\
\text { Unit }\end{array}$ & $1000 \mathrm{~kg}$ (1 metric ton) of yogurt \\
$\begin{array}{l}\text { System } \\
\text { boundary }\end{array}$ & Cradle to grave \\
$\begin{array}{l}\text { LCI data } \\
\text { sources }\end{array}$ & \\
$\begin{array}{l}\text { Allocation } \\
\text { Method }\end{array}$ & Filling, distribution, and use of PLA yogurt cups is essentially identical to \\
$\begin{array}{l}\text { LCIA Method } \\
\text { Pesult/Impact }\end{array}$ & Own calculations \\
Categories & \\
\hline
\end{tabular}

Chen, L., Pelton, R.E. and Smith, T.M. (2016). Comparative life cycle assessment of fossil and bio-based polyethylene terephthalate (PET) bottles. Journal of Cleaner Production, 137, pp.667676. http://doi.org/ 10.1016/j.jclepro.2016.07.094

\section{Product Bottles produced from Fossil based, Bio-based, and Partially fossil based PET}

Geography United States

Systems/

Scenarios
- The PET used to produce bottles created from either EG or PTA precursors, each of which can fossil or bio-based, yielding the following configurations:

- Fossil based PET made from fossil EG and fossil PTA

- Partially fossil based PET made from

- Fossil PTA and corn EG

- Fossil PTA and switchgrass EG

- Fossil PTA and wheat straw EG 
- Wood PTA and fossil EG

- Corn Stover PTA and fossil EG

- $100 \%$ bio-based PET made from

- Wood PTA and Corn EG

- Wood PTA and switchgrass EG

- Wood PTA and wheat straw EG

- Corn Stover PTA and corn EG

- Corn Stover PTA and switchgrass EG

- Corn Stover PTA and wheat straw EG

Key Findings - Results indicate that woody-biomass based PET bottles have $21 \%$ less global warming potential and require $22 \%$ less fossil fuel than their fossil based counterparts, but perform worse in other categories such as ecotoxicity and ozone depletion impacts.

- Results are sensitive to impact allocation assumptions as well as parameter input assumptions related to isobutanol production.

- Impacts without including displacement credits: almost all categories, bio-PET bottles (both partial and fully bio-based ones) have worse performance than their $100 \%$ fossil-based counterparts.

- Impacts including displacement credits: bottles made from woody biomass PTA show significant advantage over fossil PTA and corn Stover PTA bottles.

\begin{tabular}{ll}
$\begin{array}{l}\text { Functional } \\
\begin{array}{l}\text { Unit } \\
\text { System } \\
\text { boundary }\end{array}\end{array}$ & 1 kg of bottles (approximately 100 bottles with 0.5L capacity) \\
\hline $\begin{array}{l}\text { LCI data } \\
\text { sources } \\
\text { Allocation } \\
\text { Method }\end{array}$ & Ecoinvent, Gabi, U.S. LCI database, and literature sources \\
LCIA Method & System expansion used to determine avoided burdens \\
$\begin{array}{l}\text { Result/Impact } \\
\text { Categories }\end{array}$ & $\bullet$ Acidification \\
& $\bullet$ Climate Change \\
& $\bullet$ Ecotoxicity \\
& $\bullet$ Human Health Impacts \\
& $\bullet$ Smog Formation \\
&
\end{tabular}

Detzel et al. (2013). Study of the Environmental Impacts of Packagings Made of Biodegradable 
Plastics. Accessed from:

http://www.umweltbundesamt.de/sites/default/files/medien/461/publikationen/4446.pdf, June 27, 2017.

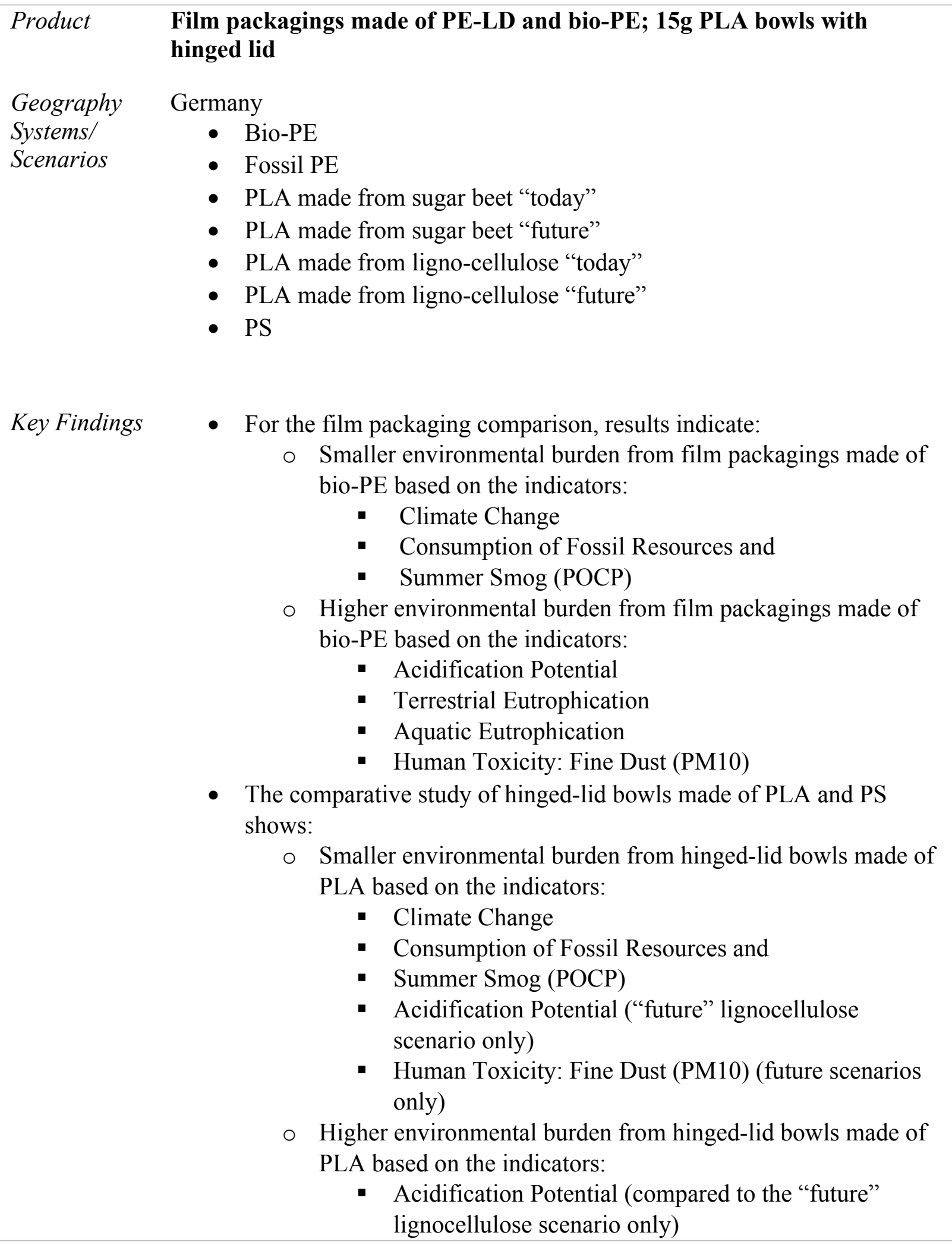


- Terrestrial Eutrophication

- Aquatic Eutrophication

- Human Toxicity: Fine Dust (PM10) (compared to status-quo scenarios only)"

\begin{tabular}{|c|c|}
\hline $\begin{array}{l}\text { Functional } \\
\text { Unit } \\
\text { System } \\
\text { boundary }\end{array}$ & $30 \mathrm{~g} / 15 \mathrm{~g}$ of various materials \\
\hline $\begin{array}{l}\text { LCI data } \\
\text { sources } \\
\text { Allocation } \\
\text { Method }\end{array}$ & \\
\hline LCIA Method & Various, based on reviewed articles \\
\hline $\begin{array}{l}\text { Result/Impact } \\
\text { Categories }\end{array}$ & $\begin{array}{l}\text { - Acidification } \\
\text { - Climate Change } \\
\text { - Eutrophication } \\
\text { - Fossil Fuel Depletion/Energy } \\
\text { - Human Health Impacts } \\
\text { - Smog Formation }\end{array}$ \\
\hline
\end{tabular}

Groot, W.J. and Borén, T. (2010). Life cycle assessment of the manufacture of lactide and PLA biopolymers from sugarcane in Thailand. The International Journal of Life Cycle Assessment, 15(9), pp.970-984.1042-8

\section{Product Lactide and PLA biopolymers (plastic)}

Geography Thailand

Systems/ - L-lactide

Scenarios

- D-lactide

- PLLA

- PLLA/PDLA blend (sugarcane)

Key Findings - PLLA results in significantly lower emissions of greenhouse gasses, and less use of material resources and nonrenewable energy, compared to fossil-based polymers. Being based on an agricultural system the bio-based PLA gives rise to higher contributions to acidification, photochemical ozone creation, eutrophication, and farm land use compared to the fossil polymers.

\section{Functional 1 ton \\ Unit}




\begin{tabular}{ll}
$\begin{array}{l}\text { System } \\
\text { boundary }\end{array}$ & Cradle-to-gate \\
\hline $\begin{array}{l}\text { LCI data } \\
\text { sources } \\
\text { Allocation }\end{array}$ & \\
Method & \\
\hline $\begin{array}{l}\text { LCIA Method } \\
\text { Result/Impact }\end{array}$ & - Acidification \\
Categories & - Climate Change \\
& - Eutrophication \\
& - Fossil Fuel Depletion/Energy \\
& - Land use \\
& - Smog Formation
\end{tabular}

Günkaya, Z. and Banar, M. (2016). An environmental comparison of biocomposite film based on orange peel-derived pectin jelly-corn starch and LDPE film: LCA and biodegradability. The International Journal of Life Cycle Assessment, 21(4), p.465. http://doi.org/10.1007/s11367-0161042-8

\section{Product Orange peel-derived pectin jelly-cornstarch LDPE film}

Geography Germany

Systems/

Scenarios

- Biocomposite film

- LDPE film

Key Findings - LCA results show that biocomposite film has a slightly higher impact than LDPE film for all categories with probabilities ranging between 50 and $100 \%$ except for acidification. Uncertainty for several categories (terrestrial ecotoxicity, abiotic depletion (element), photochemical oxidation, human toxicity, and fresh water aquatic ecotoxicity) is mainly a result from electricity consumption for extrusion and film forming and modified starch addition. These two processes are mainly responsible for the environmental impact of the biocomposite film

Functional $\quad 1 \mathrm{~m}^{2}$ of packaging film

Unit

System Cradle-to-gate

boundary

LCI data

sources

Allocation

Method 


$\begin{array}{ll}\text { LCIA Method } & \text { CML-IA baseline (v.3) } \\ \text { Result/Impact } & \text { - Acidification } \\ \text { Categories } & \text { - Climate Change } \\ & \text { - Ecotoxicity } \\ & \text { - Eutrophication } \\ & \text { - Fossil Fuel Depletion/Energy } \\ & \text { - Ozone Dealth Impacts } \\ & \text { - Resource Depletion (Non-Energy) } \\ & - \text { Smog Formation }\end{array}$

Hermann, B.G., Blok, K. \& Patel, M.K. (2010). Twisting biomaterials around your little finger: environmental impacts of bio-based wrappings. Int J Life Cycle Assess (2010) 15: 346. http://doi.org/10.1007/s11367-010-0155-8

$\begin{array}{lc}\text { Product } & \text { Laminated, printed film } \\ \text { Geography } & \text { EU (inferred) } \\ \text { Systems/ } & \text { - Paper } \\ \text { Scenarios } & \text { - polylactic acid } \\ & \text { - bio-based polyethylene } \\ & \text { - bio-based polyester } \\ & \text { - polypropylene } \\ & \text { polyethylene }\end{array}$

Key Findings Compared bio-based materials (paper, polylactic acid, bio-based polyethylene, and a biobased polyester) with conventional materials (polypropylene, polyethylene). Found that laminates and films (partly) consisting of bio-based polymers offer opportunities for significantly reducing environmental impacts of food packaging; however, large variations in land use can occur depending on the material type used.

$\begin{array}{ll}\begin{array}{l}\text { Functional } \\ \text { Unit }\end{array} & 1 \mathrm{~m}^{2} \text { of packaging film } \\ \text { System } & \text { Cradle-to-gate } \\ \text { boundary } & \\ \text { LCI data } & \\ \text { sources } & \\ \text { Allocation } & \\ \text { Method } & \\ \text { LCIA Method } & \text { CML } 2 \text { baseline } 2000\end{array}$


Result/Impact

Categories

Hong, J., Zhou, J. and Hong, J. (2015). Environmental and economic impact of furfuralcohol production using corncob as a raw material. The International Journal of Life Cycle Assessment, 20(5), p.623. http://doi.org/10.1007/s11367-015-0854-2

\section{Product \\ furfuralcohol}

Geography

Systems/

Scenarios

Key Findings
- furfuralcohol from corncob

- The key factors that contribute to reducing the overall environmental and economic impacts are increasing electricity consumption efficiency and furfural product yield, decreasing transport distance from corncob buyers to suppliers, choosing the appropriate corncob compression technology, and optimizing the wastewater reuse system.

\begin{tabular}{ll} 
Functional & 1 ton of furfuralcohol \\
Unit & \\
System & Cradle-to-gate \\
boundary & \\
LCI data & \\
sources & \\
Allocation & \\
Method & \\
LCIA Method & \\
Result/Impact & \\
Categories & \\
\hline
\end{tabular}

Hottle, T.A., Bilec, M.M. and Landis, A.E. (2013). Sustainability assessments of bio-based polymers. Polymer Degradation and Stability, 98(9), pp.1898-1907.

https://doi.org/10.1016/j.polymdegradstab.2013.06.016

\section{Product Biopolymers (PLA, PHA, TPS)}

Geography

Systems/

Scenarios

Key Findings
- Sustainability assessments of bio-based polymers

- Study compares standard database results for three bio-based polymers, polylactic acid (PLA), polyhydroxyalkanoate (PHA), and thermoplastic starch (TPS) with five common petroleum derived 
polymers. The literature showed that biopolymers, coming out of a relatively new industry, exhibit similar impacts compared to petroleum-based plastics. The studies reviewed focused mainly on global warming potential (GWP) and fossil resource depletion while largely ignoring other environmental impacts, some of which result in environmental tradeoffs. The studies reviewed also varied greatly in the scope of their assessment. Studies that included the end of life (EOL) reported much higher GWP results than those that limited the scope to resin or granule production. Including EOL in the LCA provides more comprehensive results for biopolymers, but simultaneously introduces greater amounts of uncertainty and variability. Little life-cycle data is available on the impacts of different manners of disposal, thus it will be critical for future sustainability assessments of biopolymers to include accurate end of life impacts.

Functional
Unit
System
boundary
$\begin{aligned} & \text { LCI data } \\ & \text { sources } \\ & \text { Allocation }\end{aligned}$
Method
$\begin{array}{ll}\text { LCIA Method } & \\ \text { Result/Impact } & \text { - Climate Change } \\ \text { Categories } & \text { - Fossil Fuel Depletion/Energy }\end{array}$

T. A. Hottle, M. M. Bilec, and A. E. Landis. (2017). Biopolymer production and end of life comparisons using life cycle assessment. Resour. Conserv. Recycl., vol. 122, pp. 295-306, Jul. 2017. https://doi.org/10.1016/j.resconrec.2017.03.002

\section{Product Biopolymers, fossil based plastics}

Geography U.S., Brazil

Systems/

- Eight polymers were evaluated, mostly produced in the U.S.

Scenarios (geographical locations of interest named in parenthesis):

$\circ$ PLA (made in the U.S.)

- Bio-PET, Bio-HDPE, and Bio-LDPE (raw material from Brazil, shipped to U.S. for production) 
- TPS (global corn market, U.S. production)

- HDPE, LDPE, and PET (traditional fossil-based polymers, made in the U.S.)

- Three End-of-Life (EOL) scenarios are considered: recycle, compost, and landfill.

- For each polymer, 2 scenarios are considered: $100 \%$ landfill and another $100 \%$ EOL treatment, with linear correlations used to interpolate all intermediate ratios between the two $100 \%$ scenarios.

- PLA has 2 landfill processes to model boundary scenarios due to high uncertainties with PLA landfill degradation.

Key Findings

- Production impacts for Bio-PET, Bio-HDPE, and Bio-LDPE manufacturing using raw materials from Brazil are greater for all impact categories except GWP and fossil fuel depletion when compared to fossil based polymers. Most impactful stages were farming, distillation, dehydration, and transportation.

- PLA and TPS (corn based) have greater production impacts than fossil based plastics for acidification and eutrophication due to fertilizer use and effluent waste.

- For EOL, landfill scenarios vary significantly depending on degradation assumptions for PLA.

- TPS and high degradation assumption for PLA (37\% degradation over 100 years) results in higher GWP than composting due to methane emissions.

- Low degradation assumption for PLA (no degradation over 100 years) results in carbon sink assumption and thus lower GWP than composting.

- Composting PLA and TPS results in higher impacts than landfilling for smog, acidification, carcinogens, non-carcinogens, respiratory effects, ecotoxicity, and fossil fuel depletion. This is caused by diesel fuel and additional water use associated with heavy machinery and the composting process, respectively.

- For recyclable polymers, recycling decreases impacts associated with production due to offsetting of virgin production, even achieving negative impacts for recyclable biopolymers.

- Sensitivity:

- Transportation proved to be the most significant process for GWP sensitivity due to shipping distance (Brazil to US for production; US to China for EOL). 
- PET and HDPE were sensitive to sorting methods used to recycle them. Also, most polymers were sensitive to alternative recycling allocation methods (e.g. including correction factors to account for material losses during EOL, changing whether fossil-based or bio-based production was substituted by recycling).

- Overall, recycling still one of the better EOL treatment options.

○ Benefits of recycling can be extended to biopolymers if they can be included in existing waste streams.

\begin{tabular}{|c|c|}
\hline $\begin{array}{l}\text { Functional } \\
\text { Unit } \\
\text { System } \\
\text { boundary }\end{array}$ & $\begin{array}{l}\text { System boundary includes raw material extraction, transportation (for } \\
\text { production from Brazil for some biopolymers and EOL treatment shipped to } \\
\text { China for some recycling scenarios), polymer production, waste collection, } \\
\text { and EOL treatments. Boundary does not include product formation (i.e. } \\
\text { specific types of packaging) and use due to the wide variety of products and } \\
\text { production pathways currently available. }\end{array}$ \\
\hline $\begin{array}{l}\text { LCI data } \\
\text { sources }\end{array}$ & $\begin{array}{l}\text { Inventory data is a mix of primary data, collected through site visits to } \\
\text { several facilities in Arizona (mostly for EOL processes), and secondary data } \\
\text { from literature and LCA databases (mostly for polymer production } \\
\text { processes). Secondary data modified to better reflect U.S. conditions where } \\
\text { appropriate. } \\
\text { - All of the biopolymers were credited for the use of biogenic carbon } \\
\quad \text { from raw materials acquisition from agricultural processes. }\end{array}$ \\
\hline $\begin{array}{l}\text { Allocation } \\
\text { Method }\end{array}$ & \\
\hline LCIA Method & TRACI v2.1 midpoint indicators \\
\hline $\begin{array}{l}\text { Result/Impact } \\
\text { Categories }\end{array}$ & $\begin{array}{l}\text { - Acidification } \\
\text { - } \text { Ecotoximate Change } \\
\text { - Eutrophication } \\
\text { - Fossil Fuel Depletion/Energy } \\
\text { - Human Health Impacts } \\
\text { - Ozone Depletion } \\
\end{array}$ \\
\hline
\end{tabular}

Kim, S. and Dale, B. (2005). Life cycle assessment study of biopolymers (Polyhydroxyalkanoates)-Derived from No-Tilled Corn (11 pp). The International Journal of Life Cycle Assessment, 10(3), pp.200-210. http://doi.org/10.1065/lca2004.08.171

\section{Product PHA biopolymer for packaging film}



Geography
United States (14 counties in corn belt states)
Systems/
Scenarios
- PHA -corn grain based
- PHA -corn stover based
- PS
Key Findings
- Study found that the fermentation and recovery processes used in producing PHA from corn grain and stover resulted in greater environmental impacts (i.e., photochemical smog, acidification and eutrophication) than polystyrene. The study also showed that estimating environmental impacts using expected future technology attributes and a combination of corn grain and stover (as opposed to just grain) led to fewer impacts (except eutrophication) than polystyrene.

$\begin{array}{ll}\text { Functional } & 1 \mathrm{~kg} \text { resin } \\ \text { Unit } & \\ \text { System } & \text { Cradle to gate } \\ \text { boundary } & \end{array}$

\section{LCI data}

sources

Allocation

Method

- Near future technology is an improved process that is achievable over a 2- to 3-year time horizon, extrapolating from current laboratory results

- Nonrenewable energy from the inventory analysis is defined as a sum of nonrenewable energy used in the process (i.e., fossil energy and electricity) and feedstock energy

- The environmental burdens of PHA are presented as average values over 14 counties, weighted by their corn production

$\begin{array}{lc}\text { LCIA Method } & \text { Adapted from TRACI } \\ \text { Result/Impact } & \text { - Acidification } \\ \text { Categories } & \text { - Climate Change } \\ & \text { - Eutrophication } \\ & \text { - Fossil Fuel Depletion/Energy } \\ & \text { - Smog Formation }\end{array}$

Lin, Z., Nikolakis, V. and Ierapetritou, M. (2015). Life cycle assessment of biobased p-xylene production. Industrial \& Engineering Chemistry Research, 54(8), pp.2366-2378.

http://doi.org/10.1021/ie5037287 


\title{
Product Biobased p-xylene
}

Geography

Systems/

Scenarios

Key Findings
- Lignocellulose-based p-xylene

- Petroleum-based p-xylene

- Starch-based p-xylene

- Lignocellulose-based p-xylene is comparable with the petroleumbased $\mathrm{p}$-xylene, while the starch-based $\mathrm{p}$-xylene appears less environmentally friendly

- Cultivation and processing of maize starch and heating requirements dominate total environmental impacts for starch-based p-xylene. The main contributions for the lignocellulose-based p-xylene arise from the cultivation of biomass and the large requirements of nonrenewable chemicals (i.e., the makeup solvent (THF) and ethylene).

Functional 1 metric ton of $\mathrm{p}$-xylene produced

Unit

System Only the materials used in the manufacturing are considered. The materials

boundary used in the construction, other infrastructure, and catalysts are assumed to be recycled at the end of the lifetime of the project and excluded from the scope. The labor needed in the construction is not included.

\author{
LCI data \\ sources \\ Allocation \\ Method \\ endpoint method (i.e., Eco-indicator 99) \\ Result/Impact \\ Categories \\ - Acidification \\ - Climate change \\ - Ecotoxicity \\ - Eutrophication \\ - Fossil Fuel Depletion/Energy \\ - Human Health Impacts \\ - Land Use \\ - Ozone depletion \\ - Resource Depletion (Non-Energy) \\ - Smog Formation
}

LCIA Method ReCiPe v1.0 is selected in this work, and it is a more recent midpoint and endpoint method that integrates both midpoint method (i.e., CML) and 
- Water Use

Madival, S., Auras, R., Singh, S.P. and Narayan, R. (2009). Assessment of the environmental profile of PLA, PET and PS clamshell containers using LCA methodology. Journal of Cleaner Production, 17(13), pp.1183-1194. http://doi.org/10.1016/j.jclepro.2009.03.015

\begin{tabular}{|c|c|}
\hline Product & $\begin{array}{l}\text { Strawberry packaging: Thermoformed clamshell containers with } 1 \text { lb } \\
\text { strawberries }\end{array}$ \\
\hline $\begin{array}{l}\text { Geography } \\
\text { Systems/ } \\
\text { Scenarios }\end{array}$ & $\begin{array}{c}\text { Europe/U.S. } \\
\text { - PLA } \\
\text { - PET } \\
\text { - PS }\end{array}$ \\
\hline Key Findings & $\begin{array}{l}\text { - PET showed the highest overall values for all the impact categories, } \\
\text { mainly due to the higher weight of the containers. The main impacts } \\
\text { to the environment were the resin production and the transportation } \\
\text { stage of the resins and containers, which implies that the } \\
\text { transportation stage of the package is an important contributor to the } \\
\text { environmental impact. }\end{array}$ \\
\hline $\begin{array}{l}\text { Functional } \\
\text { Unit } \\
\text { System } \\
\text { boundary }\end{array}$ & $\begin{array}{l}1,000 \text { one } 1 \mathrm{~b} . \text { containers } \\
\text { Cradle to grave }\end{array}$ \\
\hline $\begin{array}{l}\text { LCI data } \\
\text { sources } \\
\text { Allocation } \\
\text { Method }\end{array}$ & \\
\hline LCIA Method & IMPACT 2002+ \\
\hline $\begin{array}{l}\text { Result/Impact } \\
\text { Categories }\end{array}$ & $\begin{array}{l}\text { - Acidification } \\
- \text { Climate change } \\
\text { - Ecotoxicity } \\
\text { - Eutrophication } \\
\text { - Human Health Impacts } \\
\text { - Land Use } \\
\text { Smog Formation }\end{array}$ \\
\hline
\end{tabular}

Nuss, P. and Gardner, K.H., 2013. Attributional life cycle assessment (ALCA) of polyitaconic acid production from northeast US softwood biomass. The International Journal of Life Cycle Assessment, pp.1-10. http://doi.org/10.1007/s11367-012-0511-y 


\begin{tabular}{|c|c|}
\hline Product & Polyitaconic acid \\
\hline $\begin{array}{l}\text { Geography } \\
\text { Systems/ } \\
\text { Scenarios }\end{array}$ & $\begin{array}{l}\text { Northeast U.S. } \\
\text { - } \text { Softwood-based PIA } \\
\text { - } \text { Corn-based PIA } \\
\text { - } \text { Fossil-based PIA }\end{array}$ \\
\hline Key Findings & $\begin{array}{l}\text { - Softwood-based PIA may be advantageous in terms of GWP, fossil } \\
\text { energy demand, and acidification. For eutrophication and water use: } \\
\text { Softwood-based PIA has fewer impacts than corn-based PIA, but } \\
\text { greater than fossil-based PIA. Land occupation is also greater for } \\
\text { softwood compared to fossil-based PIA. } \\
\text { - Main contributors to both wood and corn-based PIA production are: } \\
\text { 1.) Electricity used during fermentation and itaconic acid (IA) } \\
\text { recovery, 2.) Activated carbon (AC) used during IA recovery and } \\
\text { sugar extraction (only for wood-based PIA), 3.) NaOH used during } \\
\text { recovery, 4.) Water use during sugar extraction and fermentation, and } \\
\text { 5.) Land occupation associated with softwood, corn, and AC inputs. } \\
\text { As a result, life cycle wide systems performance is directly affected } \\
\text { by variations in these inputs. }\end{array}$ \\
\hline $\begin{array}{l}\text { Functional } \\
\text { Unit } \\
\text { System } \\
\text { boundary }\end{array}$ & $\begin{array}{l}1 \mathrm{~kg} \text { of dry polymer } \\
\text { Cradle to gate }\end{array}$ \\
\hline $\begin{array}{l}\text { LCI data } \\
\text { sources } \\
\text { Allocation } \\
\text { Method } \\
\text { LCIA Method }\end{array}$ & \\
\hline $\begin{array}{l}\text { Result/Impact } \\
\text { Categories }\end{array}$ & $\begin{array}{l}\text { - Acidification } \\
\text { - Climate Change } \\
\text { - Eutrophication } \\
\text { - } \text { Fossil Fuel Depletion/Energy } \\
\text { - Land Use } \\
\text { - Water Use }\end{array}$ \\
\hline
\end{tabular}

Papong, Seksan, Pomthong Malakul, Ruethai Trungkavashirakun, Pechda Wenunun, Tassaneewan Chom-in, Manit Nithitanakul, and Ed Sarobol. (2014). Comparative Assessment of the Environmental Profile of PLA and PET Drinking Water Bottles from a Life Cycle 
Perspective. Journal of Cleaner Production 65: 539-50. https://doi.org/10.1016/j.jclepro.2013.09.030

\section{Product Drinking water bottles}

Geography

Systems/

Scenarios

Key Findings
Thailand

- PLA bottles produced from cassava

- PET bottles produced from fossil fuels

- 4 EOL methods considered: Composting, landfill, recycling, and incineration.

- For PLA bottles, the following scenarios were considered:

- S1 100\% composting at composting plant (assumed no composting in landfill condition based on previous literature).

- S2 100\% incineration with energy recovery

- S3 100\% landfill w/o energy recovery

- S4 100\% landfill $\mathrm{w} /$ energy recovery

- S5 100\% chemical recycling

- S6 80\% composting, $20 \%$ landfill w/ energy recovery

- S7 80\% composting, $20 \%$ incineration $\mathrm{w} /$ energy recovery.

- Results are shown for cradle-to-gate for all impact categories considered; however, cradle-to-grave only shown for GWP.

- Cradle to gate results:

- GWP: PLA bottles between 10 and 20\% lower than PET.

- Fossil CED: PLA bottles between 60 and $65 \%$ lower than PET.

$\circ$ AP: PLA bottles between 5 and $10 \%$ higher than PET.

- EP: PLA bottles between 300 and $800 \%$ higher than PET.

- HTP: PLA bottles between 85 and $95 \%$ lower than PET.

- Overall cradle to grave results indicate that PET recycling, PLA 100\% composting, PLA 100\% chemical recycling, PLA $80 \%$ composting, $20 \%$ incineration with energy recovery are all about $10 \%$ lower than base PET and comparable to each other in terms of GWP. 80\% PLA composting, 20\% landfill with energy recovery is comparable to the base case (about $3 \%$ lower). The best result was obtained by PLA $100 \%$ incineration with energy recovery (about 17\% lower). PLA landfill obtained the worst results, with between 29 and $107 \%$ higher depending on whether there was energy recovery or not.

Functional 1000 units of $250 \mathrm{ml}$ drinking water bottles.

Unit

System For PLA: Cassava cultivation and harvesting, starch production, PLA

boundary production, bottle production, disposal scenarios. 
For PET: raw material extraction, monomer production, PET production, bottle production, PET incineration.

\begin{tabular}{|c|c|}
\hline $\begin{array}{l}\text { LCI data } \\
\text { sources }\end{array}$ & $\begin{array}{l}\text { Mix of primary data (field survey, cassava farming/production/bottle } \\
\text { production) and secondary data for background processes (Ecoinvent, } \\
\text { Thailand LCI databases, other reports). Did not take into account CO2 uptake } \\
\text { during cassava growing. } \\
3 \text { different production scenarios considered for PLA: } \\
\text { - Base case, which assumes electricity from national grid, heat from } \\
\text { fuel oil and biogas } \\
\text { - Option I, electricity from national grid but heat only from biogas } \\
\text { (starch production); } \\
\text { Option II, both electricity and steam from natural gas based on CHP } \\
\text { (lactic acid \& PLA production). } \\
\text { Composting modeling was done mostly from primary data; other EOL } \\
\text { modeling mostly from secondary data. }\end{array}$ \\
\hline $\begin{array}{l}\text { Allocation } \\
\text { Method }\end{array}$ & \\
\hline LCIA Method & CML 2 baseline 2000 \\
\hline $\begin{array}{l}\text { Result/Impact } \\
\text { Categories }\end{array}$ & $\begin{array}{ll}\text { - } & \text { Acidification } \\
\text { - } & \text { Global warming } \\
\text { - } & \text { Eutrophication } \\
\text { - } & \text { Fossil energy depletion } \\
\text { - } & \text { Human toxicity }\end{array}$ \\
\hline
\end{tabular}

Rossi, V., Cleeve-Edwards, N., Lundquist, L., Schenker, U., Dubois, C., Humbert, S. and Jolliet, O. (2015). Life cycle assessment of end-of-life options for two biodegradable packaging materials: sound application of the European waste hierarchy. J. Clean. Prod., vol. 86, pp. 132145. https://doi.org/10.1016/j.jclepro.2014.08.049

\section{Product Dry packaging}

Geography

Systems/

Scenarios
EU

- PLA

- Thermoplastic Starch (TPS)

- EOL scenarios considered:

○ Mechanical recycling (MR)

- Industrial composting (IC)

- Anaerobic digestion (AD)

- Direct fuel substitution in industrial facilities (DFS)

- Incineration with heat recovery in municipal solid waste incinerators (MSWI) 
○ Land landfilling (LF).

Key Findings - Aim of this paper is to study whether well-developed end-of-life options are environmentally desirable. Selected six end-of-life options that cover the different levels of the EU waste treatment hierarchy. On average, finds that MR leads to the highest benefits, whereas IC is one of the least favorable end-of-life options.

- Sensitivity analysis revealed the most influential parameters to be the substitution chosen for the recycled material, the ability to prevent methane emissions during treatment, and the efficiency of energy recovery.

- MR and DFS have low impact rankings due credits associated with the recovery of original packing material and large amounts of thermal energy, respectively. Conversely, IC has high impacts because the polymers have low N-P-K content and cannot replace fertilizers. AD and MSWI fall in the middle due to their limited energy recovery yield. Global warming from landfilling vary between the materials due to their different degradation speed (PLA slow, TPS fast).

- Due to lack of infrastructure availability and non-optimal collection rates, mixing different EOL treatments may represent an optimal solution rather than relying on a single EOL treatment.

Functional EOL treatment of $1 \mathrm{~kg}$ of dry packaging material.

Unit

System System boundary includes material production, waste collection, EOL

boundary treatment, but notably does not include packaging manufacturing, distribution and usage.

LCI data

sources
- PLA and TPS inventories built from previous literature and available data.

- EOL inventories were developed from a mix of primary data (questionnaires sent to three distinct waste disposal companies) and literature sources, depending on the specific EOL scenario in question.

Allocation System expansion for substituted material or energy credits.

Method

LCIA Method IMPACT 2002+

Result/Impact - Acidification

Categories
- Climate Change

- Ecotoxicity

- Fossil Fuel Depletion/Energy 
- Human Health Impacts

- Land Use

- Ozone Depletion

- Resource Depletion (Non-Energy)

- Water Use

Shen, L., Worrell, E. and Patel, M.K. (2012). Comparing life cycle energy and GHG emissions of bio-based PET, recycled PET, PLA, and man-made cellulosics. Biofuels, Bioproducts and Biorefining, 6(6), pp.625-639. http://doi.org/10.1002/bbb.1368

\section{Product Plastic}

Geography Europe

Systems/

Scenarios

- Petrochemical PET

- Bio-Based PET (made from bio-based EG and petrochemical PTA)

- Recycled PET

- Recycled bio-based PET

- PLA (50\% maize-derived PLA produced in the USA and 50\% sugarcane-

- derived PLA produced in Thailand)

- PS

- Fibers (Viscose, Model, Tencel)

Key Findings - Results show that both recycled and bio-based materials offer important environmental benefits over single-use petrochemical PET. Among the four PET product systems studied, recycled (partially) bio-based PET has the lowest impacts, followed by recycled PET, (partially) bio-based PET, and petrochemical PET. PLA and manmade cellulose fibers produced in an integrated plant have lower impacts than both petrochemical PET and bio-based PET. The impacts of recycled products are strongly influenced by the choice of the allocation method applied to open-loop recycling.

\section{Functional $1 \mathrm{~kg}$ plastic}

Unit

System Cradle to grave, excluding use phase

boundary

LCI data

sources

Allocation

Method

LCIA Method

Result/Impact

Categories

- Climate Change

- Fossil Fuel Depletion/Energy 
Suwanmanee, U., Varabuntoonvit, V., Chaiwutthinan, P., Tajan, M., Mungcharoen, T. and Leejarkpai, T. (2013). Life cycle assessment of single use thermoform boxes made from polystyrene (PS), polylactic acid, (PLA), and PLA/starch: cradle to consumer gate. The International Journal of Life Cycle Assessment, 18(2), pp.401-417. https://doi.org/10.1007/s11367-012-0479-7
Product
Thermoform boxes
Geography Thailand
Systems/
Scenarios
Key Findings
- PS (petroleum-based)
- PLA (corn-based)
- PLA (cassava/starch blend-based)
- Total environmental impact including LUC emission of bio-based boxes were different when the various energy sources were supplied throughout the life cycle production stage. The PS box has lower environmental impact than PLA and PLA/starch boxes for all of the different electricity grid mixes considered. LUC of renewable feedstocks, such as corn and cassava, were considered as the biggest impact of absolute scores of PLA and PLA/starch boxes.

\begin{tabular}{|c|c|}
\hline $\begin{array}{l}\text { Functional } \\
\text { Unit } \\
\text { System } \\
\text { boundary }\end{array}$ & $\begin{array}{l}10,000 \text { units of } 8.0 \times 10.0 \times 2.5 \mathrm{~cm} \text { of PS, PLA, and PLA } / \mathrm{starch} \text { boxes which } \\
\text { weigh } 447.60,597.60 \text {, and } 549.56 \mathrm{~kg} \text { respectively. } \\
\text { Cradle to gate }\end{array}$ \\
\hline $\begin{array}{l}\text { LCI data } \\
\text { sources } \\
\text { Allocation } \\
\text { Method }\end{array}$ & \\
\hline $\begin{array}{l}\text { LCIA Method } \\
\text { Result/Impact } \\
\text { Categories }\end{array}$ & $\begin{array}{l}\text { CML } 2 \text { baseline } \\
\begin{array}{l}\text { - Acidification } \\
\text { - Climate Change } \\
\text { - Land Use } \\
\text { - Smog Formation }\end{array}\end{array}$ \\
\hline
\end{tabular}

Tsiropoulos, I., Faaij, A.P., Lundquist, L., Schenker, U., Briois, J.F. and Patel, M.K. (2015). Life cycle impact assessment of bio-based plastics from sugarcane ethanol. Journal of Cleaner Production, 90, pp.114-127. https://doi.org/10.1016/j.jclepro.2014.11.071

\section{Product \\ Bio-plastics}

Geography Europe, Brazil, India

Systems/

- Bio-PE

Scenarios 
- Partially Bio-based PET (sugarcane ethanol)

Key Findings - This study found that petrochemical HDPE has significantly greater greenhouse gas emission and non-renewable energy use impacts than bio-based HDPE. The difference in impacts between both HDPE materials is decreased when indirect land use change is considered; however, the bio-based HDPE was still found to be more environmentally-friendly.

Functional $1 \mathrm{~kg}$ of bio-based HDPE and $1 \mathrm{~kg}$ partially bio-based PET

Unit

System Cradle to gate

boundary

LCI data

sources

Allocation

- Process electricity is sourced from the national grid or produced by

Method natural gas depending on the allocation approach (conservative system expansion, optimistic system expansion, or economic allocation)

LCIA Method IMPACT 2002+

Result/Impact - Climate Change

Categories

- Ecotoxicity

- Human Health Impacts

- Water Use

- Fossil Fuel Depletion/Energy

Yates, M.R. and Barlow, C.Y. (2013). Life cycle assessments of biodegradable, commercial biopolymers - a critical review. Resources, Conservation and Recycling, 78, pp.54-66. https://doi.org/10.1016/j.resconrec.2013.06.010

\section{Product \\ Plastic}

Geography

Systems/

- PLA

Scenarios

- PHA

- starch-based polymers

Key Findings

Functional

Unit

System

boundary 
Supporting Information for The Significance of Environmental Attributes as Indicators of the Life Cycle Environmental Impacts of Packaging and Food Service Ware

\section{LCI data}

sources

Allocation

Method

LCIA Method

Result/Impact

Categories 


\section{Compostable}

V. Girgenti, C. Peano, C. Baudino, and N. Tecco, "From 'farm to fork' strawberry system: Current realities and potential innovative scenarios from life cycle assessment of nonrenewable energy use and greenhouse gas emissions," Sci. Total Environ., vol. 473-474, pp. 48-53, Mar. 2014. https://doi.org/10.1016/j.scitotenv.2013.11.133

\section{Product Strawberry flowpack}

Geography Italy

Systems/

Scenarios

Key Findings
- Materials considered:

○ PE and PVC Sheets/wrappings

- Biodegradable bioplastic sheets/wrappings/trays (MaterBi and PLA)

- Types of waste treatment considered:

○ Conventional Disposal (80/20 Landfill/Incineration) for $\mathrm{PE} / \mathrm{PVC}$

○ On site composting for MaterBi/PLA

- Two Scenarios considered

- Scenario 1 (conventional scenario) evaluates all the stages in the production of strawberries in the area analyzed

$\circ$ In Scenario 2, the mulching and packaging materials (PE and PVC) were replaced with bio-based materials (Mater$\mathrm{BI} \circledast$ and PLA $($ )

- Results

$\circ$ For scenario 1, field and nursery stages accounted for $60 \%$ of GWP and Fossil Fuel Depletion/Energy; waste PE and PE used for packaging account for approximately $30 \%$ of GWP and Fuel Depletion/Energy.

○ For scenario 2, field and nursery stages accounted for $70 \%$ of GWP and approximately 55\% of Fuel Depletion/Energy.

$\circ$ Replacing conventional packaging materials (scenario 1) with bio-based materials (scenario 2 ) results in a reduction of $20 \%$ in both GWP and Fuel Depletion/Energy.

\footnotetext{
Functional 250-gram flow pack (consumer unit).

Unit

System System boundaries divided by scenarios: Stages of strawberry production boundary included in study include all processes from nursery to sales point, excludes use phase, but includes disposal.

LCI data sources

Allocation

Method

- Life cycle inventory obtained from a mix of primary data (provided by farms/distributors) and secondary data (Ecoinvent 2.2, background inventory data).
} 
LCIA Method For climate change, carbon footprint is based on the IPCC 2007 GWP characterization factors. For energy depletion, the study "calculated from the energy contents of the required resources (non-renewable energy primary MJ eq."

Result/Impact - Global Warming Potential

Categories

- Fossil Energy Depletion

Hermann BG, Debeer L, De Wilde B, et al. (2011). To compost or not to compost: Carbon and energy footprints of biodegradable materials' waste treatment. Polym Degrad Stab 96:11591171. http://doi.org/10.1016/j.polymdegradstab.2010.12.026

\section{Product Biopolymers}

Geography

Systems/

Scenarios

Key Findings

\section{EU}

- Materials considered:

- Paper (chemical pulp)

- Cellulose (mechanical pulp)

- Starch

- Polylactic acid (PLA)

- Starch/polycaprolactone (MaterBi)

- Polybutyrate-adipate-terephthalate (PBAT, Ecoflex) (petrochemical biodegradable material)

- Polyhydroxyalkanoates (PHA)

- Types of waste treatment considered:

- Home composting

○ Industrial composting

- Anaerobic digestion

- Incineration

- For all materials, digestion is the preferred waste treatment option as it combines energy recovery with the production of digestate which can be used as a soil conditioner.

- Home composting and incineration are comparable in terms of GWP, but energy credits are higher for incineration.

- Home and industrial composting are comparable in GWP but differ significantly in energy impacts, with home composting receiving higher energy credits because it replaces mostly peat as a soil conditioner while industrial composting replaces both peat and straw (peat has higher fossil fuel consumption).

- Only for cellulose (mechanical pulp) are GWP impacts comparable across waste treatment methods, due to incomplete degradation in composting which in turn leads to higher soil conditioner credits. 
- Not all materials degrade in all types of biological treatment; e.g., PLA does not degrade in home composting; PBAT \& cellulose do not degrade in anaerobic digestion.

- Sensitivity:

- Assuming straw displaced by composting is used for electricity production would make energy impacts for industrial composting comparable to home composting.

- Results are not sensitive to different allocation schemes for nitrogen credits, as they represent a small fraction of overall impacts (material degradation and carbon credits being the most important aspects).

- Higher temperatures for home composting (from 23 to $38^{\circ} \mathrm{C}$ ) results in $20 \%$ decrease in GWP.

- Results are sensitive to rate of biodegradation, which can change depending on material shape and composting conditions.

$\begin{array}{ll}\text { Functional } & 1 \mathrm{~kg} \text { of material } \\ \text { Unit } & \\ \text { System } & \text { Focused on waste treatment of products only, excluding use phase and } \\ \text { boundary } & \begin{array}{l}\text { transportation. }\end{array}\end{array}$

LCI data sources

Allocation Method
- For waste treatment options, compiled readily available data from databases and publications per type of material:

- Industrial composting: based on 8 datasets, chosen because they specify carbon input and biogenic $\mathrm{CO}_{2}$ emissions from the composting stage, which allow calculation of carbon balance.

- Home composting: based on a set of experiments carried out in Belgium, the goal of which were to quantify gaseous emissions from the system.

- Anaerobic digestion: Used several literature sources for green waste, and created datasets for the materials under consideration extrapolating from these studies.

- Incineration: study calculated results for incineration with energy recovery modelling of materials according to their carbon and energy contents.

- To work with realistic biodegradation/composting levels, study conducted a literature survey of biodegrading rates of the selected materials in industrial composting as well as expert knowledge.

- Biogenic carbon accounted for by:

○ using IPCC 2007 GWP characterization factors, which assume that any such carbon stored in the materials is deducted during the production phase

- Assigning a value of 0 to biogenic emissions of soil conditioners replaced by compost (straw, peat). 
LCIA Method For climate change, carbon footprint is based on the IPCC 2007 GWP characterization factors.

Result/Impact - Global Warming Potential

Categories - Fossil Fuel Depletion/Energy

Krüger, Martina, Benedikt Kauertz, and Andreas Detzel. (2009). Life Cycle Assessment of Food Packaging Made of IngeoTM Biopolymer and (r)PET: Addendum to the LCA Study on Food Packaging Made of NatureWorks ${ }^{\circledR}$ Biopolymer and Alternative Materials [2006]. Heidelberg GmbH: Institut für Energieund Umweltforschung (IFEU). Retrieved from https://www.natureworksllc.com/ /media/Files/NatureWorks/What-is-Ingeo/Why-itMatters/LCA/IFEU_LCA_Ingeo_Full_Report_012709_FINAL_pdf.pdf?la=en

2006 report: Life Cycle Assessment of POLYLACTIDE (PLA) - A comparison of food packaging made from NatureWorks ${ }^{\circledR}$ PLA and alternative materials. Retrieved from https://www.ifeu.de/oekobilanzen/pdf/LCA\%20zu\%20PLA\%20erstellt\%20fuer\%20NatureWork $\underline{\mathrm{s} \% 20(\mathrm{Okt} \% 202006) . \mathrm{pdf}}$

\begin{tabular}{|c|c|}
\hline Product & Clamshell food packaging made from Polylactide (Ingeo TM) \\
\hline Geography & EU15 \\
\hline Systems/ & - Materials Considered \\
\hline Scenarios & $\begin{array}{ll}\circ & \text { Ingeo } 5 \text { ("base" PLA polymer) } \\
\circ & \text { IngeoNGT ("next generation" PLA polymer) }\end{array}$ \\
\hline & $\begin{aligned} &- \text { Types of waste treatment considered } \\
& \circ \text { Industrial Composting } \\
& \circ \text { Landfilled } \\
& \circ \text { Incineration }\end{aligned}$ \\
\hline Key Findings & $\begin{array}{l}\text { - IngeoNGT performs better for all impact categories than Ingeo5 } \\
\text { - Incineration with energy recovery of the clamshells performs better than } \\
\text { landfill or composting for most impact categories considered }\end{array}$ \\
\hline $\begin{array}{l}\text { Functional } \\
\text { Unit }\end{array}$ & 1000 clamshells \\
\hline $\begin{array}{l}\text { System } \\
\text { boundary }\end{array}$ & Cradle-to-pellet and waste management, excluding use phase. \\
\hline $\begin{array}{l}\text { LCI data } \\
\text { sources }\end{array}$ & Primary data provided by Ingeo producer (NatureWorks LLC) \\
\hline $\begin{array}{l}\text { Allocation } \\
\text { Method }\end{array}$ & $\mathrm{N} / \mathrm{A}$ \\
\hline
\end{tabular}


LCIA Method Study calculated individual indicators for each impact category based on inventory flows. See 2006 report for details.

Result/Impact Categories

- Global warming potential

- Acidification

- Eutrophication

- Smog

- Human toxicity

- Fossil Fuel Depletion/Energy

- Land Occupation

T. Leejarkpai, T. Mungcharoen, and U. Suwanmanee, "Comparative assessment of global warming impact and eco-efficiency of PS (polystyrene), PET (polyethylene terephthalate) and PLA (polylactic acid) boxes," J. Clean. Prod., vol. 125, pp. 95-107, Jul. 2016.

https://doi.org/10.1016/j.jclepro.2016.03.029

\section{Product Thermoform boxes (single use)}

Geography Thailand

Systems/

- Materials considered:

Scenarios

$\circ$ polystyrene (PS)

$\circ$ polyethylene terephthalate (PET)

- polylactic acid (PLA)

- Types of waste treatment considered:

$\circ \quad$ Landfilling (PS, PET, PLA)

- Composting (PLA)

Key Findings

- Results: GWP results from cradle to consumer gate:

○ PLA" showed the worst result, $219.5 \mathrm{~kg} \mathrm{CO} 2 \mathrm{e} / \mathrm{FU}$;

- PET, approximately $180 \mathrm{~kg} \mathrm{CO} 2 \mathrm{e} / \mathrm{FU}$;

- PLA', approximately $60 \mathrm{~kg} \mathrm{CO} 2 \mathrm{e} / \mathrm{FU}$;

- PS, approximately $50 \mathrm{~kg} \mathrm{CO} 2 \mathrm{e} / \mathrm{FU}$ (last 3 values measured on screen from figure 8).

- For cradle to grave GWP results:

- Lowest GWP attributed to PS due to low GWP during production and no emissions during waste management scenario.

- All PLA scenarios exhibited PLA/PS ratios $>1$ of total GWP, ranging from 3.33 to 16.7. The lower PLA estimate is from the $100 \mathrm{C}$, no land use change PLA scenario, while the higher PLA estimate is from 100L, land use change PLA.

- PET/PS ratio was 3.67, meaning only the lower PLA scenario was better than the PET option.

- Due to high cost of resin for the PLA boxes, PS and PET were considered to have a higher eco-efficiency. 
Functional 1000 boxes with carrying capacity of $100 \mathrm{~g} /$ box and volume $2 * 10-4 \mathrm{~m} 3$ per

Unit

System

boundary box.

- Includes raw materials acquisition, material production, box forming, box use, and waste management scenarios.

- Raw materials for PLA (corn plantation) are considered both without and with land use change (LUC; PLA' and PLA" respectively)

- 4 waste management scenarios considered:

- $100 \%$ landfill (100L), for PS (base case), PET, PLA', and PLA",

- $96 \%$ landfill $/ 4 \%$ composting $(96 \mathrm{~L} / 4 \mathrm{C}$, current situation in Thailand) for PLA' and PLA",

- 50/50 landfill/composting (50L/50C) for PLA' and PLA",

- $100 \%$ composting (100C) for PLA' and PLA"

LCI data sources
- Used previous studies for LCI of PS and PET pellet production, and primary data for the production of PLA from interviews with farmers in Thailand.

- LCI of transportation was calculated using average distance between Bangkok to landfill sites and composting plants.

- LCI of waste management was collected during biodegradation studies of PS and PLA boxes.

- PS did not degrade under landfill conditions, and it was assumed PE would not either; thus, 0 GHG emissions CO2eq for their $100 \mathrm{~L}$ waste management scenarios.

- PLA sheets achieved $100 \%$ degradation in 16 months under landfill conditions (anaerobic reaction)

- Used the ISO14855-1, 2005 standard to test the level of degradation during controlled composting conditions

Allocation

- Biogenic carbon accounted for using mass balance calculations

Method

LCIA Method IPCC 2007 100y

Result/Impact • Global Warming Potential

Categories

F. Razza, F. Degli Innocenti, A. Dobon, C. Aliaga, C. Sanchez, and M. Hortal, "Environmental profile of a bio-based and biodegradable foamed packaging prototype in comparison with the current benchmark," J. Clean. Prod., vol. 102, pp. 493-500, Sep. 2015. https://doi.org/10.1016/j.jclepro.2015.04.033

\section{Product $\quad$ Port-hole spacer for washing machines (rigid packaging)}




\section{Geography Europe}

Systems/

Scenarios

Key Findings
- Materials considered:

- Expanded Polystyrene (EPS, Conventional Material)

- Prototype biodegradable expanded bioplastic, starch based

- Types of waste treatment considered:

○ Industrial composting for prototype plastic (41/59 Composted Landfilled)

- Landfill (EPS)

○ Recycling (30/70 and 50/50 Recycled/Landfilled for EPS)

- Prototype performed better than conventional system for nonrenewable energy use, GWP, photochemical ozone ( $\mathrm{smog}$ ) formation potential, and abiotic depletion potential (from $-90 \%$ to $-50 \%$ ), similar in ozone depletion potential and worse for acidification potential and eutrophication potential (10 and 30\%).

- For EOL stage only, where composting is relevant, the base prototype/base conventional ratios are: 0.6 renewable energy use; 0.26 GWP; N/A photochemical ozone (smog) formation potential (i.e., $0 / 0$ ); 2 abiotic depletion potential; 1.33 ozone depletion potential; N/A acidification potential (e.g. 0.002/0); and 1.33 eutrophication potential.

- The enhanced recycling scenarios for conventional packaging were an improvement over the conventional base case, but not as good as the prototype base case.

- The enhanced prototype case did not show significant improvements over the base prototype case.

- Results were sensitive to allocation (mass vs. economic for prototype raw materials), Land Use Change (-61\% GWP compared to conventional EPS w/o LUC to $+13 \%$ with LUC), change in electrical grid composition, change in landfill biodegradation levels, and recycling rate.

\footnotetext{
Functional Production, use, and disposal of 100 port-hole spacers

Unit

System

boundary

- Cradle-to-grave analysis: System boundary includes raw material production, granule production, granule expansion, and EOL; does not include washing machine production.

$\circ$ EOL assessed by taking into account the different waste treatment technologies applicable to the different packaging.

- Prototype assumed to be suitable for industrial composting.

- Produced and consumed mostly in Europe (98\% distribution of washing machines in Europe); prototype raw materials imported from Thailand.
} 


\begin{tabular}{|c|c|}
\hline $\begin{array}{l}\text { LCI data } \\
\text { sources }\end{array}$ & $\begin{array}{l}\text { For the prototype system, primary data was collected from semi- } \\
\text { industrial trials from the research project and was used for granule } \\
\text { production and expansion processes. Secondary data was from } \\
\text { literature sources used for raw material production (e.g. starch). } \\
\text { - For the conventional system, secondary data was used for granule } \\
\text { production (Ecoinvent v2.2), and a mix of primary data and literature } \\
\text { sources were used for granule expansion } \\
\text { - For both systems, secondary data was used for background inventory } \\
\text { data } \\
\text { - System expansion is applied to EOL scenarios and used to credit the } \\
\text { avoided impacts from replacement of electricity, virgin EPS, and } \\
\text { fertilizers to the packaging systems. }\end{array}$ \\
\hline $\begin{array}{l}\text { Allocation } \\
\text { Method }\end{array}$ & Mass balance performed on biogenic carbon. \\
\hline LCIA Method & Indicated for each impact category [bracketed] \\
\hline $\begin{array}{l}\text { Result/Impact } \\
\text { Categories }\end{array}$ & 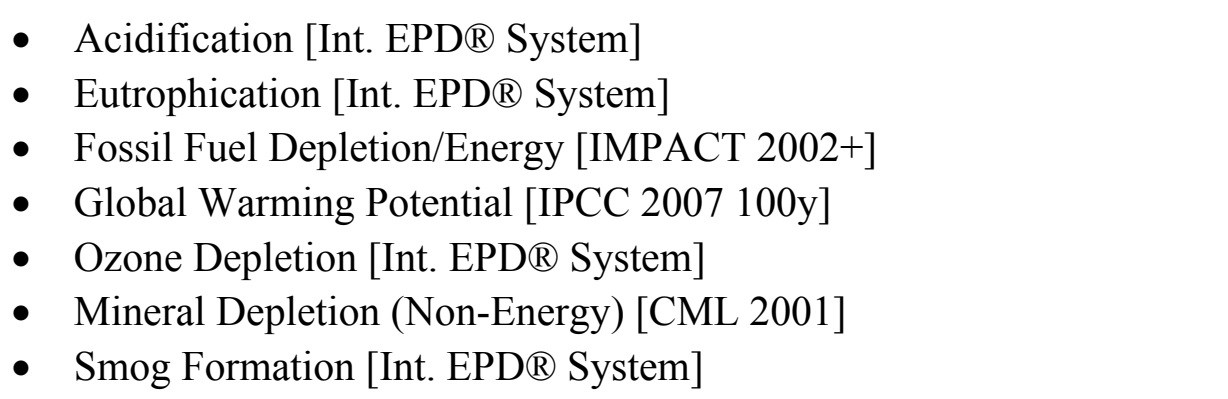 \\
\hline
\end{tabular}

Quantis (2011). Comparative Full Life Cycle Assessment of B2C Cup of Espresso Made Using a Packaging and Distribution System from Nespresso Espresso and Three Generic Products. Prepared by Quantis Suisse for Nestlé Nespresso.

\section{Product}

Geography France, Switzerland

Systems/ Four systems considered for French and Swiss scenarios.

Scenarios

- Nespresso capsule \& packaging system:

$\circ$ Aluminum capsule, aluminum membrane coating. 1.1

g/capsule

- Portion of a sleeve in SBB. $1.6 \mathrm{~g} /$ capsule.

$\circ$ Tertiary packaging. $0.8 \mathrm{~g} /$ capsule.

- Generic capsule 1

○ PP capsule, aluminum-PE membrane. $1.5 \mathrm{~g} /$ capsule

- Surpackaging, PE-aluminum-PET laminate. $1.6 \mathrm{~g} / \mathrm{capsule}$

- Portion of a sleeve in SBB. $3.7 \mathrm{~g} /$ capsule 
- Tertiary packaging. $3.3 \mathrm{~g} /$ capsule

- Generic product 2

○ PP capsule, PET membrane. $1.7 \mathrm{~g} /$ capsule

○ Surpackaging, PE-aluminum-PET laminate. $0.9 \mathrm{~g} / \mathrm{capsule}$

- Portion of a sleeve in SBB. $2.8 \mathrm{~g} /$ capsule

○ Tertiary packaging. $1.8 \mathrm{~g} / \mathrm{capsule}$

- Generic product 3

- Bioplastic capsule made of a mix of PLA and starch. Paper filter and laminate membrane. $4.4 \mathrm{~g} /$ capsule

- Overwrap, PP and PET, paper label and cardboard insert. 0.3 $\mathrm{g} /$ capsule.

- Portion of a sleeve in SBB. $2.3 \mathrm{~g} /$ capsule

$\circ$ Tertiary packaging. $1 \mathrm{~g} /$ capsule.

- EOL scenarios

○ Trash: household waste. $100 \%$ incineration with energy recovery in Switzerland, 51\% incineration with energy recovery and $49 \%$ landfill in France.

○ $100 \%$ recycling

- $100 \%$ Direct fuel substitution (DFS)

- $100 \%$ Anaerobic Digestion (AD)

- $100 \%$ Industrial composting (IC)

- Note that only the Trash scenario applies to all products.

- All EOL scenarios other than Trash referred to as "valorization bins" in the study.

Note that sleeves are made of solid bleached board.

- The espresso made with a Nespresso Espresso capsule has the lowest greenhouse gases emissions impacts, whether disposed of as Trash or through the "valorization bin".

- Best results for GHG is the Nespresso capsule sent to recycling and the generic product 2 capsule sent to a hypothetical DFS route. The next best scenarios are the Nespresso capsule sent to Trash and generic product 3 sent to $\mathrm{AD}$.

- Worst French scenario is generic product 3 sent to trash due to methane emissions from starch degradation in landfills. The worst result for the Swiss scenarios is the generic product 1 sent to trash or DFS.

- Similar results to the ones described above are reported for resource consumption and human health. Nespresso and generic product 2 perform slightly better in ecosystem quality impacts. No conclusions could be drawn for water use.

- If only packaging production and EOL are considered, the Nespresso recycling scenario has lower GHG impacts than the generic product 1 
or 3 capsules for all EOL, and lower impacts than generic product for all EOL except the hypothetical DFS where impacts are similar.

Functional To provide a $40 \mathrm{ml}$ cup of espresso coffee prepared in a Nespresso machine Unit in a business-to-consumer (B2C) environment (at home) for a Swiss and French market.

System Cradle to grave. The analysis includes the coffee supply, the packaging, the boundary production center, the distribution, the use and the end-of-life stages.

LCI data Life cycle inventory is based on information is collected directly from sources Nespresso staff for production, distribution and use of the Nespresso capsules, including manufacturing inputs, manufacturing processes, distance to immediate suppliers, distribution distances, transportation modes and use. Background data obtained from Ecoinvent 2.2.

Allocation System expansion.

Method

LCIA Method IMPACT 2002+ endpoint. Sensitivity analysis done with ReCiPe endpoint method.

Result/Impact Categories
- Global Warming Potential

- Fossil Energy Depletion

The studies summarized below were used to provide context for the discussion of compostable packaging in the main document. They did not provide relevant quantitative comparisons of compostable and non-compostable packaging options.

J. Morris, H. S. Matthews, and C. Morawski, "Review of LCAs on Organics Management Methods \& Development of an Environmental Hierarchy." Alberta Ministry of the Environment, Apr-2011. http://zerowaste.com/images/Organics-LCAs-Review-Project-Report-Final.pdf

- Report is a literature review of 82 LCAs for managing organic waste and assess the relative environmental impacts several EOL management options.

- They did a literature search similar to this one, except they placed more emphasis on bibliographies that members had on hand due to past project participation and in reaching out to experts and government studies and models.

- Despite large number of LCAs reviewed, data was adequate to draw conclusions about only 4 main EOL options:

- Aerobic composting (AC)

- Anaerobic digestion (AD)

- Mass burn waste-to-energy (WTE)

- Landfill gas-to-energy (LFGTE). 
- Environmental impact categories considered include: Climate change, human respiratory effects, human toxicity, human carcinogenicity, ecotoxicity, acidification, eutrophication, ground level smog, and ozone depletion.

- Results:

- For climate change impacts, $\mathrm{AC}$ and $\mathrm{AD}$ have significantly lower impacts than WTE and LFGTE, but the data was not conclusive enough to discern which has better between the two. Similarly, the data was not conclusive enough to determine the better method between WTE and LFGTE.

- For non-climate change impacts, the relative rankings of the four methods are similar to the rankings for climate change, but with much less certainty, such that there is no definitive statement on which methods are better, but rather that more research is needed.

- Results for all impact categories are statistically sensitive to small sample sizes and outliers; individual EOL systems are sensitive to management practices and displacement assumptions (e.g. energy offset, avoided electricity consumption, etc.).

- The study further verifies the preference for $\mathrm{AC}$ by using and environmental benefits calculator (MEBCalc) to specific sample data, which confirmed $\mathrm{AC}$ as the method with lowest impacts when compared to LFGTE and WTE (AD not included due to lack of empirically reliable test data).

- Article published in Waste Management journal based on the report summarized above has same overall content and conclusions.

Meeks, T. Hottle, M. M. Bilec, and A. E. Landis, "Compostable biopolymer use in the real world: Stakeholder interviews to better understand the motivations and realities of use and disposal in the US," Resour. Conserv. Recycl., vol. 105, pp. 134-142, Dec. 2015. https://doi-org.pitt.idm.oclc.org/10.1016/j.resconrec.2015.10.022

- Goal: to provide understanding on how compostable biopolymers are being used by consumers (residential and commercial) so that decision makers can commission and use assessments that "are not limited to using wide ranging assumptions and can produce more meaningful results".

- Study conducts stakeholder and user interviews and audits of bioplastics in grocery stores to understand where compostable plastics are used and disposed, and the motivations behind purchasing and disposal decisions. Interviews/audits conducted in the U.S.

- Stakeholders: producers, distributors, and experts of compostable biopolymers; decision makers who manage such products (e.g. MSW professionals or commercial composters).

- Users: organizations that use compostable biopolymers (e.g. cafés, cafeterias, recreational concessions).

- Grocery store audits were conducted in the Phoenix area and data was visually collected and documented, focusing on the number and type of polymer (rigid plastics and biopolymers)

- Preliminary interviews were conducted with producers/distributors 
- After preliminary interviews and store audits, it was determined that residential users do not come into contact with biopolymers on a regular basis. Interviews were modified to identify organizations that use and dispose of compostable biopolymers.

○ Focused turned to food service industry and hospitals; list of establishments for a second set of interviews were identified

- Responses to second set of interviews classified into:

$\circ$ motivations behind compostable polymer purchase

○ disposal practice

- motivation behind disposal practice.

- Results:

- The main motivations for food service industry establishments to purchase compostable polymers is that it aligned with their goal of being a sustainable business and/or to conform to expectations.

- Most types of food establishments (caterers, limited food service establishments, etc.) landfilled their compostable biopolymers, mostly due misunderstanding of biodegradability/composting process or lack of institutional resources to appropriately manage and dispose of their waste.

- Cafeterias were the only establishment type that sent compostable polymers to compost facilities, and did so citing specific and measurable waste reduction goals they were trying to achieve. Additionally, these particular cafeterias were part of large organizations with strategic sustainability plans (ASU, Stanford, and Intel).

- This suggests that even if most establishments have sincere sustainable motivations, there is a need for specialized management for effective waste disposal.

- Another barrier to effective disposal is a lack of access to commercial composting facilities which are able to accept compostable polymers, despite efforts to find one.

- Only in places where the compost market is developed are composting facilities adequate (e.g., near Stanford University in CA) and thus suitable for effective disposal of compostable polymer waste.

Bernstad Saraiva Schott A, Wenzel H, la Cour Jansen J. (2016). Identification of decisive factors for greenhouse gas emissions in comparative life cycle assessments of food waste management an analytical review. J Clean Prod 119:13-24. doi: 10.1016/j.jclepro.2016.01.079. Accessed September 7, 2017: https://doi.org/10.1016/j.jclepro.2016.01.079

- Results: Results from multiple studies of impacts of composting vary widely due to the inconsistencies in system boundaries, assumptions regarding credits for nutrients assigned to compost, and amount of fertilizer displaced by compost in each study. 


\section{Food Service Ware}

Pro.mo/Unionplast. (2015). Comparative Life Cycle Assessment Study of Tableware for Alimentary Use. Milan, Italy. Retrieved from http:/www.pro-mo.it/data/uploads/report-lcaeng.pdf.

\begin{tabular}{|c|c|}
\hline Product & Cups, Dishes \\
\hline Attribute & Compostable, Recyclable, Biobased \\
\hline $\begin{array}{l}\text { Geography } \\
\text { Systems/ } \\
\text { Scenarios }\end{array}$ & $\begin{array}{l}\text { Italy } \\
\text { Cups and dishes made from: } \\
\text { - Plastic (PP, PS) } \\
\text { OOL Scenarios: } \\
\text { - Target: } 50 / 50 \text { recycling/energy recovery } \\
\text { - Conservative: } 100 \text { landfill } \\
\text { - Real: } 38.6 / 36.8 / 24.6 \text { recycling/energy recovery/landfill } \\
\text { - PLA/cellulose pulp } \\
\text { EOL Scenarios: } \\
\text { - Target: } 50 / 50 \text { composting/energy recovery } \\
\text { - Conservative: } 100 \text { landfill } \\
\text { - PE laminated cardboard } \\
\text { EOL Scenarios: } \\
\text { - Target: } 100 \text { recycling } \\
\text { - Conservative: } 100 \text { landfill } \\
\text { Glass (cups only) } \\
\text { EOL Scenarios: } \\
\text { - Target, after } 1000 \text { reuses: } 100 \text { recycling } \\
\text { - Conservative: } 100 \text { landfill } \\
\text { Porcelain (dishes only) } \\
\text { EOL Scenarios, after } 1000 \text { reuses: }\end{array}$ \\
\hline Key Findings & $\begin{array}{l}\text { - The products made of bio-polymers present average values higher than } \\
\text { those made of conventional polymers for numerous significant impact } \\
\text { categories } \\
\text { - Reusable tableware has impact categories values significantly lower } \\
\text { than disposable tableware, but the most impacting phase proves to be } \\
\text { the use phase, with the washing process. } \\
\text { - The products derived from the wood processing industry (cellulose } \\
\text { fiber or cardboard) have their environmental performance very much } \\
\text { influenced by tableware production technologies } \\
\text { - Sensitivity analysis for EOL options showed no significant changes } \\
\text { from main results, indicating that composting is still inferior to } \\
\text { recycling and energy recovery. }\end{array}$ \\
\hline
\end{tabular}


Functional 1000 tableware uses for containing meals in the case of the dishes and for Unit containing $200 \mathrm{ml}$ of beverage in the case of cups.

System Cradle to grave (includes use) boundary

LCI data Primary data used for the production processes of disposable tableware, sources acquired in 2014 directly at the production facilities of one of the Group companies. Data relate, in particular, to electric energy consumption, water consumption and the consumption of inputs in the form of raw materials.

Secondary data obtained from the database Ecoinvent v. 3.1. These data have been used for pre-production and post-production processes, i.e. for the extraction and processing of raw materials phases, for the production of basic materials and chemicals, for energy production and, in general, for all those processes in which it was not possible to acquire specific data.

Tertiary data obtained from estimates based on similar processes whose data are known, or from literature. This type of data has been used in the absence of specific or generic data.

Allocation Avoided burden for recycling and incineration; no credits given for Method composting of PLA and cellulose pulps due to lack of data.

LCIA Method ILCD 2011 midpoint + (used for comparisons in this review); CML-IA baseline

Result/Impact - Global warming potential

Categories

- Ozone depletion

- Human toxicity

- Smog

- Acidification

- Eutrophication

- Ecotoxicity

- Land occupation

- Water consumption

- Mineral depletion

Fieschi, Maurizio, and Ugo Pretato. (2018). Role of Compostable Tableware in Food Service and Waste Management. A Life Cycle Assessment Study. Waste Management 73 (March): 14-25. https://doi.org/10.1016/j.wasman.2017.11.036.

Product Tableware - plate, knife, fork, cup, napkin, tray mat

Attribute Compostable

Geography Europe 
Systems/

Scenarios

Key Findings
- Tableware

- Compostable tableware, made from PLA, MaterBi, paperboard and paper

- Biodegradability under composting conditions is determined by applying the standard EN 134328

- Study uses the Product Environmental Footprint (PEF) approach.

- Fossil based tableware, made from PS and general-purpose polystyrene (GPPS).

- Both types of tableware use same mold designs, only differences are materials

- Scenario A: food service using biodegradable and compostable tableware, collecting the total waste in a single homogeneous stream followed by organic recycling through composting ( $100 \%$ composting EOL)

- Scenario B: food service using traditional tableware, collecting the total waste in a single heterogeneous stream and disposing it of by means of incineration and landfilling (55/45 Landfilling/incineration)

- No waste sorting is requested by diners; Reusability is explicitly excluded

- Biodegradable and compostable tableware combined with organic recycling is the preferred option for catering in quick service restaurants, contract catering and events

- Significant reduction in carbon, water and resource footprint

- The most relevant contributions come from tableware production for all impact categories for both scenarios.

- The dinner plate and cutlery production were the most relevant items, in terms of environmental loads in both scenarios due to their relatively higher mass in the catering.

- Paper production was also significant in both systems, especially for fresh water eutrophication and human toxicity, non-cancer effects.

- The treatment of wet bio-waste in incineration and landfill generates more impacts compared to composting

- Sensitivity analysis on the amount of food waste per meal does not change the relative results between scenarios, but does confirm that the higher the amount of food waste the greater the benefits of compostable tableware.

Functional the supply of 1000 meals using 1000 single use tableware, which generates

Unit waste consisting of $150 \mathrm{~kg}$ of food waste $(0.150 \mathrm{~kg} / \mathrm{meal})$ and tableware

System boundary
Cradle to grave. Excludes food production, meal preparation, and meal distribution. 


\begin{tabular}{ll}
$\begin{array}{ll}\text { LCI data } \\
\text { sources }\end{array}$ & $\begin{array}{l}\text { Primary data for production of polyester, MaterBi, PLA, cutlery, as well as for } \\
\text { organic waste composition. Secondary sources for the remaining processes } \\
\text { (production of PS, PP, paper, dinner plate and cups, energy recovery from } \\
\text { incineration, and percentage of compost use and peat substitution). }\end{array}$ \\
$\begin{array}{ll}\text { Allocation } \\
\text { Method }\end{array}$ & \\
\hline LCIA Method & ILCD 2011 midpoint \\
Result/Impact & - Global warming potential \\
Categories & - Ozone depletion \\
& - Human toxicity \\
& - Smog \\
& - Acidification \\
& - Eutrophication \\
& - Ecotoxicity \\
& - Wand occupation \\
& Mineral depletion
\end{tabular}

Potting, José, and Eugenie van der Harst. (2015). Facility Arrangements and the Environmental Performance of Disposable and Reusable Cups. The International Journal of Life Cycle Assessment 20 (8): 1143-1154. https://doi.org/10.1007/s11367-015-0914-7

\section{Product Disposable and Reusable Cups used with hot beverage vending machines in Dutch office settings}

\section{Attribute Biobased/Renewable, Compostable, Reusable, Recyclability}

Geography The Netherlands

Systems/ This article considers two studies, described as study 1 and study 2 in the Scenarios article.

- Materials considered for disposable cups (study 1 in paper)

- PS, fossil based cup

- PLA (compostable, compostability label EN 13432), biobased cup

- Biopaper (compostable, compostability label EN 13432), biobased cup

- Waste management for disposable cups (study 1)

○ For all cups

- Incineration with energy recovery

- Mechanical recycling

- For biobased cups 
- Composting

- Anaerobic digestion with energy recovery from the combustion of gas produced

- Note that the Netherlands does not allow landfilling of combustible materials so this was not considered as a waste disposal option.

- Materials considered for reusable cups (study 2)

○ PS, disposable cups

- Handwashed, reusable cups

- Dishwasher washed, reusable cups

- Reusable cups assumed to be used 1,750 times before taken to the incinerator

Key Findings - Disposable PS cups not better or worse than biobased cups from PLA or biopaper

- End of life treatment of disposable cups is significant, and influenced by the large credits for avoided electricity production

$\circ$ Composting of biobased cups is worse than other disposal options

- Composting experiments in semi industrial conditions showed visible traces of incompletely composted PLA from the cups, which makes the compost unfit for commercial sales.

- Anaerobic digestion performs better than incineration for PLA cups

- Recycling performs slightly better than incineration for bio cups, but not for PS cups

- Sensitivity on the avoided energy from incineration (using the hydro-dominated Norwegian grid rather than the more fossil dependent Dutch grid) makes recyclable more appealing, as the avoided impacts from energy production are reduced.

- Results for reusable cups are highly uncertain due to widely varying user behavior, though they usually outperform disposable cups.

- Disposable cups that are reused have comparable impacts to reusable cups

Functional Serving of one hot beverage from vending machine

Unit

System Cradle to grave

boundary

LCI data Information in this section is obtained from the following study, which is sources referenced in this article as the source for LCI data:

- Harst, Eugenie van der, José Potting, and Carolien Kroeze. (2014). "Multiple Data Sets and Modelling Choices in a Comparative LCA of 
Disposable Beverage Cups". Science of The Total Environment 494495 (October): 129-43.

https://doi.org/10.1016/j.scitotenv.2014.06.084.

Multiple inventory data sets are used for all life cycle stages, and multiple recycling crediting principles are used for recycling for the disposable cups included in study 1 . Sources used for each type of cup include Ecoinvent database, ELCD database, literature sources, and primary data from various sources.

Biogenic $\mathrm{CO}_{2}$ was taken into account for PLA and wood production for the biobased cups.

Allocation System expansion (avoided burden) for both recycling and incineration with Method energy recovery.

For recycling, avoided burdens were

- virgin PS for PS cups

- PLA credited like PS due to lack of data for PLA recycling

- Recycled paper from biobased cups was credited as unbleached sulphate pulp.

For energy recovery, avoided burdens were electricity production from the Dutch grid.

LCIA Method CML 2001 baseline, supplemented with CED from Ecoinvent

Result/Impact - Global warming potential

Categories

- Acidification

- Eutrophication

- Ozone Depletion

- Smog

- Human Toxicity

- Ecotoxicity

- Fossil Fuel/Energy Demand

- Mineral Depletion

Broca, Mita. (2008). A Comparative Analysis of the Environmental Impacts of Ceramic Plates and Biodegradable Plates (Made of Corn Starch) Using the Life Cycle Assessment Tool. Masters, New Delhi, India: TERI School of Advanced Studies. http://sustainability.tufts.edu/wpcontent/uploads/LifeCycleAnalysisPlasticPlatevsCeramic.pdf.

\section{Product Ceramic and biodegradable plates}

Attribute Bio-based/Renewable with quantitative results; reusability reported using eco indicator 99, only for breakeven point

Geography United States 
Systems/

Scenarios

Key Findings
- Ceramic plates, incinerated then landfilled

- PLA plates, incinerated

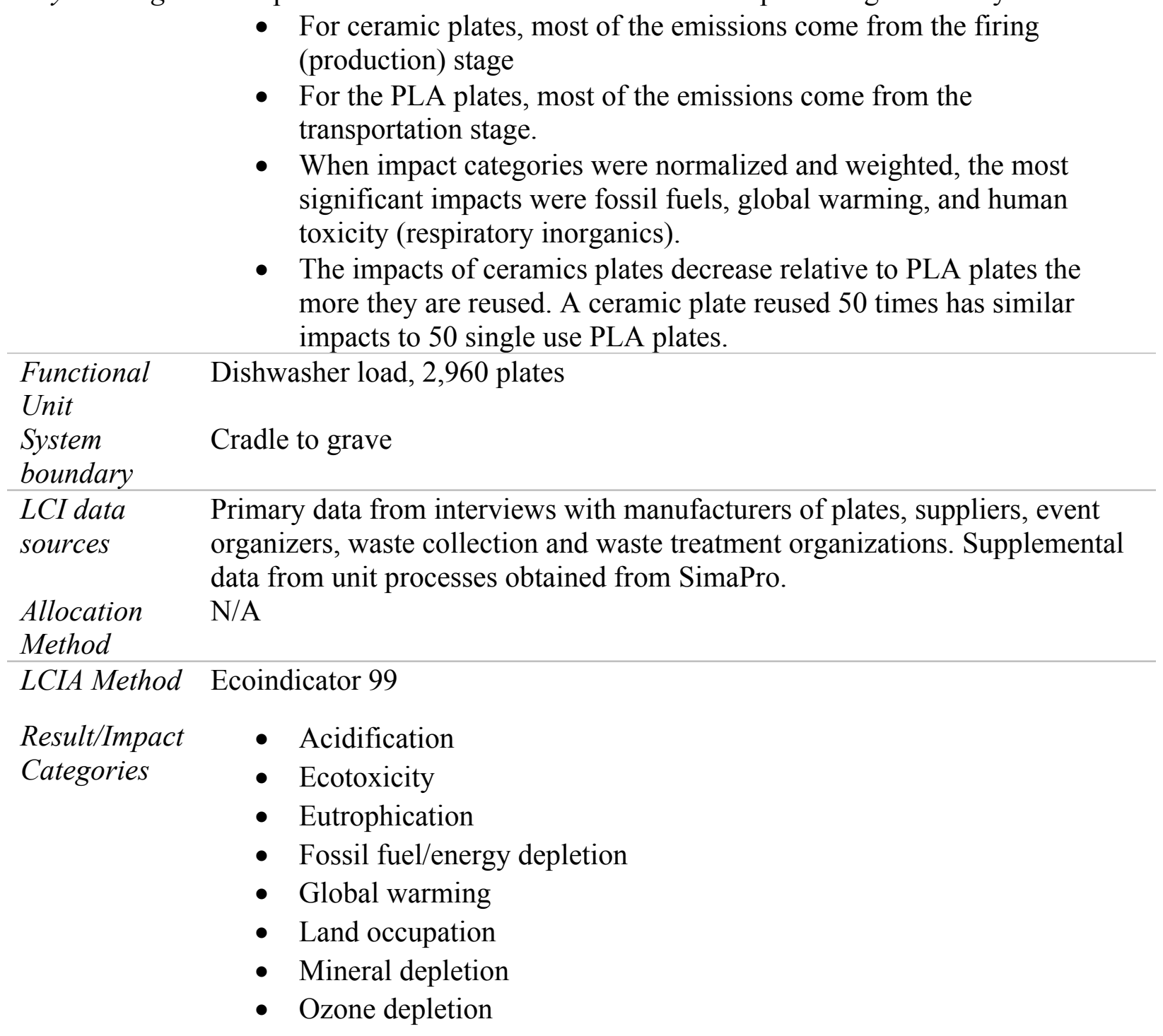

Madival, S., Auras, R., Singh, S.P. and Narayan, R. (2009). Assessment of the environmental profile of PLA, PET and PS clamshell containers using LCA methodology. Journal of Cleaner Production, 17(13), pp.1183-1194. http://doi.org/10.1016/j.jclepro.2009.03.015

\section{Product \\ Strawberry packaging: Thermoformed clamshell containers with $1 \mathrm{lb}$ strawberries}

\section{Attribute Bio-based/Renewable}

Geography Europe/U.S. 


\begin{tabular}{|c|c|}
\hline $\begin{array}{l}\text { Systems/ } \\
\text { Scenarios }\end{array}$ & $\begin{array}{l}\text { - } \text { PLA } \\
\text { - } \text { PET } \\
\text { - } \text { PS } \\
\text { - } 5 \text { EOL scenarios for each material: } \\
\quad \circ \text { 1: } 40 \text { recycled } / 30 \text { landfilled } / 30 \% \text { incinerated } \\
\quad \text { ○ } 2: 100 \% \text { landfilled } \\
\quad \text { o } 3: 100 \% \text { recycled } \\
\quad \circ \text { 4: } 50 \text { landfilled } / 50 \% \text { incinerated } \\
\quad \text { 5: } 56.5 \text { landfilled / } 23.5 \% \text { incinerated (current situation) }\end{array}$ \\
\hline Key Findings & $\begin{array}{l}\text { PET showed the highest overall values for all the impact categories, } \\
\text { mainly due to the higher weight of the containers. The main impacts } \\
\text { to the environment were the resin production and the transportation } \\
\text { stage of the resins and containers, which implies that the } \\
\text { transportation stage of the package is an important contributor to the } \\
\text { environmental impact. }\end{array}$ \\
\hline $\begin{array}{l}\text { Functional } \\
\text { Unit } \\
\text { System }\end{array}$ & $\begin{array}{l}1,000 \text { one } \mathrm{lb} . \text { containers } \\
\text { Cradle to grave }\end{array}$ \\
\hline $\begin{array}{l}\text { LCI data } \\
\text { sources } \\
\text { Allocation } \\
\text { Method }\end{array}$ & $\begin{array}{l}\text { Simapro and Ecoinvent for resin production, container production, and end- } \\
\text { of-life management, with recycling data compiled by Pre Consultants. } \\
\text { N/A }\end{array}$ \\
\hline LCIA Method & IMPACT $2002+$ \\
\hline $\begin{array}{l}\text { Result/Impact } \\
\text { Categories }\end{array}$ & $\begin{array}{l}\text { - } \text { Acidification } \\
\text { - Ecotoxicity } \\
\text { - Fossil fuel/energy depletion } \\
\text { - Global warming } \\
\text { - Land occupation } \\
\text { - Mineral depletion } \\
\text { - Ozone depletion }\end{array}$ \\
\hline
\end{tabular}

Note: Study also included in the Biobased/Renewable packaging section

Vercalsteren, An, Carolin Spirinckx, and Theo Geerken. (2010). Life Cycle Assessment and Eco-Efficiency Analysis of Drinking Cups Used at Public Events. The International Journal of Life Cycle Assessment 15 (2): 221-230. https://doi.org/10.1007/s11367-009-0143-z

\section{Product Drinking Cups}

Attribute Biobased/Renewable, Reusability in 2006 report (not in journal article)

Geography Belgium (Flanders) 
Systems/

Scenarios

Key Findings

Functional

Unit

System Cradle to grave

boundary

LCI data

sources

Allocation N/A

Method

LCIA Method Eco-Indicator 99

Result/Impact

Categories respectively
- FSW options considered:

- Reusable Polycarbonate (PC) cup (assume used 2.5 times during an event)

- One-way polypropylene (PP) cup

- One-way cup in polyethylene (PE) coated cardboard

- One-way PLA cup

- EOL options for FSW:

○ PP and PE cups: 50\% Incineration in municipal solid waste incinerator (MSWI), 50\% co-combustion in cement kiln

○ PLA cup: $50 \% \mathrm{MSWI} / 50 \%$ Composing

- PC reusable cup: $100 \%$ MSWI for cups that have reached end of useful life (i.e. no more reuses).

- Comparative LCA did not provide an overall environmentally superior cup system

- For all one-way cup systems production dominates environmental impacts for both small scale (2,000-2,500 visitors) and large-scale events ( $>30,000$ visitors).

- Impacts differ most for reusable PC cups between small and largescale events

- Differences caused by impacts of machine cleaning at large scale events (vs. manual cleaning) and trip rates to events

- Sensitivity analysis

- Trip rate is a sensitive factor for reusable cups

- Results are not sensitive to different EOL configurations (e.g. higher percentage PP cups going to kiln).

- Results of PLA cups sensitive to PLA cup weight, which is dependent on future manufacturing technologies for PLA

- Eco-efficiency analysis: reusable cups have a better environmental eco-efficiency score for small events, but higher cost score than the other cups. Results are inconclusive for large events.

$100 \mathrm{~L}$ of beer or soft drinks at small scale in-door or large scale outdoor event,

Most data inventory based on inquiry among different stakeholders in Belgium, some from literature (paper is unclear on what is based on inquiry and what is based on literature).

- Acidification/Eutrophication

- Ecotoxicity 
- Global warming potential

- Fossil Fuel/Energy depletion

- Mineral depletion

- Human toxicity

- Ozone depletion

Note: This journal article presents the same LCA results as a report previously published in 2006, which can be accessed at:

https://www.natureworksllc.com/ /media/Files/NatureWorks/What-is-Ingeo/Why-it-

Matters/LCA/OVAM Cup ComparativeLCA FullReport 0206 pdf.pdf

Pladerer, Christian, Markus Meissner, Fredy Dinkel, Mischa Zschokke, Günter Dehoust, and Schüler, Doris. (2008). Comparative Life Cycle Assessment of Various Cup Systems for the Selling of Drinks at Events. Prepared for Austrian Federal Ministry of Agriculture and Forestry, Environment and Water Management and the Swiss Federal Environment Authority. http://www.meucopoeco.com.br/environmental_study.pdf.

\section{Product Drinking Cups}

Attribute Biobased/Renewable, Reusability with quantitative results for individual impact categories

\section{Recycled Content and Compostable with aggregate environmental quantitative comparisons (not for individual impact categories)}

Geography

Systems/

Scenarios
Germany, Austria, Switzerland

- FSW options considered with quantitative results for individual impact categories, for Euro 2008 tournament

- PET in Waste Incineration Plant (WIP) with energy and heat recovery

- PS in WIP

- Cardboard in WIP

- Belland ${ }^{\circledR}$ material, intermediate storage

- Plastic designed to be dissolved with little effort and used as a basic material for the production of new goods with a high proportion of recycled material

$\circ$ PLA in WIP (biogenic $\mathrm{CO}_{2}$ accounted for)

○ PP Euro without branding

- branding prohibits commercial use of cup after event. $98 \%$ domestic reuse, $2 \%$ open loop recycling.

- PP Euro with branding, souvenir displacement

- $73 \%$ used as souvenirs, displace production of other souvenirs that will end in WIP; $27 \%$ open loop recycling

○ PP Euro with branding, displacement according to experts 
- Sensitivity

- Various home use options

○ PS with open loop recycling ("material utilization"), $80 \% \mathrm{RC}$

- PLA with composting

- Belland material, $50 \%$ RC

Key Findings

- All reusable cup scenarios show lower environmental burden compared to the examined disposable cup scenarios. The scenario with subsequent reuse of the cups, PP Euro without branding, performs best

- Results are similar for two different sport settings, short term tournament (UEFA EURO 2008 tournament, summer) and longer tournament (Bundesliga tournament, year-long)

- An important factor on the results is the number of cups that are taken home, their influence on the displacement of use of other cups

- The environmental burden of disposable PLA cups is comparable to that of disposable PET cups and much higher than that of disposable cups made of cardboard.

- Composting of the cups does not result in a reduced environmental burden because composting of this type of plastic does not render any tangible ecological benefit. Also, the effects of disposal are marginal compared to the production of the cups.

- A functioning recycling system for Belland material has not been realized. If Belland material is assumed to be produced with $50 \%$ of recyclable material (example for sensitivity assumption), the environmental burden would be lower but still remain significantly higher than that of the examined reusable versions.

Functional $\quad 0.5 \mathrm{~L}$ cup (beer or soft drink)

Unit

System Cradle to grave

boundary

LCI data Manufacturer data, ecoinvent 2.01

sources

Allocation $\quad 50 / 50$ for open loop recycling

Method $\quad \mathrm{RC}$ for Belland system

LCIA Method - Method of economic scarcity (environmental burden points, EBP 2006)

- Eco-indicator 99 (EI 99) method with HA weighing (hierarchist average)

- UBA procedure "evaluation in LCAs" (Federal German Ministry of the Environment (Umweltbundesamt) in Dessau) 
Note that only the UBA procedure LCIA method provides estimates for the individual impact categories. Thus, the results represented in the comparisons are those that use this method.

Result/Impact For the UBA LCIA method: Categories

- Acidification

- Eutrophication

- Fossil Fuel/Energy depletion

- Global warming

- Human toxicity

- Smog formation (oxidization potential)

PE Americas. (2009). Comparative Life Cycle Assessment IngeoTM Biopolymer, PET, and PP Drinking Cups. Prepared for Starbucks Coffee Company Seattle, WA \& NatureWorks LLC. Joint Venture of Five Winds and PE International. http://www.ingeo.natureworksllc.com/ /media/The_Ingeo_Journey/EcoProfile_LCA/LCA/PEA Cup_Lid_LCA_FullReport_ReviewStatement_121209 pdf.pdf.

Product Drinking Cups and flat lids

\section{Attribute Biobased/Renewable}

Geography US

Systems/

- Materials

Scenarios

○ PET $15.5 \mathrm{~g} / 2.5 \mathrm{~g}(\mathrm{Cup} / \mathrm{Lid})$

○ PP $13.18 \mathrm{~g} / 2.12 \mathrm{~g}$

○ PP $12.73 \mathrm{~g} / 2.05 \mathrm{~g}$

○ Ingeo 2009 (PLA) 13.6g/2.19 - Assuming energy production requirements similar to PET cups (Prod PET)

○ Ingeo 2009 (PLA) 13.6g/2.19 - Prod PP

○ Ingeo 2009 (PLA) 14.4g/2.32 - Prod PET

○ Ingeo 2009 (PLA) 14.4g/2.32 - Prod PP

- EOL is landfilled for all scenarios

Key Findings $\quad$ - PP shows better environmental performance than PET for all considered categories Ingeo and PP produce lower impacts than PET for the energy demand global warming potential, and smog formation impact categories.

- The weight of the cups and lids are an influential parameter. The contribution of the environmental impact of the cup is mainly determined by the material of choice and weight as impacts from manufacturing are similar for all three materials 
- Transportation and landfill impacts are negligible

Functional 16-ounce single use cold beverage plastic cup with flat lid

Unit

System Cradle to grave, excluding cup use, capital equipment and maintenance,

boundary overhead (heating, lighting) of manufacturing facilities, labor, and transportation of materials within a facility.

\begin{tabular}{|c|c|}
\hline $\begin{array}{l}\text { LCI data } \\
\text { sources }\end{array}$ & $\begin{array}{l}\text { Primary data were collected for currently used technology on the production of } \\
\text { PP and PET cups. Ingeo production was modeled according to unit process } \\
\text { information as provided by Ingeo }{ }^{\mathrm{TM}} \text { for their operation in Blair, Nebraska. } \\
\text { Secondary data and GaBi databases } 2006 \text { used for processes where no primary } \\
\text { data was available. }\end{array}$ \\
\hline $\begin{array}{l}\text { Allocation } \\
\text { Method }\end{array}$ & $\mathrm{N} / \mathrm{A}$ \\
\hline LCIA Method & CML \\
\hline $\begin{array}{l}\text { Result/Impact } \\
\text { Categories }\end{array}$ & $\begin{array}{l}\text { - Acidification } \\
\text { - } \text { Eutrophication } \\
\text { - } \text { Fossil Fuel/Energy depletion } \\
\text { - Smog warming potential } \\
\text { - Water consumption }\end{array}$ \\
\hline
\end{tabular}

Francesco Razza, Maurizio Fieschi, Francesco Degli Innocenti, Catia Bastioli. (2009).

Compostable cutlery and waste management: An LCA approach. Waste Management, Volume 29, Issue 4. Pages 1424-1433. https://doi.org/10.1016/j.wasman.2008.08.021.

\section{Product Biodegradable and compostable (B\&C) cutlery}

\section{Attribute Compostable}

Geography Italy

Systems/

- Current Scenario: Serving meals using non-B\&C disposable cutlery

Scenarios made from general purpose polystyrene (GPPS), collecting waste in a single heterogenous stream, and disposing by using current waste management practices (84/16 landfilling/incineration with energy recovery).

- Virgin GPPS pellets assumed for cutlery production

- Sensitivity analysis considered 50/50 landfilling/incineration scenario.

- Alternative Scenario: Serving meals using B\&C cutlery made from Mater-Bi (starch based), collecting waste in a single homogenous stream, and composting.

- Biological $\mathrm{CO}_{2}$ and $\mathrm{CH}_{4}$ quantified for $\mathrm{B} \& \mathrm{C}$ materials. 
- Complies with compostable packaging requirements standard EN 13432:2000.

Key Findings - Composting of $\mathrm{B} \& \mathrm{C}$ results in lower impacts for all categories

$\circ$ This is still the case for the 50/50 landfilling/incineration sensitivity scenario

- Composting of the food waste itself is also preferable to landfilling.

- Granule production was the LC phase with most impacts for both types of cutlery for most categories.

Functional Serving 1,000 meals

Unit

System Cradle to grave for cutlery. Meal production excluded.

boundary

LCI data Primary data used for Mater-Bi production from manufacturer (Novamont).

sources Secondary data used for other life cycle stages and for non-B\&C cutlery (Ecoinvent, 1.01 database, other literature). End of life inventory for food waste elaborated with I-LCA database. Compost was modeled to accrue benefits of peat substitution, partial reduction of fertilizers, and reduction in irrigation water.

Allocation N/A

Method

LCIA Method Impact 2002+ method.

Result/Impact

- Acidification

Categories

- Eutrophication

- Fossil Energy Depletion

- Global Warming

Harnoto, Monica. (2013). A Comparative Life Cycle Assessment of Compostable and Reusable Takeout Clamshells at the University of California, Berkeley. Retrieved from https://nature.berkeley.edu/classes/es196/projects/2013final/HarnotoM_2013.pdf.

\section{Product Clamshells}

\section{Attribute Compost, Recycling, Reusability}

Geography

Systems/

Scenarios
- Materials:

- Bagasse-based compostable clamshell (single use)

- PP based reusable clamshell

- EOL

- When using the By Design functional unit:

- $100 \%$ composted for 360 compostable clamshells

- $100 \%$ recycled after 360 reuses of 1 clamshell

- When using the Pilot program functional unit: 
- $25 \%$ composted, $75 \%$ landfilled for 43 compostable clamshells

- $21 \%$ recycled, $79 \%$ landfilled after 43 reuses of 1 clamshell

Key Findings - PP clamshells perform better for the global warming and energy consumption categories for both functional units; PP performs better for material waste under the pilot program functional unit, and they are both assumed to produce no waste under the By Design functional unit.

- Compostable clamshells perform better for water consumption

$\circ$ The higher the number of reuses, the greater the water consumption by the PP clamshells

Functional Use by design (as specified by manufacturer): 360 reuses of PP clamshell and Unit $\quad 360$ compostable clamshells Pilot Program (average number of reuses until breakage of PP clamshell): 43 reuses of PP clamshell and 43 compostable clamshells

System Cradle to grave boundary LCI data For both compostable and reusable clamshells, primary data for use phase, sources while literature sources were used for raw materials acquisition, manufacturing, and EOL treatments (energy and water use for recycling and composting processes, and the fertilizer resulting from composting).

Allocation Not specified Method LCIA Method None (results reported as physical flows)

Result/Impact - Global warming Categories

- Fossil Fuel/Energy depletion

- Water Consumption

Franklin Associates. (2011). Life cycle inventory of foam polystyrene, paper-based, and PLA food service products. Prepared for the Plastic Food service Packaging Group. Retrieved from https://www.plasticfood servicefacts.com/wp-content/uploads/2017/12/Peer_Reviewed_Food service LCA_Study-2011.pdf

\section{Product Hot cups, cold cups, plates, clamshells}

\section{Attribute Bio-based/Renewable}

Geography United States

Systems/ Materials

Scenarios

- 16-ounce hot cups (EPS foam, poly-coated paperboard with and without a corrugated sleeve, PLA-coated paperboard with and without a corrugated sleeve) 
- 32-ounce cold cups (EPS foam, poly-coated paperboard, wax-coated paperboard, solid PLA)

- 9-inch high-grade plates (GPPS foam, poly-coated paperboard, bleached molded pulp, solid PLA)

- Sandwich-size clamshells (GPPS foam, corrugated paperboard, solid PLA)

Disposal

- 80/20 Landfill/Incineration with energy recovery

- Assume no degradation for PLA products based on manufacturer data $\left(\mathrm{CO}_{2}\right.$ sequestration credit assigned)

- End-of-life results for decomposition scenarios of landfilled paperboard FSW ranging from no decomposition to maximum decomposition of bleached paperboard from landfill simulation experiments

- Accounts for biogenic $\mathrm{CO}_{2}$ (considered carbon neutral)

Key Findings

- Most of the environmental for each type of food service item is from the production of the materials used.

○ Most of the energy requirements are from material production

- Some energy is recovered from postconsumer material when the material is combusted, as well as when combustion of landfill gas produced from paperboard decomposition.

- Total energy requirements for EPS foam products across the different product categories are generally lower than total energy requirements for the equivalent number of (heavier) PLA or paperboard products analyzed.

- Total energy requirements for LDPE-coated cold cups, LDPE-coated plates, and molded pulp plates are not significantly different from energy requirements for the corresponding EPS products.

- The plastic foam systems have lower density than paperboard and PLA systems, and thus produce less weight but comparable volumes of solid waste.

- The majority of GHG emissions for all systems are related with combustion of fossil fuels during production and transportation stages.

- For PLA, there are also significant GHG emissions from the fertilizer used for corn cultivation.

- EOL GHG emissions vary considerable based on assumptions about decomposition.

- Water use for paperboard products is 20 to 30 percent higher than for the corresponding EPS foam products, while and water use for the solid PLA products is 2 to 4 times as high as for the corresponding EPS foam products.

$\circ$ The differences in the weights of the solid PLA and EPS foam products are a significant driver for the comparative water use results. 


\begin{tabular}{|c|c|}
\hline Functional & 10,000 items of each FSW product. \\
\hline $\begin{array}{l}\text { System } \\
\text { boundary }\end{array}$ & Cradle to grave. Excludes use phase (i.e. contact with food). \\
\hline $\begin{array}{l}\text { LCI data } \\
\text { sources }\end{array}$ & $\begin{array}{l}\text { Primary data for PLA production (NatureWorks). Mixture of primary (private } \\
\text { producer) and secondary (ACC industry average) data for EPS and paperboard } \\
\text { production. Secondary data for U.S. grid and fuel use (U.S. LCI database), } \\
\text { water use (U.S. LCI, Ecoinvent), and end of life modeling (U.S. EPA). }\end{array}$ \\
\hline $\begin{array}{l}\text { Allocation } \\
\text { Method }\end{array}$ & N/A \\
\hline LCIA Method & $\begin{array}{l}\text { None, as the study is an LCI. Exception is Global warming (IPCC Second } \\
\text { Assessment Report } 100 \text {-year GWP factors) }\end{array}$ \\
\hline $\begin{array}{l}\text { Result/Impact } \\
\text { Categories }\end{array}$ & $\begin{array}{l}\text { - Fossil energy depletion } \\
\text { - Global warming } \\
\text { - Water consumption }\end{array}$ \\
\hline
\end{tabular}

Häkkinen, Tarja, and Sirje Vares. (2010). Environmental Impacts of Disposable Cups with Special Focus on the Effect of Material Choices and End of Life. Journal of Cleaner Production 18 (14): 1458-63. https://doi.org/10.1016/j.jclepro.2010.05.005.

\begin{tabular}{ll} 
Product & Cups \\
\hline Attribute & Biobased \\
Geography & Europe \\
Systems/ & $\bullet$ Carton based cup covered with LDPE or PLA \\
Scenarios & $\bullet$ PET Cups \\
& $\bullet$ EOL is landfilling or incineration for both cups
\end{tabular}

Key Findings - Carton cups have considerably lower GHG impacts when incinerated, and slightly higher impacts when landfilled when compared to PET cups.

Functional 100,000 cups

Unit

System Cradle to grave

boundary

LCI data Primary data from manufacturers for carton cups. Secondary sources for PET sources cups and LDPE and PLA coverings

Allocation

Method N/A

LCIA Method Not specified

Result/Impact - Global warming potential

Categories 


\section{Considerations Related to Reusable Food Service Ware}

While reusability as an attribute is outside of the scope of this work, and studies with quantitative results for reusable packaging were not identified during the literature review, reusable food service ware is well represented in LCA literature. Some of the studies included in the FSW review that considered one or more of the four main attributes also included quantitative results for reusability of FSW products as part of their analyses. Additionally, several studies were also found that focused exclusively on environmental aspects of reusability of FSW products (Garrido \& Alvarez del Castillo, 2007; Woods \& Bakshi, 2014). While studies that focused only on reusable food service ware and quantitative comparisons focusing of reusability of FSW from the studies included for other attributes were not performed and not included in the scope of this review, the prevalence of reusability in the literature suggests it is an active area of research for sustainability of FSW products. Below is a qualitative discussion of the findings for reusable FSW of the studies included in this review for one or more of the other attributes.

Five studies included in this review provide results for individual impact categories for reusability in their analysis of FSW products in addition to results for at least one other attribute. Additionally, Broca (2008) included aggregate environmental results for a comparison of reusable vs. incinerated plates. Results from these studies suggest that after certain number of cleaning cycles, reuse of FSW products is usually environmentally preferable when compared to disposable FSW options, though results depend on the specific comparisons considered. The exact number of uses needed for impacts of reusability to be less than the impacts of a functionally equivalent number of disposable FSW items varies by study, item type, and materials of the compared items. Select results for reusability from these studies are summarized below.

Reusability is usually preferable to most EOL options for disposable FSW. For example, the Pro.mo industry group (2015) compared the impacts of glass cups after 1,000 reuses against the impacts of 1,000 disposable cups, made from plastic (PS, PP) and biobased (PLA, cellulose pulp) materials. They also compared reusable porcelain dishes against disposable dishes of the same disposable materials as the cups. Both reusable options performed better than disposable alternatives for all ten impact categories considered (the energy demand category was not included in the analysis). This result was consistent regardless of whether the disposable products were landfilled, incinerated, recycled, or disposed with some combination of these methods. Most of the impacts for the glass cups and porcelain dishes are from the multiple machine-washing cycles, with water consumption and land use being the two categories with the highest impacts.

Though reusability is usually preferable, the way reusability is measured effected the results. Indeed, Potting and van der Harst (2015) compared PS cups disposed via incineration vs. reusable cups, both hand and machine-washed. However, the comparisons for this study focused on the impacts of reusing the cups a certain number of times before washing them. The authors considered this approach a more just comparison between the two types of cups because the disposable cups can also be reused before being discarded, and the authors consider the washing phase of the reusable cup similar to the disposal of the PS cup. Results vary by number of reuses before washing of the cups. With only one use before washing, the reusable cup performs better 
in 4 of the 8 impact categories measured when machined-washed, and worse in all categories when hand-washed. When used two or more times before washing, the reusable cups perform better than the disposable cups in all categories except ozone depletion (for which the study does not provide a break-even point) for both types of washing. However, the authors note that the results for the reusable cups are more uncertain than the results for the PS cup due to the larger uncertainty in the end-of-life for the reusable cups (modeling of the washing process) than for the PS cups (modeling of the disposal for PS cups).

Two of the studies included in this review analyzed the impacts of reusable vs. disposable cups at different types of events, where the results for reusable cups were not always clearly preferable. Pladerer and colleagues (2008) compared the impacts of PET, PS, PLA, and paperboard cups against reusable cups during two different soccer tournaments: a summer long international tournament which lasted three months, and a domestic league soccer season which lasted nine months. Results were favorable in all comparisons for the reusable cups, even in situations where the visitors took the reusable cups with them after the events. On the other hand, Vercalsteren and colleagues ${ }^{12}$ analyzed PE, PP, PLA, and reusable cups at both small and large events, defined as less than 2,500 people and greater than 30,000 people, respectively. Their analysis did not provide an overall superior cup system. The results were dependent on cup weight for the disposable cups and on distance shipped and washing method for the reusable cups, with various combinations of reusable cup shipping distance and washing methods performing worse or better than using disposable cups for the events.

Broca (2008) and Harnoto ${ }^{13}$ analyzed the reusability of FSW products other than cups, but likewise found that reusable materials usually perform better after a certain number of reuses. Broca compared ceramic vs. PLA plates, and while the study did not provide results for individual impact categories, aggregate results using Eco-indicator 99 show that ceramic plates become environmentally preferable after 50 use cycles when compared to an equal number of disposed plates. Harnoto compared bagasse based compostable clamshells vs. polypropylene based reusable clamshells for takeout. The study compared the average number of reuses of the PP clamshells before breaking (43, determined by testing at a pilot site) as well as for number of reuses specified by the manufacturer of PP clamshells (360, using several PP clamshells) against a like number of compostable shells. Overall, the PP clamshells performed better for the global warming and energy consumption categories for both functional units while the compostable clamshells perform better for water consumption.

Reusability was not an attribute included in the scope of this work. As a result, a thorough literature review was not performed for reusability, and the results presented above represent only a qualitive description of the analyses performed in the studies mentioned. Additional literature review and more quantitative comparisons of the results of studies concerning reusable FSW should be performed before a definitive conclusion can be reached. 


\section{Advisory Group}

The following entities comprised the advisory group for this research. Representatives were included from scoping through the development of the final report. Their input is reflected in the final technical report. However, recommendations at the end of each attribute-specific technical summary are the recommendations of the Oregon DEQ.

County of Alameda, CA

StopWaste.org, CA

Washington Department of Ecology

Portland Metro, OR

City of Seattle, WA

Minnesota Pollution Control Agency

CalRecycle

Sustainable Packaging Coalition

Sustainable Purchasing Leadership Council

City of Eugene, OR

U.S. Green Building Council

City of Portland, OR

NEWMOA - Northeast Waste Management Officials Association 


\section{References}

(1) IPCC. Climate Change 2014: Synthesis Report; Contribution of Working Groups I, II and III to the Fifth Assessment Report of the Intergovernmental Panel on Climate Change [Core Writing Team, R.K. Pachauri and L.A. Meyer (eds.)], Ed.; Intergovernmental Panel on Climate Change: Geneva, Switzerland, 2014.

(2) Sonnemann, G.; Valdivia, S. Medellin Declaration on Marine Litter in Life Cycle Assessment and Management: Facilitated by the Forum for Sustainability through Life Cycle Innovation (FSLCI) in Close Cooperation with La Red Iberoamericana de Ciclo de Vida (RICV) on Wednesday 14 of June 2017. Int. J. Life Cycle Assess. 2017, 22 (10), 1637-1639. https://doi.org/10.1007/s11367-017-1382-z.

(3) Weidema, B. Avoiding Co-Product Allocation in Life-Cycle Assessment. J. Ind. Ecol. 2000, 4 (3), 11-33. https://doi.org/10.1162/108819800300106366.

(4) Toniolo, S.; Mazzi, A.; Pieretto, C.; Scipioni, A. Allocation Strategies in Comparative Life Cycle Assessment for Recycling: Considerations from Case Studies. Resour. Conserv. Recycl. 2017, 117, 249-261. https://doi.org/10.1016/j.resconrec.2016.10.011.

(5) Johnson, J. X.; McMillan, C. A.; Keoleian, G. A. Evaluation of Life Cycle Assessment Recycling Allocation Methods. J. Ind. Ecol. 2013, n/a-n/a. https://doi.org/10.1111/jiec.12050.

(6) Federal Trade Commission. Part VII, 16 CFR Part 260: Guides for the Use of Environmental Marketing Claims; Final Rule. Fed. Regist. 2012, 77 (197), 62122-62132.

(7) Nicholson, A. L.; Olivetti, E. A.; Gregory, J. R.; Field, F. R.; Kirchain, R. E. End-of-Life LCA Allocation Methods: Open Loop Recycling Impacts on Robustness of Material Selection Decisions. In 2009 IEEE International Symposium on Sustainable Systems and Technology; IEEE, 2009; pp 1-6. https://doi.org/10.1109/ISSST.2009.5156769.

(8) Atherton, J. Declaration by the Metals Industry on Recycling Principles. Int. J. Life Cycle Assess. 2007, 12 (1), 59-60. https://doi.org/10.1065/lca2006.11.283.

(9) World Steel Association. Life Cycle Assessment Methodology Report; World Steel Association: Brussels, Belgium, 2011.

(10) Garrido, N.; Alvarez del Castillo, M. D. Environmental Evaluation of Single-Use and Reusable Cups. Int. J. Life Cycle Assess. 2007, 12 (4), 252-256. https://doi.org/10.1065/lca2007.05.334.

(11) Woods, L.; Bakshi, B. R. Reusable vs. Disposable Cups Revisited: Guidance in Life Cycle Comparisons Addressing Scenario, Model, and Parameter Uncertainties for the US Consumer. Int. J. Life Cycle Assess. 2014, 19 (4), 931-940. https://doi.org/10.1007/s11367-013-0697-7.

(12) Vercalsteren, A.; Spirinckx, C.; Geerken, T.; Claeys, V. Comparative LCA of 4 Types of Drinking Cups Used at Events; Flemish Institute for Technological Research (VITO): Commissioned by Public Waste Agency for the Flemish Region (OVAM), 2006.

(13) Harnoto, M. A Comparative Life Cycle Assessment of Compostable and Reusable Takeout Clamshells at the University of California, Berkeley; 2013. 